\title{
The Hearts and Minds in Conflict and Peace
}

\author{
Citation for published version (APA):
}

Wong, P. H. (2017). The Hearts and Minds in Conflict and Peace: The Economics of Counterinsurgency and the Psychology of Reconstruction. [Doctoral Thesis, Maastricht University]. Datawyse / Universitaire Pers Maastricht. https://doi.org/10.26481/dis.20170713phw

Document status and date:

Published: 01/01/2017

DOI:

10.26481/dis.20170713phw

Document Version:

Publisher's PDF, also known as Version of record

\section{Please check the document version of this publication:}

- A submitted manuscript is the version of the article upon submission and before peer-review. There can be important differences between the submitted version and the official published version of record.

People interested in the research are advised to contact the author for the final version of the publication, or visit the DOI to the publisher's website.

- The final author version and the galley proof are versions of the publication after peer review.

- The final published version features the final layout of the paper including the volume, issue and page numbers.

Link to publication

\footnotetext{
General rights rights.

- You may freely distribute the URL identifying the publication in the public portal. please follow below link for the End User Agreement:

www.umlib.nl/taverne-license

Take down policy

If you believe that this document breaches copyright please contact us at:

repository@maastrichtuniversity.nl

providing details and we will investigate your claim.
}

Copyright and moral rights for the publications made accessible in the public portal are retained by the authors and/or other copyright owners and it is a condition of accessing publications that users recognise and abide by the legal requirements associated with these

- Users may download and print one copy of any publication from the public portal for the purpose of private study or research.

- You may not further distribute the material or use it for any profit-making activity or commercial gain

If the publication is distributed under the terms of Article $25 \mathrm{fa}$ of the Dutch Copyright Act, indicated by the "Taverne" license above, 
THE HEARTS AND MINDS IN CONFLICT AND PEACE PUI HANG WONG 
(C) Pui Hang Wong 2017

All rights reserved. No part of this publication may be reproduced, stored in a retrieval system, or transmitted in any form, or by any means, electronic, mechanical, photocopying, recording or otherwise, without the prior permission in writing, from the author.

ISBN 9789461597298

Publisher: Datawyse - Universitaire Pers Maastricht, Maastricht

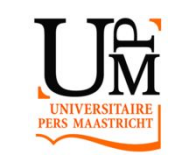

Cover image: Otto van Veen, 1574 - 1629. Distribution of Herring and White Bread at the Relief of Leiden, 3 October 1574. Digital image courtesy of the Rijksmuseum. 


\title{
The Hearts and Minds in Conflict and Peace: The Economics of Counterinsurgency and the Psychology of Reconstruction
}

\author{
DISSERTATION
}

\begin{abstract}
To obtain the degree of Doctor at Maastricht University, on the authority of the Rector Magnificus Prof. Dr. Rianne M. Letschert, in accordance with the decision of the Board of Deans, to be defended in public on Thursday, 13 July 2017, at 9:45 hours
\end{abstract}

by

Pui Hang Wong 
Promoter:

Prof. Dr. Khalid Koser

Co-Supervisor:

Dr. Lutz F. Krebs

Assessment Committee:

Prof. Dr. Pierre Mohnen (Chair)

Prof. Dr. Scott Gates, University of Oslo

Prof. Dr. Kristian Skrede Gleditsch, University of Essex

Dr. Kaj Thomsson

Dr. Thomas Ziesemer 
To my parents 



\section{ACKNOWLEDGEMENTS}

Pursuing a PhD is like withdrawing to intellectual exile. I am nicely surprised, therefore, to see how many people have been around during this journey, making my $\mathrm{PhD}$ adventure a much more enriching experience. First and foremost, I would like to thank my supervisors, Khalid Koser and Lutz Krebs. Not only for your encouragement and guidance, but also for your patience and understanding, making my $\mathrm{PhD}$ experience far less frustrating. You have demonstrated the highest level of adaptability that I think a supervisor can possibly have, tolerating my endless drifts in interests and topics. I always think that I would have written a worse thesis if I had not had you both in my supervision team. I would also like to take this chance to express my gratitude to the staff for the help they offered at various points of time: Eveline in de Braek, Howard Hudson, Sueli Brodin, Susan Roggen, and Herman Pijpers. Thank you, Mindel van de Laar and Tatiana Skripka, for the opportunities and encouragements during these years.

While I am not sure about the state of existence of our conflict group, what I am sure about is that the sense of existence means a lot to me, as a graduate student who always doubts whether he made the right choice when he decided to invest the best six years of his life in an institute that hosts such a diverse group of people who have only little research interests in common. Thank you, Ortrun Merkle, Ayokunu Adedokun, Tamara Kool, Diego Salama, Elvis Amoateng. I will remember the time we have spent in San Francisco, Budapest, Brussels, and certainly, Maastricht.

Thank you, Serdar and Güney, for always being around, sharing your stories and lives, fooling me into thinking that I am a better researcher than I truly am. Thank you, Toby for curing my nostalgia with foods and movies for many weekends in the past few years. Thanks also go to friends in my cohort and the institute, for all the encouragement, emotional support, bad jokes, and good laughs: Valery Shyrokov, Andrea Franco-Correa, Richard Bluhm, Omar Rodriguez, Paula Nagler, Mahmut Kobal, Patricia Silva, Clotilde Mahé, Bruhan Konda, Shivani Achrekar, Halefom Nigus, Ibrahima Kaba, Tobias Broich, Yesuf Awel, Eleni Yitbarek, Cheng Boon Ong, Dorcas Mbuvi, Nevena Zhelyazkova, Sachin 
Badkas, Oxana Slobozhan, Iman Rajabzadeh, Sheng Zhong, and Gintare Mazeikaite.

For various reasons, most of the manuscripts that I have written during these years are not included in my dissertation. Comments and criticisms on my other works, however, have significantly shaped my course of research during my PhD journey. I would like to thank Michael Baumgartner, Jeffrey Checkel, Scott Gates, Jacob Shapiro, Joseph Wright, Marijke Verpoorten, Christian von Haldenwang, Kristen Ringdal, David Van Slyke, among others, for their feedback on my work. Explicitly and implicitly, your comments and criticisms make my work better.

Chapter 5 is based on my paper published in the Journal of Peace Research 53(6): 772-785. Chapters 2, 3 and 4 were submitted to different journals before. I would like to thank the anonymous reviewers for their comments on the manuscripts. These papers have also been presented at different venues. I would also like to thank the discussants and participants at ISA, Asian Polmeth, EnCoRe Workshops, and Eurasian Peace Science Conference for their constructive feedback.

Finally, I would also like to thank the Research School on Peace and Conflict and the European Network of Conflict Research for providing me financial support to participate in training sessions and workshops.

Pui Hang Wong Maastricht, 18 May 2017 


\section{CONTENTS}

1 INTRODUCTION

1.1 Development programs and counterinsurgency . . . . . 2

1.2 Employment and reintegration ............ 6

1.3 Public services and state building .......... 8

I THE ECONOMICS OF COUNTERINSURGENCY II

2 DEVELOPMENT AID 13

2.1 Impacts of foreign aid on political violence . . . . . . . 15

2.2 Local politics and the effect of development aid in Iraq . . . 16

2.3 Data.................... 20

2.4 Models ...................... 23

2.5 Empirical findings .................. 24

2.6 Looking into the mechanisms . . . . . . . . . . . 28

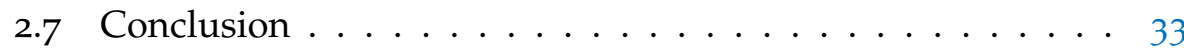

3 SPILLOVER 35

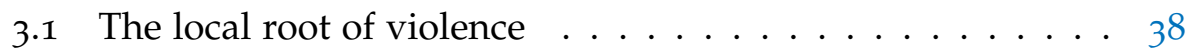

3.2 Empirical consequences of spillover .......... . $4^{1}$

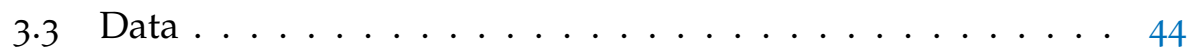

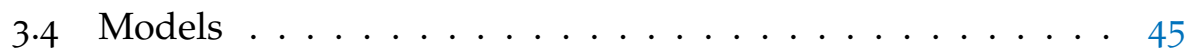

3.5 Empirical findings ........................ 48

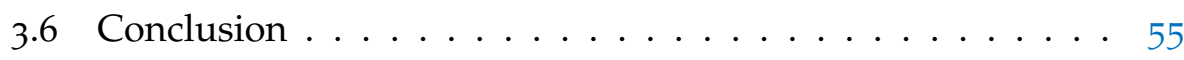

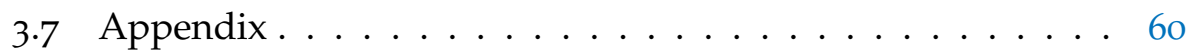

II THE PSYCHOLOGY OF RECONSTRUCTION 63

4 MENTAL HEALTH AND REINTEgRATiON 65

4.1 Barriers to participation ................... 68

4.2 DDRR in post-conflict Liberia . . . . . . . . . . . . 69

4.3 Avoidance and reintegration ............ . $7^{1}$ 
4 4 Data and model . . . . . . . . . . . . . . . 73

4.5 Empirical findings . . . . . . . . . . . . . . . . . . . . .

4.6 Conclusion . . . . . . . . . . . . . . . . . 79

4.7 Appendix I . . . . . . . . . . . . . . . . 82

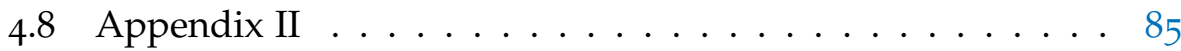

5 Political trust and state building 87

5.1 Building political trust after civil war . . . . . . . 90

5.2 Data . . . . . . . . . . . . . . . . 95

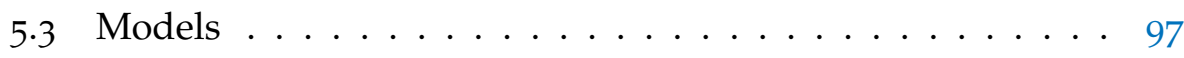

5.4 Empirical findings . . . . . . . . . . . . . . . . 99

5.5 Exploring the trust-building mechanism . . . . . . . 106

5.6 Conclusion . . . . . . . . . . . . . . . 109

5.7 Appendix...................... III

6 CONCLUSION 119

6.1 To valorize . . . . . . . . . . . . . . . 120 


\section{LIST OF FIGURES}

Figure 2.1 Distribution of aid programs between 2004 and 200920

Figure 2.2 Iraqis' confidence in the US occupation forces and CERP spending . . . . . . . . . . . 33

Figure 3.1 Shift of insurgency from Madain to Baladrooz . . . 43

Figure 3.2 Spatial effects of three counterinsurgency policies, with synergy . . . . . . . . . . . . . 56 56

Figure 3.3 Synergy effects of SOI and troop surge, with synergy 57 Figure $5.1 \quad$ Marginal effect of the variable listen . . . . . . . 99

Figure 5.2 The mediation effects of responsiveness of government . . . . . . . . . . . . . . 107 


\section{LIST OF TABLES}

Table 1.1

Table 2.1

Table 2.2

Table 2.3

Table 2.4

Table 3.1

Table 3.2

Table $3 \cdot 3$

Table 4.1

Table 4.2

Table 4.3

Table $4 \cdot 4$

Table 4.5

Table 5.1

Table 5.2

Table $5 \cdot 3$

Table $5 \cdot 4$

Table $5 \cdot 5$

Table 5.6

Table $5 \cdot 7$

Table 5.8
Thesis structure . . . . . . . . . . . . 2

Major US assistance programs in Iraq . . . . . . . . . . . . 22 Summary statistics . . . . . . . . . . . . . . 23

Effect of foreign assistance on conflict intensity in Iraq: Static models . . . . . . . . . . . . . . . . 25

Dynamic effects of foreign assistance on conflict intensity in Iraq . . . . . . . . . . . . . . 27 Effect of counterinsurgency policies in Iraq: Benchmark . . . . . . . . . . . . . . . . 49 Spatial effect . . . . . . . . . . . . . . . . . . . . . . . . . Synergy effect . . . . . . . . . . . . . . . . . . . . . . . . . . . Sample characteristics . . . . . . . . . . . . . . . . . . . . . . . . . . . . . Avoidance and dropout . . . . . . . . . . . . . . . . . . . . . . . . . .

Determinants of avoidance . . . . . . . . . . 80 Propensity to engage in mercenary activities of the dropouts . . . . . . . . . . . . . . . 84 Summary statistics . . . . . . . . . . . . . . . . . . . . . . . . . . . . Determinants of change in trust attitude . . . . . 100 Robustness checks . . . . . . . . . . . . . . . . . . . . . . . . . 103 Robustness checks . . . . . . . . . . . . . . 105 Direct and indirect effects of institution and development project on trust-building . . . . . . . . I10 List of variables . . . . . . . . . . . . . III Summary statistics . . . . . . . . . . . 115 Robustness checks . . . . . . . . . . . . . 116

Estimation results using multinomial logit (base outcome: Trust $_{2007}=0$; Trust $_{2008}=0$ ) $\ldots \ldots$. . II7 
ABC News American Broadcasting Company News

$A B U$

Agricultural Business Unit

AQI

Al-Qaeda Iraq

$\operatorname{AR}(1)$

Autoregressive model of order 1

$\mathrm{AR}(2)$

Autoregressive model of order 2

$\mathrm{BBC}$

British Broadcasting Corporation

BCLSDV

Bias-Corrected Least Square Dummy Variable

BSF

Berman, Shapiro, and Felter, 2011

CERP

Commander's Emergency Response Program

CPA

Coalition Provisional Authority

COIN

Counterinsurgency

DD

Disarmament and Demobilization

DDR

Disarmament, Demobilization and Reintegration

DDRR

Disarmament, Demobilization, Rehabilitation and

Reintegration

DFI

Development Fund for Iraq

DSM-IV-TR

Diagnostic and Statistical Manual of Mental Disorders (IV), Text Revision

ELF

Ethnolinguistic Fractionalization

ESF

Economic Support Fund

FE

Fixed Effect

GMM

Generalized Method of Moments

IED

Improvised Explosive Device

IRCBP

IRRF

Institutional Reform and Capacity Building Project

ISFF

Iraq Relief and Reconstruction Fund

JAM

Iraq Security Forces Fund

MINUSCA

Jaysh Al-Mahdi

United Nations Multidimensional Integrated Stabilization Mission in the Central African Republic

MINUSMA United Nations Multidimensional Integrated Stabilization Mission in Mali 
MINUSTAH United Nations Stabilization Mission in Haiti

NGO Non-Governmental Organization

NHK

Nippon Hoso Kyokai; Japan Broadcasting Corporation

NPS National Public Services

MNF-I Multi-National Force - Iraq

OLS Ordinary Least Squares

PTSD Post-Traumatic Stress Disorder

RE Random Effect

RR Rehabilitation and Reintegration

SD Standard Deviation

SEM Structural Equation Model

SIGACT Significant Activities

SIGIR The Office of the Special Inspector General for Iraq Reconstruction

SOI Sons of Iraq

UNDP United Nations Development Programme

UNMIL United Nations Mission in Liberia

UNOCI United Nations Operation in Côte d'Ivoire

US The United States of America

USACE US Army Corps of Engineers

USAID US Agency for International Development

USD United States Dollar

VAR Vector Autoregressive Models 
Taking an interdisciplinary approach, this dissertation explores the economic and psychological dimensions of conflict resolution. It is comprised of four essays. The first two essays, Chapter 2 and Chapter 3, examine to what extent development projects can be used to quell violent oppositions by competing for public support with insurgents (i.e. the heartsand-minds tactic). The two other essays focus on the psychological aspect of post-conflict reconstruction. Chapter 4 looks into the link between excombatants' psychological well-being and reintegration and Chapter 5 investigates the nature of trust-building. While all four essays look at the ending phase of a violent conflict, the first two concentrate on negative peace, or the absence of violence, in the short run, and the latter two concentrate on positive peace, or the sustainment of social cooperation, in the medium and long run. ${ }^{1}$ Each chapter addresses a specific question behind an important policy debate:

1. What is the short-run effect of development aid on insurgent attacks? (Chapter 2)

2. What explains the decrease of insurgency in Iraq starting 2008? (Chapter 3)

3. Why do some ex-combatants choose to opt out of the disarmament, demobilization, and reintegration (DDR) program? (Chapter 4)

4. How can political trust be built after civil wars? (Chapter 5)

Table 1.I provides an overview of the four chapters from a comparative perspective.

In spite of their differences in focus, the four essays seek to question, challenge, and, hopefully, refine a prominent approach in conflict resolution-buying peace with cash. The cash to buy peace can take different forms: aid, community projects, job creations, and public services provision. In the rest of this chapter, I will first provide the background

1 The distinction between positive and negative peace is based on Galtung (1969). 
Table 1.1: Thesis structure

\begin{tabular}{|c|c|c|c|c|}
\hline & CHAPTER 2 & CHAPTER 3 & CHAPTER 4 & CHAPTER 5 \\
\hline Discipline & Economics & Economics & Psychology & Psychology \\
\hline $\begin{array}{l}\text { Concept of } \\
\text { peace }\end{array}$ & Negative & Negative & Positive & Positive \\
\hline Time horizon & Short & Short & Medium & Long \\
\hline Policy area & COIN & COIN & DDR & State building \\
\hline Country & Iraq & Iraq & Liberia & Sierra Leone \\
\hline $\begin{array}{l}\text { Unit of analy- } \\
\text { sis }\end{array}$ & District & District & Individual & Individual \\
\hline
\end{tabular}

about the approach and place the findings from each individual chapter in this context.

\subsection{DEVELOPMENT PROGRAMS AND COUNTERINSURGENCY}

What does one need to win a war? The Gulf War between 1990 and 1991, and the invasions of Afghanistan and Iraq in the early 2000s are good examples demonstrating how superior military capability and advanced technology can bring lightning victory in an interstate conflict. Troop size, technology, and weapons are integral to the calculus of war. In the 2003 invasion of Iraq, in less than a month's time, the Coalition forces took down Baghdad, toppled the Ba'ath regime, and achieved a decisive victory. The nuclear arms race and the Treaty on the Non-Proliferation of Nuclear Weapons also indirectly demonstrate the significance of military capacity in determining the course and outcome of an armed conflict. It is the fear of being dominated by forces that drives a country to pile up enough lethal weapons to wipe out humankind. All of the above seems to suggest that military power plays a pivotal role in attaining military success.

After the end of the Cold War, however, we observe a fundamental change in the form of warfare, namely that armed conflicts are increasingly asymmetric (Kaldor, 1999). While conventional military weapons and battlefield tactics remain relevant, they are no longer dictating the outcome of a war. Weak non-state actors become more frequently win- 
ners in an intra-state armed conflict (Arreguín-Toft, 2001) and supreme military power becomes insufficient in guaranteeing military victory. In other words, when talking about irregular intra-state conflicts, an urgent need for a new strategy emerges.

Undeniably, winning by force remains the dominant approach in the attempt of terminating a violent conflict. But as most strategists such as T. E. Lawrence and Che Guevara know well, there is always another battlefield taking place in people's hearts and minds. One can win a war on the ground but lose the tug of war in people's hearts. The wisdom indeed becomes the guiding principle of conducting modern counterinsurgency warfare.

According to the US Department of Army (2006, pp. 1-1), counterinsurgency, also known as COIN, can be defined as the 'military, paramilitary, political, economic, psychological, and civic actions taken by a government to defeat insurgency'. The concept of counterinsurgency is contingent on that of insurgency, defined as a violent contest over a political space between a state (or an occupying force) and non-state challengers (McCormick, Horton, and Harrison, 2006, p. 3). And it is because the objective of the insurgency has two parts, namely toppling the old regime and establishing a new political order, military power alone, which only takes care of the first part of the objectives, becomes insufficient. The task of establishing a new political order cannot be accomplished with force alone. In order to govern a country, one also needs to gain popular support.

The 'hearts and minds' tactic, termed by Field Marshal Sir Gerald Templer to describe the British approach to counterinsurgency in Malaya (1948-1960), is often associated with the 'minimum force' approach to counterinsurgency. The tactic holds the view of minimizing military as well as civilian casualties (Dixon, 2009; Porch, 2013). But as Dixon (2009) argues, the campaign in Malaya was no less coercive than other campaigns, so the two approaches are better seen as complements in the formula for successful counterinsurgency.

At the same time, one should note that the concept of insurgency is constantly evolving. As Kilcullen (2006, p. 115) points out, modern insurgents may not stick to the ultimate goal of displacing a government. Instead, their aims seem to be to discredit, fragment, and paralyze a state. In this light, the insurgency in Iraq can perhaps be better called a 'resistance' insurgency rather than a 'revolutionary' insurgency. And given 
the changing nature of insurgency, the concept of counterinsurgency also follows suit.

In spite of the evolution of the concept, the tactic of winning public support holds its value in contributing to military and political success and has been adopted in the counterinsurgency warfare in Iraq, Afghanistan, and Pakistan. In the case of Pakistan, at the national level, the US has used foreign assistance to induce the Pakistani government to cooperate in its efforts to defeat Al-Qaeda and other militant groups that threaten its homeland security. In the case of Iraq and Afghanistan, the old regimes were removed by the US forces. Although the US military forces still kept a certain degree of control on the ground during the transition periods, insurgencies were still active. As a part of its counterinsurgency strategy, the occupying force introduced the Commander's Emergency Response Program (CERP), a set of contingent development projects aiming to reconstruct local communities, by putting local people into work and preventing them from engaging in insurgency attacks (Berman, Shapiro, and Felter, 2011).

It is generally believed that this hearts and minds strategy has worked for three reasons. First, it can be used to win emotional support (i.e. the hearts) from the civilians and to induce them to cooperate with the military, for instance, by providing intelligence to the authority. Second, gaining people's hearts helps to cut off potential support to the insurgents, which includes logistical support and human resources (i.e. recruits). An effective program can also change the incentive structure. Material benefits, in terms of development outcomes and job opportunities, can induce people to pursue their rational self-interests (i.e. the minds) and to stop working for the insurgents. In fact, Berman, Shapiro, and Felter (2011) believe that these are the major reasons behind the reduction in the number of attacks against the Coalition forces in Iraq since 2007. Finally, a successful campaign can also shape public opinion, making military casualties and the use of violence against insurgents more tolerable in people's eyes, making people can no longer distinguish between a struggle against social injustice and the acts of terrorism.

Against this backdrop, Chapters 2 and 3 look at two separate issues in the counterinsurgency literature. The first issue, addressed in Chapter 2 , is on the unintended effects of foreign aid. The hearts-and-minds tactic employed by the US military to quell the attacks against the coalition forces in Iraq can be regarded as a form of development aid. Yet, the debate over the net effect of aid on conflict remains unsettled. While one 
set of literature contends that development aid can be an effective tool to counter insurgency, recent evidence shows that aid can threaten security as well. Chapter 2 investigated whether CERP has the claimed effect on suppressing the level of insurgency activities in Iraq. More specifically, Chapter 2 describes how local political dynamics can complicate the causal effect of development assistance on insurgent attacks. Using data from Iraq between 2004 and 2008, my dynamic panel data analysis shows that that development assistance induced more attacks against the Coalition forces. To further uncover the causal mechanism behind the relationship, Chapter 2 also examines three prominent explanations in the literature. The analysis reveals that the level of violence increased neither because insurgency became a more attractive option than legal economic activities (the opportunity costs explanation) nor because the insurgents tried to sabotage the development projects to preempt the hearts and minds effect (the preemption explanation). Furthermore, although the third, enrichment explanation can be applied to the case of Iraq, further analysis reveals that Iraqi insurgents became stronger not only by looting, as most studies suggest. The level of violence increased because project contractors needed to pay local leaders and insurgents to get access and buy security. While the US military brought down violence against them, discontented leaders contracted violence out to third-party (e.g. foreign fighters) to initiate attacks against the coalition on their behalf.

The second issue, addressed in Chapter 3 , is about the methodology of evaluating counterinsurgency policies. Recent studies, in general, confirm the effectiveness of US counterinsurgency programs in Iraq (e.g. Berman, Shapiro, and Felter, 2011). The right mix of coercion, ethnic alliance, and development projects, it is argued, makes Iraqis less likely to rebel against the US army and the Iraqi government, thus reducing the number of insurgent attacks. In fact, the number of attacks dramatically declined shortly after changes in the counterinsurgency strategy in 2007. But how robust is the positive finding? A common assumption behind the previous analyses is that insurgent attacks have a strong local root, and hence they are unlikely to be reproduced in other areas. Violation of this spatial independence assumption, however, can potentially bias towards the positive result. Based on a spatial dynamic panel data model, my analysis shows that the assumption of spatial independence is far from innocuous and should be addressed rather than being assumed away. Results based on the new model also reveal that, conditional upon other strategies, the effects of a counterinsurgency strategy vary considerably both in mag- 
nitude and direction, suggesting that some policy mixes can actually be counterproductive.

\subsection{EMPLOYMENT AND REINTEGRATION}

The economic paradigm not only finds its place in counterinsurgency but also in post-conflict reintegration. One daunting task of post-conflict stabilization is disarmament, demobilization, and reintegration (DDR). According to the United Nations Department of Peacekeeping Operations (2010a, p. 4), disarmament can be defined as the collection, documentation, control and disposal of weapons and demobilization as the controlled discharge of active combatants to the civilian society. Demobilization usually involves the provision of training to ex-combatants in cantonment sites or temporary centers. Reintegration is a social and economic process that enables ex-combatants to resume their civilian lives. DDR is increasingly included as part of a peacekeeping operation. For example, most of the recently established operations (MINUSCA in the Central African Republic (2014 - present), MINUSMA in Mali (2014 - present), MINUSTAH in Haiti (2004 - present), and UNOCI in Côte d'Ivoire (2004 - present) include DDR in their mandates.

The practice of DDR has evolved over time (United Nations Department of Peacekeeping Operations, 201ob, p. 9). The focus prior to the 1980 s was more on disarmament and demobilization. In the late 1980 s, the UN expanded the set of activities to include the building of democratic institutions. Since the early 1990s, the UN and its agencies have adopted a more development-oriented approach to DDR, embracing new considerations that include the livelihoods of ex-combatants and local communities. Second generation DDR no longer limits itself to military structures but covers communities as well. What remains unchanged, however, is the primacy of the economic security of ex-combatants, particularly in the reintegration part of the program. This emphasis is intuitive, especially in light of the robust empirical relationship between the level of economic development, income level and conflict relapse (Collier, Hoeffler, and Söderbom, 2004; Walter, 2004).

While macro, country-level evidence between income and peace is wellestablished, micro-level evidence on the relationship between individual economic security and reintegration is surprisingly weak. For example, the pioneering study by Humphreys and Weinstein (2007) finds no sys- 
tematic evidence that those internationally funded programs promote reintegration in post-conflict Sierra Leone. Using data from Afghanistan, Iraq, and the Philippines, Berman et al. (2011) do not find any significant relationship between unemployment and insurgent attacks. An experiment study by Blattman, Fiala, and Martinez (2014) in Uganda, similarly, did not find government programs targeting the poor and the unemployed to have significant impact on social cohesion, antisocial behavior, or protest. More recently, a field experiment with ex-fighters in Liberia does not find any support for the effects of training on reducing exfighers' interests in joining mercenary work (Blattman and Annan, 2016). Finally, there is no evidence showing that employment facilitates social integration among ex-combatants in Colombia (Kaplan and Nussio, 2015).

Why do most of the traditional DDR programs not work? I found that the relationship can be masked by a selection effect. Existing studies usually look past the problem of program dropout. Intuitively, people who are self-selected not to participate or to drop out from the reintegration program are different from those who opt-in and complete it. Chapter 4 looks at this issue and seeks to improve our understanding on what happens to people who have fallen outside of programs and what determines the participation and the dropout decisions of an ex-combatant. Using data from a randomized vocational training program in Liberia, Chapter 4 provides supportive evidence to the hypothesis that, compared to graduates, non-participants and dropouts of a training program show greater interests in returning to the battlefield. Further analysis also reveals that the psychological well-being of an individual is a strong predictor of non-participation. More specifically, in Chapter 4, I argue that past wrongdoings of former fighters may develop a strong moral emotion of shame once they are withdrawn from the wartime value system. In some cases, the moral emotion of shame can induce psychological trauma (Lee, Scragg, and Turner, 2001). As a part of the psychological adaptive strategy, the psychologically distressed individuals may choose to escape from stimuli associated with war memory and social rejection, showing the symptoms of psychological avoidance and social withdrawal. While this is a necessary part of the recovery process in some cases, the behavioral responses may sustain and further develop into post-traumatic stress disorders (PTSD) and hinder future reintegration. Chapter 4 provides evidence to the claim that the development of symptoms is partially shaped by the wartime experience of an ex-fighter. While the development of symptoms is only weakly correlated with the time that the ex-combatants 
spent in warring factions, the number of violent acts that the respondents were forced to commit has a strong predictive power to the incidence of psychological avoidance. Overall, the findings suggest that mental health is not only a public health issue that affects ex-combatants' quality of life, but that it can also embroil reintegration and endanger regional security.

\subsection{PUBLIC SERVICES AND STATE BUILDING}

Long-term peace needs to be buttressed by a functioning and legitimate state institution (Menocal, 2011). The process of re-creating and strengthening the required state structure to achieve this goal is called state building (e.g. see Fukuyama, 2004). Two prominent examples of reforms are democratization and economic liberalization (Jahn, 2007; Lake, 2010). The optimism towards the approach has been shared by many international donors and development agencies. For example, the general election system was re-introduced in Sierra Leone in the midst of the conflict in 1996. And a decentralization reform was proposed and implemented in the same country in 2004. International donors conceived that economic liberalization is a precondition for the development of a healthy economy. As a well-functioning economy contributes to growth and development, and democratization broadens the base of public support, thus enhancing the legitimacy of a government, both types of reform have a promising effect of ending a conflict and sustaining social cooperation (Jahn, 2007).

But as Menocal (2011) pointed out, central to the state building process is the state-society relations. As political trust is a major component of the relations, trust-building is an integral part of the state-building strategy. In fact, trust has become a fundamental concept in peace research. Many studies have shown that political trust, or the lack of it, is associated with the onset of violent conflict, the instability of negotiated settlement, and sustainability of peace (Walter, 1997; Walter, 1999). One way to build trust, according to conventional analyses, is to improve the provision of public services such as education and health care (Hetherington, 1998; Levi, Sacks, and Tyler, 2009; Rothstein, 2009). As the primary function of a state is to solve the free-riding problem associated with the public good property of these public services, it is reasoned, improved public services provision can render government legitimacy and cultivate trust in government. This relationship, however, may not hold in a postconflict setting because the state usually does not have the required ca- 
pacity to perform this function. People living in post-conflict countries are also likely to have different preferences and priorities than those living in stable democracies. For these reasons, the conventional wisdom gained from the experience of stable democracies may not be applicable in a post-conflict state.

We still know little about the trust-building process in a critical environment. Chapter 5 tries to address this knowledge gap. While previous studies have demonstrated that improved provision of public services plays a positive and significant role in trust-building, Chapter 5 shows a more nuanced picture, namely that service enhancement only works if the services are needed by people. Development projects that do not properly mirror the needs of people are found to have no direct impact on trust-building. Using micro-level data from Sierra Leone, I found that people are more likely to trust governments that are willing to listen and respond to their needs and demands. Though government performance carries the previously hypothesized effect, its explanatory power diminishes substantively once responsiveness is introduced into the whole picture. This finding also holds when potential biases due to endogeneity and sample selection are considered. Results from a mediation analysis also indicate that if government performance has any effect, it is transmitted through the responsiveness mechanism. In other words, listening and responding to the demands of the people are the most effective and direct ways of restoring trust and peace.

In the following chapters, I will elaborate on my investigation in detail. 

Part I

THE ECONOMICS OF COUNTERINSURGENCY 

Despite its uncertain effects on political violence, foreign aid is still used as a means to counter insurgency. Recent examples include the US Commander's Emergency Response Program (CERP) in Iraq and Afghanistan. This chapter describes how local political dynamics can complicate the causal effect of development assistance on insurgent attacks and estimates the effect of small development projects on attacks targeting foreign donors. Dynamic panel data analysis shows that development assistance sometimes induced more attacks against the Coalition forces, rather than reduced them. To further uncover the causal mechanism behind the relationship between aid and insurgency, I examine three prominent explanations in the literature. The analysis reveals that the level of violence increased neither because insurgency became a more attractive option than legal economic activities (the opportunity costs explanation) nor because the insurgents tried to sabotage the development projects to pre-empt the hearts and minds effect (the pre-emption explanation). Furthermore, although the third, enrichment explanation fits with the case, my analysis reveals that Iraqi insurgents became more capable in launching attacks not only through looting, as most studies suggest. The level of violence in Iraq increased because project contractors needed to pay local leaders and insurgents to secure access and buy security. While the US military buys down violence against them, discontented leaders contract violence out to third-party, most likely foreign fighters, to initiate attacks against the Coalition forces on their behalf. In this light, future counterinsurgency efforts need to bear in mind the ties between aid recipients and other actors, provide better security to contractors, or try to allocate aid more strategically.

This chapter is based on Wong, Pui-Hang. 2017a. How development aid explains (or not) the rise and fall of insurgent attacks in Iraq. UNUMERIT Working Paper 2017-006. 
Development assistance has long been employed by many state authorities as a policy tool to counter with (violent) oppositions. It has been used to win the hearts and minds of the public in exchange for support and intelligence (Berman, Shapiro, and Felter, 2011; Galula, 1964; Owens, 2013), especially in counterinsurgency. Its effectiveness, however, has been a subject of debate among scholars and policy makers alike. While some empirical studies have shown that aid is effective in deterring or ending violent conflicts (Bazzi and Blattman, 2014; Berman, Shapiro, and Felter, 2011; Collier and Hoeffler, 2002a; de Ree and Nillesen, 2009; Savun and Tirone, 2012), some have found it ineffective or, in some cases, counterproductive (Crost, Felter, and Johnston, 2014; Dube and Naidu, 2015; Narang, 2014; Narang, 2015; Nunn and Qian, 2014; Sollenberg, 2012; Wood and Sullivan, 2015).

This chapter provides further empirical evidence to the debate and finds that development assistance induced more violence in Iraq in the short run, a finding consistent with the second body of literature discussed above and in contrast to the 'hearts and minds effect' reported in Berman, Shapiro, and Felter (2011) and endorsed by Martins (2004). ${ }^{1}$ This chapter argues that the relationship between aid and insurgency in Iraq is determined by local political dynamics, which can cause an endogeneity problem that may bias the analysis. This empirical problem is particular challenging when the number of endogenous variables is big and high-quality data are lacking at the same time, a problem commonly encountered by analysts studying a conflict-ridden region. To engage this challenge, I employ a standard technique frequently applied in dynamic panel data estimation (Arellano and Bond, 1991; Blundell and Bond, 1998), which consists in instrumenting all policy variables with their own lags and estimating the models with the difference-GMM and system-GMM methods. ${ }^{2}$ My analysis shows that the pacifying effect can be explained by the security-related component of the Commander's Emergency Response Program (CERP), instead of the development components centered on the hearts and minds argument. To further disentangle the mechanism that links aid and violence, this chapter also examines which existing theory is most likely to explain the positive relationship between the two. My analysis suggests that the violence-inducing effect of aid can be explained by the capacity explanation, which states that aid may em-

I See Rangwala (2009) and Cohen (2014) for criticisms to the approach.

2 See Dreher, Marchesi, and Vreeland (2008), Fuchs and Klann (2013), Touchton (2016) for examples of application. 
power rebels and fuel further violence (e.g. Narang, 2014). This finding also provides a refinement to the theory. Instead of saying that insurgents become more powerful through looting, as most studies propose (e.g. Wood and Sullivan, 2015), this chapter suggests that corruption and the commensal relationship among local leaders, contractors, and insurgents can also explain the violence-inducing effect of aid in the case of Iraq. While the US military directly paid the Sunni sheikhs to buy down violence, local leaders contracted violence out to (foreign) fighters to induce more attacks. Making use of the payments from sheikhs and project contractors to reinvest in the insurgency, insurgents were able to initiate more attacks on behalf of the discontented tribal leaders.

In the following sections, I will first provide an overview of the literature, then discuss the local dynamics in Iraq and finally explain how these dynamics can influence the validity of the results reported in earlier studies. After introducing the data and methodology used, and presenting my econometric results, I will show which theory can better explain the violence-inducing effect of aid in the case of Iraq. The final section will highlight some policy lessons and conclude.

\subsection{IMPACTS OF FOREIGN AID ON POLITICAL VIOLENCE}

In a series of studies, Collier and Hoeffler propose that foreign aid is likely to have a pacifying effect in reducing the risks of civil conflict (Collier and Hoeffler, 1998; Collier and Hoeffler, 2002a; Collier and Hoeffler, 2002b). In brief, they argue that aid can improve the economic health of a country. As a better and healthier economy will raise the opportunity costs of rebellion, aid can help a country escape a conflict trap. Many of the follow-up studies try to identify this pacifying effect of aid in different ways. For example, applying the classical military deterrence argument, Bazzi and Blattman (2014) propose that aid can deter rebellion by increasing the military capacity of the recipient governments. Focusing on aid withdrawal, Nielsen et al. (2011) argue that aid withdrawal will weaken the military capacity of governments that have long been dependent on foreign assistance to buy peace from potential rebels. In another study, Savun and Tirone (2012) posit that aid can alleviate income shocks and hence prevents the occurrence of conflict by allowing recipient governments to distribute resources to potential rebels to pre-empt violent oppositions in times of severe economic downturns. In another study, 
Berman, Shapiro, and Felter (2011) theorize that development assistance from the US has improved the living conditions of Iraqis. Accordingly, development assistance wins the hearts and minds of the population, inducing a higher level of public support and cooperation, discouraging public support to insurgents, facilitating intelligence gathering, and discouraging public support to insurgents. In common, these studies portray a negative relationship between aid and conflict and consider aid as an income source that can strengthen a country's position in combating or co-opting oppositions inside the country.

Yet, every story has a dark side. Some researchers contend that aid can induce violence. According to Hirshleifer (1991) and Grossman (1992), aid generates economic rents and raises the expected returns on insurrection. Therefore, it increases the chances of conflict. Similar arguments have been put forth by more recent studies. For example, Wood and Sullivan (2015) state that aid is frequently stolen or looted en route by armed groups. Nunn and Qian (2014) point out that donors may have difficulty excluding local armed groups from benefiting from food aid if their members are malnourished and hence qualified to receive it. Chacón (2013) finds that rebel groups in Colombia often attacked local authorities in order to capture more fiscal transfers from the central governments. Dube and Naidu (2015) add that foreign military assistance can also strengthen armed non-state actors, undermining political institution in Colombia. Finally, Narang (2014) and Narang (2015) theorize that because humanitarian assistance can improve the bargaining position of the aid recipients, it may exacerbate the commitment problem and increases the chances of war recurrence.

\subsection{LOCAL POLITICS AND THE EFFECT OF DEVELOPMENT AID IN IRAQ}

In spite of the controversy, foreign aid is still used as a tool to counter with insurgencies, for example, by the US military in Iraq and Afghanistan. In a review of the program, Lieutenant Colonel Martins (2004) refers to CERP as a program that wins trust and meets emergency needs of civilians in Iraq and Afghanistan. According to Martins (2004), the source of the funds originally came from the loots of the Ba'ath Party, which the US forces had discovered shortly after the Iraq War in 2003. The resources were designated to be spent on emergency relief and reconstruc- 
tion in areas such as food, sanitation, infrastructure, health care, education, telecommunications, transportation, and irrigation systems, to name but a few. Later on, the use was extended to pay for services provided by the local people, which included repair and installation of generators, reconstruction of bridges, roads, schools, hospitals, and government buildings. The idea was to let local people engage in economic activities that contribute to the rebuilding of the country. Moreover, the assets were also allowed to be used to recruit, train, and deploy police, security guards and civil defense corps units (Martins, 2005, p. 49). In other words, CERP is not only a development program that aims to improve the livelihoods of the local people. It is also a security program that tries to enhance law and order in the country thought development. While Berman, Shapiro, and Felter (2011) argue that CERP successfully won the hearts and minds of Iraqis, and that its success explains the decline of insurgent attacks against the Coalition forces, one may contend, in light of the empirical debate and the political dynamics to be discussed below, that development assistance may not work through the hearts-and-minds argument as proposed.

Many studies have demonstrated that rebels are more adaptive than what policy makers believe them to be (e.g. Hoffman, 2004). When foreign assistance is used by the domestic government to mobilize public support, rebel groups are well aware of the potential challenges that the assistance could bring. In fact, they have used the same tactics to gain popularity and legitimacy in their struggles with the authorities. 3 This interaction between the local government and rebel groups not only means that aid is usually assigned according to the level of violence in a region, but it also implies that the assistance itself could be a potential cause of further violence against the state. In their empirical analysis, Crost, Felter, and Johnston (2014) show that development assistance, in the short run, induced more violence in the Philippines. Using the regression discontinuity design, their study exploits the fact that only the poorest 25 per cent of municipalities in participating provinces were eligible for the community-driven development programs in the country. The program design essentially created a discontinuity in aid assignment that enables the scholars to estimate the causal effect of development aid on conflict causalities. Their study found that municipalities that had been barely

3 One popular example is Hamas. By providing local communities with the necessary public goods and services like education, the organization secured popular support and political legitimacy among the public (Berman et al., 2011; Levitt, 2008). 
eligible to development program experienced a large increase in conflict casualties when compared to those just ineligible to it.

Although the clever research design clearly shows that development assistance in some cases does cause more violence, we do not know to what extent the effect is linked to the mechanisms proposed by the different theories. Furthermore, one major issue related to the argument is that the insurgent attacks may also undermine public support for the rebels because the public knows that violence also affects local development and exacerbates their plight, which in turns may create a similar, higher-order, hearts-and-minds effect.

Although in a slightly different way, the dynamics described above are indeed observed in the case of Iraq. One component of the Commander's Emergency Response Program (CERP) involves payments to the local militia, also known as the Sons of Iraq (SOI) program in the country (Marten, 2012; Martins, 2005). While the motives of the local Sunni tribes to join the SOI program were diverse, a reason that compelled them to ally with their former enemies was to seek protection from the US military against Al-Qaeda Iraq's (AQI) prey on them (Biddle, Friedman, and Shapiro, 2012). As McCary (2009) outlined, AQI had gradually taken over profitable businesses and smuggling routes from the local tribes. AQI also forcibly married (i.e. kidnapped and raped) Iraqi women and tortured, assassinated, and murdered tribal leaders (Long, 2008; Marten, 2012; McCary, 2009, pp. 77, 150, 47). These acts of violence led local sheikhs to feel that AQI was competing with them for authority and the control of money. Although the acts of AQI were driven by their religious ideology and economic interests, and hence cannot be explained by the preemptive motive underlying in the Philippines case discussed before, they produced the same effect of relinquishing public support to their enemy, the US military. As the dynamics above explain both the decline of attacks directed towards the Coalition forces after the formation an alliance and the allocation of aid at the same time, this third factor may confound with the hearts and minds effect claimed by previous research.

Other dynamics, which are specific to the Iraqi case at hand, are related to the self-selected nature of the SOI program. As Marten (2012, p. 44) suggests, the militias enrolled in the SOI program were non-random and self-selected armed bands. Many of them were part of Saddam Hussein's security forces and the Iraqi Army, which were dismissed by the Coalition Provisional Authority (CPA) immediately after the US occupation in 2003 (Dobbins, 2009). As Biddle $(2008$, p. 5) testified before the US Senate 
Committee on National Security on Foreign Relations, those formations "are essentially the same units, under the same leaders, that fought Coalition forces until agreeing to stop in 2007". This observation is important because it points out to the fact that the potential recipients of the funds were also the insurgents who were responsible for the attacks. In a nutshell, the SOI program can be understood as "a series of bilateral contractual agreements in which particular groups of local Iraqis agree not to fight the United States" (Biddle, 2008, p. 3). In other words, at least part of the aid was reversely determined by the number of attacks directed at the Coalition forces.

Furthermore, the security situation of the local community affects the startup and progress of development projects. In its quarterly report to the Congress, the US Department of Defense (2008) stated that the Coalition forces had seized the opportunities of enhanced security to promote reconciliation with the local people. Examples of these reconciliation efforts include the reopening of schools, clinics, markets, and other social services (US Department of Defense, 2008). The possibility of implementing these projects indicates that a region was stable enough for reconstruction. 4 This implies that aid can be a product instead of a cause of the enhanced security. Consequently, empirical tests that do not distinguish between them are likely to overstate the effect of CERP.

The issues discussed above point to the fact that the relationship between development assistance and conflict is not always straight-forward and is more complicated than what existing theories assume it to be. More importantly, these dynamics imply that reverse causality and common third-factor are shaping the relationship at the same time. Given the challenge of data deficiency in conflict-ridden regions, this kind of endogeneity is difficult to be accounted for. In the chapter, I model the relationship between aid and violence using a dynamic panel data model and instrument all policy variables with their own lags (Arellano and Bond, 1991). Admittedly, this identification strategy is based on statistical assumptions (to be validated by statistical tests) rather than on a more acclaimed quasiexperimental design. But when instruments are not available given the

4 As the CERP variable is calculated by distributing the project money throughout the project period, a secure environment that enables a project to be implemented more smoothly will translate into higher policy intensity in the model. For example, suppose that the cost of a project is $\$ 100,000$. If it is completed in 10 months, the CERP spending is $\$ 10,000$ per month. If the project is finished in 5 months, the spending becomes $\$ 20,000$ per month. A shorter project period due to increased security is translated into higher policy 'intensity'. 
difficulty of finding valid ones for each of the policy variables, this approach at least gives us more reliable results than the usual OLS and fixed-effect models do.

\subsection{DATA}

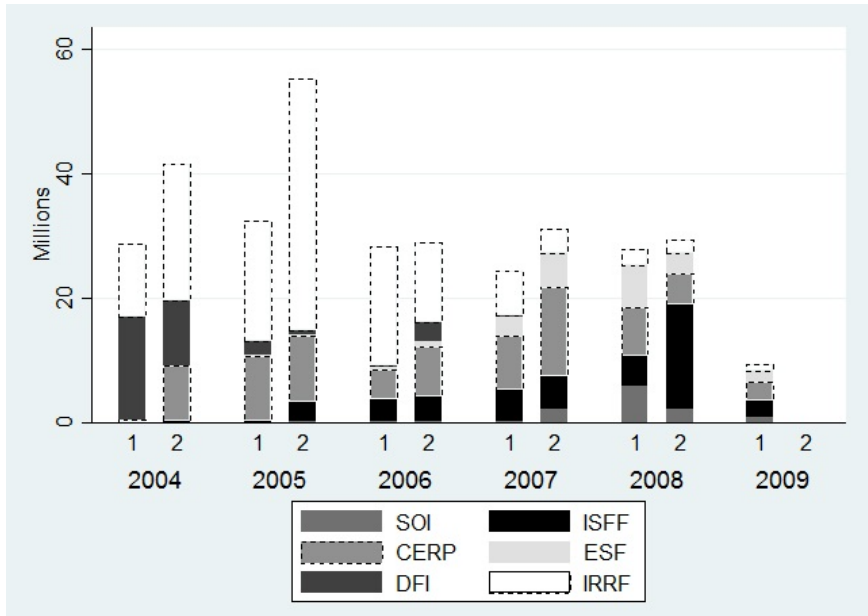

Figure 2.1: Distribution of aid programs between 2004 and 2009

To foster comparability between findings across studies, following Berman, Shapiro, and Felter (2011), I used the number of attacks against the Coalition forces divided by the size of the population as the dependent variable. 5 The key independent variables are different types of funds. In their study, Berman, Shapiro, and Felter (2011), henceforth BSF, only made use of the funding data on the Commander's Emergency Response Program (CERP). The spending on CERP, however, represents only a portion of the project money to the country between 2004 and 2009. As Figure 2.I shows, a larger share of funds originates from other programs such as the Iraq Relief and Reconstruction Fund (IRRF). Given the size and possible correlation between project money and the CERP spending, leaving these funds out in an analysis may lead to omitted variable bias, overestimating the true impact of CERP on the insurgency in Iraq.

Fortunately, the original dataset used by BSF contains detailed information on different types of funds. Based on their dataset, among all 40

5 Note that the population data is imperfect as population size may change over time. 
funds, I augmented my empirical model by including four other major funds: Iraq Security Forces Fund (ISFF), IRRF, Economic Support Fund (ESF), and Development Fund for Iraq (DFI). These four programs, plus CERP, in total cover about 90 per cent of all projects recorded in the dataset. A brief description of these funds can be found in Table 2.1.

To capture the effect of the alliance between the Coalition forces and local power, I rely on the Sons of Iraq (SOI) indicator in the BSF dataset, which indicates whether or not the payments were deemed to be made to the local militias. Based on the dataset, payments to SOI mainly came from four different programs and CERP accounts for 99.6 per cent of them. In their chapter, BSF did not distinguish the payments made for development projects and security because both elements form an integral part of their theoretical model. In this way, the negative effect they found may be due to the payments for security, instead of the ones for development. To further partial out the effect due to development assistance, this study makes such distinction, so the CERP variable in this study is different from the one in BSF and captures mainly the development components (i.e. the non-SOI part) of the program. According to the dataset, about 10 per cent of all CERP projects are related to SOI.

I also included a number of control variables in my analysis. They are population, income change between 2002 and 2004, the share of Sunni population, unemployment rate, troop size, and pipeline volume (weighted by the prices of oil and gas adjusted for inflation). Except for the troop size data, which is from Belasco (2009), all data come from the original dataset used by BSF. The cross-sectional unit is district (104 districts) and the time unit is half-year (10 periods). Table 2.2 below provides the summary statistics of the variables used in the analysis. 
Table 2.1: Major US development assistance in Iraq

\begin{tabular}{ll}
\hline \multicolumn{1}{c}{ FUND } & \multicolumn{1}{c}{ DESCRIPTION } \\
\hline Iraq Security Forces Fund (ISFF) & $\begin{array}{l}\text { The Fund provides assistance to the se- } \\
\text { curity forces of Iraq, including training } \\
\text { and provision, transportation, and mainte- } \\
\text { nance of equipment. }\end{array}$ \\
\hline Iraq Relief and Reconstruction & $\begin{array}{l}\text { The Fund disburses relief aid (e.g. food, } \\
\text { medicine, and water) and provides assis- } \\
\text { tance to the rebuild of infrastructure (e.g. } \\
\text { electricity) and institution (e.g. election) in } \\
\text { the country. }\end{array}$ \\
\hline Economic Support Fund (ESF) & $\begin{array}{l}\text { The Fund supports programs that help } \\
\text { achieve U.S. foreign policy objectives, e.g. } \\
\text { building accountable and transparent insti- } \\
\text { tutions, creating economic and educational } \\
\text { opportunities for youth, and countering ex- } \\
\text { tremist ideology. }\end{array}$ \\
\hline Development Fund for Iraq (DFI) & $\begin{array}{l}\text { Managed by the Coalition Provisional Au- } \\
\text { thority, the fund aims to strengthen the fi- } \\
\text { nancial stability of the Iraq economy. For } \\
\text { example, it is used to meet cash payment } \\
\text { requirements in the wheat purchase pro- } \\
\text { gram, the currency exchange program, the } \\
\text { electricity and oil infrastructure programs, } \\
\text { equipment for Iraqis security forces, and } \\
\text { for Iraqi civil service salaries and ministry } \\
\text { budget operations. }\end{array}$ \\
\hline & \\
\hline &
\end{tabular}

Source: Coalition Provisional Authority (2004), US Department of Defense (2012), US Department of State (2006), and US Department of State (2010) 
Table 2.2: Summary statistics

\begin{tabular}{lrrrrr}
\hline \multicolumn{1}{c}{ VARIABLES } & N & MEAN & \multicolumn{1}{c}{ SD } & MIN & MAX \\
\hline Intensity (no. of attacks /wk) & 1,040 & 66.54 & 179.40 & 0 & 2,275 \\
Troops ('ooo persons) & 1,040 & 189.90 & 13.22 & 170.5 & 219.00 \\
Unemployment (\%) & 1,040 & 10.51 & 6.95 & 0 & 50.90 \\
Sunni share (\%) & 1,144 & 19.99 & 34.02 & 0 & 100.00 \\
Income change ('ooo IQD / mth) & 1,100 & -334.10 & 655.70 & $-1,837$ & 1,642 \\
ln(pop) & 1,040 & 12.04 & 1.03 & 9.303 & 14.34 \\
Resources (mil. USD) & 1,144 & 11.36 & 25.63 & 0 & 220.80 \\
SOI (USD/persons) & 1,040 & 0.04 & 0.46 & 0 & 14.18 \\
ISFF (USD/persons) & 1,040 & 0.19 & 1.88 & 0 & 53.64 \\
CERP (USD/persons) & 1,040 & 0.40 & 2.98 & 0 & 78.18 \\
ESF (USD/persons) & 1,040 & 0.041 & 0.28 & 0 & 8.018 \\
DFI (USD/persons) & 1,040 & 0.30 & 6.10 & 0 & 189.00 \\
IRRF (USD/persons) & 1,040 & 0.57 & 5.26 & 0 & 157.30 \\
\hline
\end{tabular}

\subsection{MODELS}

My analysis will begin with OLS, and then proceed with the typical fixedeffect and random-effect models. A potential problem with the estimates from OLS and fixed-effect model is that the level of violence is inherently time-dependent. The time dependence is not only due to district-specific characteristics (e.g. being the capital of the country, which is taken care of by the fixed effect) but also inertia (e.g. taking time for adjustments). If time dependence matters, all results based on OLS, fixed-effect, and random-effect models can be potentially biased. Another problem is that OLS and fixed-effect estimators assume that the independent variables are exogenous. This assumption is likely to be violated when the allocation of funds is a response to the level of violence observed in a district (i.e. reverse causality).

To engage the above empirical challenges, I will use a dynamic panel data model in my estimation, with the lags of the endogenous variables as instruments (Arellano and Bond, 1991; Holtz-Eakin, Newey, and Rosen, 1988). ${ }^{6}$ In this type of model, estimation can be challenging because

6 Interested readers are referred to Roodman (2009) for further discussion on the method. 
our data only have a short time-dimension. This induces the Nickell bias when the past level of violence is correlated with the fixed-effect (Nickell, 1981). Serial correlation and the endogenous nature due to time dependence will also produce inconsistent estimates. To address these issues, the difference GMM (Arellano and Bond, 1991) and system GMM (Blundell and Bond, 1998) estimators are used to obtain more accurate estimates. In difference GMM, the first-difference transformation is used to eliminate the fixed-effect to get rid of the correlation between the fixedeffect and the error term. In system GMM, lag terms that are uncorrelated with the fixed-effect are used as instruments. A weakness of difference GMM is that we are going to lose some data because of differencing. As a sensitivity check, I estimate the model using both methods.

\subsection{EMPIRICAL FINDINGS}

The estimation results are reported in Table 2.3. Results based on OLS estimation suggest that development programs such as CERP have a positive effect on the level of violence. A higher payment amount spent on development projects is associated with a higher level of violence. Payments to militia have a similar effect. By contrast, the size of troops on the ground seems to reduce the number of attacks effectively. The model specified in column (2) extends the one in column (1) by including other projects. The inclusion of the new variables seems to have no significant impact as the estimates have similar size across two models. Only DFI is found to have a negative and statistically significant effect on the level of violence.

Results based on OLS are prone to unit-specific unobserved heterogeneity and can be seriously biased. Examples of this unit-specific effect include proximity to the country's political center and the symbolic importance of a place. To account for these time-invariant effects, I re-estimated the two models using both fixed-effect and random-effect estimators. The p-values obtained from the Hausman test suggest that the fixed-effect model better fits the data. Estimation results from the fixed-effect model are reported in columns (3) and (4). Notice that due to data limitation, the Sunni share and income change variables are time-invariant. Therefore, both variables are dropped in the reported fixed-effect models. ${ }^{7}$ In the

7 Sunni share and income change data for four districts were not available. This explains why we have more observations with the fixed-effect than with the OLS model. 
Table 2.3: Effect of foreign assistance on conflict intensity in Iraq: Static models

\begin{tabular}{|c|c|c|c|c|c|c|c|c|}
\hline & $\begin{array}{l}\text { (1) } \\
\text { OLS }\end{array}$ & & $\begin{array}{l}(2) \\
\text { OLS }\end{array}$ & & $\begin{array}{l}\text { (3) } \\
\mathrm{FE}\end{array}$ & & $\begin{array}{l}(4) \\
\text { FE }\end{array}$ & \\
\hline Pop & $\begin{array}{l}-12.237 \\
(12.980)\end{array}$ & & $\begin{array}{l}-12.108 \\
(12.839)\end{array}$ & & $\begin{array}{l}-25.173 \\
(24.857)\end{array}$ & & $\begin{array}{l}-24.083 \\
(24.906)\end{array}$ & \\
\hline Resources & $\begin{array}{r}-0.707 \\
(0.371)\end{array}$ & * & $\begin{array}{r}-0.682 \\
(0.371)\end{array}$ & * & $\begin{array}{r}-0.116 \\
(0.258)\end{array}$ & & $\begin{array}{r}-0.085 \\
(0.253)\end{array}$ & \\
\hline Unemployment & $\begin{array}{l}-3.480 \\
(1.603)\end{array}$ & $* *$ & $\begin{array}{l}-3.496 \\
(1.599)\end{array}$ & $* *$ & $\begin{array}{r}0.076 \\
(0.731)\end{array}$ & & $\begin{array}{r}0.060 \\
(0.737)\end{array}$ & \\
\hline Troops & $\begin{array}{l}-1.256 \\
(0.382)\end{array}$ & $* * *$ & $\begin{array}{l}-1.146 \\
(0.347)\end{array}$ & $* * *$ & $\begin{array}{l}-1.193 \\
(0.332)\end{array}$ & & $\begin{array}{r}-1.171 \\
(0.337)\end{array}$ & \\
\hline CERP & $\begin{array}{c}57.080 \\
(22.877)\end{array}$ & $* *$ & $\begin{array}{c}57 \cdot 714 \\
(22.970)\end{array}$ & $* *$ & $\begin{array}{r}6.601 \\
(0.641)\end{array}$ & $* * *$ & $\begin{array}{r}6.189 \\
(0.696)\end{array}$ & $* * *$ \\
\hline SOI & $\begin{array}{l}15.892 \\
(5.884)\end{array}$ & $* * *$ & $\begin{array}{l}15.741 \\
(5.914)\end{array}$ & $* * *$ & $\begin{array}{r}-40.126 \\
(6.710)\end{array}$ & $* * *$ & $\begin{array}{r}-40.160 \\
(6.747)\end{array}$ & $* * *$ \\
\hline ISFF & & & $\begin{array}{r}-0.969 \\
(1.537)\end{array}$ & & & & $\begin{array}{r}-2.812 \\
(1.173)\end{array}$ & $* *$ \\
\hline IRRF & & & $\begin{array}{r}-0.431 \\
(0.553)\end{array}$ & & & & $\begin{array}{r}0.364 \\
(0.275)\end{array}$ & \\
\hline ESF & & & $\begin{array}{c}-8.952 \\
(14.609)\end{array}$ & & & & $\begin{array}{r}-1.755 \\
(6.990)\end{array}$ & \\
\hline DFI & & & $\begin{array}{r}-14.893 \\
(5.879)\end{array}$ & ** & & & $\begin{array}{r}-0.786 \\
(0.180)\end{array}$ & $* * *$ \\
\hline Sunni & $\begin{array}{r}2.110 \\
(0.532)\end{array}$ & $* * *$ & $\begin{array}{r}2.152 \\
(0.547)\end{array}$ & $* * *$ & & & & \\
\hline Income & $\begin{array}{r}-0.048 \\
(0.022)\end{array}$ & $* *$ & $\begin{array}{l}-0.048 \\
0.022)\end{array}$ & $* *$ & & & & \\
\hline Cons & $\begin{array}{l}425.497 \\
(208.703)\end{array}$ & $* *$ & $\begin{array}{l}404.689 \\
(204 \cdot 380)\end{array}$ & * & $\begin{array}{l}582.159 \\
(344.524)\end{array}$ & * & $\begin{array}{l}565.113 \\
(346.190)\end{array}$ & \\
\hline $\begin{array}{l}\text { Period dummy } \\
\mathrm{R}^{2} \\
\text { Hausman test } \\
\text { (p-value) }\end{array}$ & $\begin{array}{r}\text { Yes } \\
0.261\end{array}$ & & $\begin{array}{r}\text { Yes } \\
0.263\end{array}$ & & $\begin{array}{r}\text { Yes } \\
0.132 \\
0.000\end{array}$ & & $\begin{array}{r}\text { Yes } \\
0.135 \\
0.000\end{array}$ & \\
\hline $\begin{array}{l}\text { No. districts } \\
\text { Observations }\end{array}$ & $\begin{array}{r}100 \\
1,000\end{array}$ & & $\begin{array}{r}100 \\
1,000\end{array}$ & & $\begin{array}{r}104 \\
1,040\end{array}$ & & $\begin{array}{r}104 \\
1,040\end{array}$ & \\
\hline
\end{tabular}

Note: Robust standard errors in parentheses. Standard errors are clustered by districts.

$$
{ }^{* * *} \mathrm{p}<0.01,{ }^{* *} \mathrm{p}<0.05,{ }^{*} \mathrm{p}<0.1
$$

new models, similar results were obtained, but the estimates corresponding to the SOI variables now have the expected sign and are statistically significant at 1 per cent level.

We move on to the results based on dynamic panel data models, which further guard us against bias due to the time-dependent nature of violence and the endogenous relationship between violence and counterinsurgency efforts. Estimates based on the dynamic panel data model, re- 
ported in Table 2.4 give results similar to what we have found thus far: CERP has a positive effect and SOI has the expected negative effect on violence. In short, this finding suggests that the negative net effect reported in BSF is likely to be due to the SOI component instead of the development component of CERP. ${ }^{8}$

Regarding estimates of other control variables, the share of Sunni in the population, income change, the approximated size of the population, and unemployment are found to have the expected effects, but they are not statistically significant most of the coefficients. The effect of resource rents is even less certain as the sign of the estimate is not very stable. In spite of the mostly non-significant results, the patterns are largely consistent with what other studies have reported. 9

In general, results from models based on four different estimators (OLS, two-way fixed-effect, difference GMM, and system GMM) depict a fairly consistent picture, that development aid induces violence while payments to local militias (resembling SOI) reduce it. According to the system GMM model, one million US dollars of development aid is associated with about 15 attacks per capita in a half-year period. On the other hand, the success of troop surge is only confirmed by estimation results from the OLS and the fixed-effect models. While the coefficient corresponding to the troop surge variable carries the expected sign, the size of the effect is

8 As Roodman (2009) discussed, while OLS yields upward-biased estimates of the coefficient of the lagged dependent variable, the fixed-effect model gives downward-biased estimates of the coefficient. In other words, the estimates obtained from the two models should bracket the true size of the coefficient. This property should provide a useful external check on the results obtained from the GMM estimators. As shown in columns (5) and (6), the property discussed above implies that the size of the estimate should lie in the range of 0.534 to 0.867 , which is less than one, ensuring that the system is stable. Estimates from both difference GMM and system GMM, reported in columns (7) and (8), are equal to 0.799 and 0.845 , falling within the prescribed range. As the estimate from GMM estimates could be quite unstable, this finding provides additional support to the reliability of the results obtained from the GMM estimators. In terms of substantive effect, the estimates are sizeable and statistically significant, suggesting that the dynamic effect is strong and present. Regarding the model selection, I chose the model based on the $\operatorname{AR}(2)$ and the statistic from the over-identification tests (i.e. the Hansen test and the Sargan test). Models (7) and (8) pass the AR(2) test and the over-identification test but not the $\operatorname{AR}(1)$ test. But the latter is expected because of the differencing (Roodman, 2009: 105). This property renders the AR(1) test not informative in our case.

9 For example, see Berman et al. (2011) on the non-effect of unemployment, and Bazzi and Blattman (2014) on the non-effects of income shocks. Case-study evidence has documented that much of the violence against the Coalition forces were initiated by the Sunni population in the region due to the loss of political power after the Iraq War (e.g. Marten, 2012). 
Table 2.4: Dynamic effects of foreign assistance on conflict intensity in Iraq

\begin{tabular}{|c|c|c|c|c|c|c|c|c|}
\hline & $\begin{array}{l}\text { (5) } \\
\text { OLS }\end{array}$ & & $\begin{array}{l}(6) \\
\mathrm{FE}\end{array}$ & & $\begin{array}{c}(7) \\
\text { D.GMM }\end{array}$ & & $\begin{array}{c}(8) \\
\text { s.GMM }\end{array}$ & \\
\hline$y_{t-1}$ & 0.867 & $* * *$ & $\begin{array}{r}0.534 \\
(0.052)\end{array}$ & $* * *$ & $\begin{array}{r}0.799 \\
(0.258)\end{array}$ & $* * *$ & 0.845 & $* * *$ \\
\hline Pop & $\begin{array}{r}(0.027) \\
-1.198 \\
(2.257)\end{array}$ & & $\begin{array}{c}(0.053) \\
-22.735 \\
(10.717)\end{array}$ & & $\begin{array}{c}(0.258) \\
13.416 \\
(86.615)\end{array}$ & & $\begin{array}{c}(0.199) \\
-8.152 \\
(11.857)\end{array}$ & \\
\hline Resources & $\begin{array}{r}0.026 \\
(0.055)\end{array}$ & & $\begin{array}{r}-0.033 \\
(0.358)\end{array}$ & & $\begin{array}{r}4.733 \\
(6.567)\end{array}$ & & $\begin{array}{r}-0.019 \\
(1.568)\end{array}$ & \\
\hline Unemployment & $\begin{array}{r}-0.766 \\
(0.407)\end{array}$ & * & $\begin{array}{r}-0.435 \\
(0.614)\end{array}$ & & $\begin{array}{c}17.828 \\
(12.335)\end{array}$ & & $\begin{array}{r}1.788 \\
(4.322)\end{array}$ & \\
\hline Troops & $\begin{array}{r}-0.950 \\
(0.603)\end{array}$ & & $\begin{array}{r}-0.467 \\
(0.525)\end{array}$ & & $\begin{array}{r}-6.815 \\
(5.415)\end{array}$ & & $\begin{array}{l}-3.027 \\
(2.570)\end{array}$ & \\
\hline CERP & $\begin{array}{r}3.478 \\
(0.288)\end{array}$ & $* * *$ & $\begin{array}{r}4.945 \\
(0.388)\end{array}$ & $* * *$ & $\begin{array}{l}19.683 \\
(6.184)\end{array}$ & $* * *$ & $\begin{array}{l}15.403 \\
(1.850)\end{array}$ & $* * *$ \\
\hline SOI & $\begin{array}{r}-38.837 \\
(4.537)\end{array}$ & $* * *$ & $\begin{array}{c}-52.784 \\
(9.012)\end{array}$ & $* * *$ & $\begin{array}{l}-48.916 \\
(13.459)\end{array}$ & $* * *$ & $\begin{array}{l}-66.187 \\
(20.068)\end{array}$ & $* * *$ \\
\hline ISFF & $\begin{array}{r}-1.933 \\
(0.853)\end{array}$ & $* *$ & $\begin{array}{r}-2.979 \\
(1.009)\end{array}$ & $* * *$ & $\begin{array}{l}-17.809 \\
(18.411)\end{array}$ & & $\begin{array}{r}-1.755 \\
(1.902)\end{array}$ & \\
\hline IRRF & $\begin{array}{r}-0.061 \\
(1.823)\end{array}$ & & $\begin{array}{r}0.204 \\
(1.474)\end{array}$ & & $\begin{array}{r}-29.620 \\
(7.560)\end{array}$ & $* * *$ & $\begin{array}{r}-38.154 \\
(7.041)\end{array}$ & $* * *$ \\
\hline ESF & $\begin{array}{l}-9.280 \\
(4.003)\end{array}$ & $* *$ & $\begin{array}{r}-9.761 \\
(5.030)\end{array}$ & * & $\begin{array}{l}-86.961 \\
(75.342)\end{array}$ & & $\begin{array}{c}27.872 \\
(27.484)\end{array}$ & \\
\hline DFI & $\begin{array}{r}1.325 \\
(0.343)\end{array}$ & $* * *$ & $\begin{array}{r}0.559 \\
(0.511)\end{array}$ & & $\begin{array}{c}30.885 \\
(147 \cdot 343)\end{array}$ & & $\begin{array}{l}-40.084 \\
(120.420)\end{array}$ & \\
\hline Constant & $\begin{array}{l}196.714 \\
(122.986)\end{array}$ & & $\begin{array}{l}394.845 \\
(193.495) \\
\end{array}$ & $* *$ & & & $\begin{array}{l}648.628 \\
(427.463)\end{array}$ & \\
\hline Period dummy & Yes & & Yes & & Yes & & Yes & \\
\hline $\begin{array}{l}\mathrm{R}^{2} \\
\text { GMM lag range } \\
\text { Instumented var. }\end{array}$ & 0.743 & & 0.402 & & $\begin{array}{r}5 \text { to } 8 \\
y_{t-1} \\
\text { troops } \\
\text { all } \\
\text { funds }\end{array}$ & & $\begin{array}{r}5 \text { to } 7 \\
y_{t-1} \\
\text { troops } \\
\text { all } \\
\text { funds }\end{array}$ & \\
\hline $\mathrm{AR}(1)$ test & & & & & 0.058 & & 0.068 & \\
\hline $\mathrm{AR}(2)$ test & & & & & 0.778 & & 0.176 & \\
\hline Hansen test & & & & & 0.529 & & 0.219 & \\
\hline Sargan test & & & & & 0.686 & & $0.45^{8}$ & \\
\hline No. districts & 104 & & 104 & & 104 & & 104 & \\
\hline Observations & 936 & & 936 & & 832 & & 936 & \\
\hline
\end{tabular}

Note: Robust clustered standard errors in parentheses. Number of instruments = 37 (D.GMM) and 38 (S.GMM). Degrees of freedom for the Hansen test excluding GMM instruments = 14 (D.GMM) and 13 (S.GMM).

$$
\text { *** } \mathrm{p}<0.01,{ }^{* *} \mathrm{p}<0.05,{ }^{*} \mathrm{p}<0.1 \text {. }
$$

rather uncertain; the p-values is equal to 0.221 based on the model using difference GMM and 0.242 based on the model using system GMM. 
Admittedly, results from the above analysis only inform us that development aid seems to induce more violence in Iraq in the short run. It does not tell us how that is the case. In this section, I will inspect which mechanism(s) that have been identified in the literature and reviewed in the second section of this chapter are responsible for the positive effect found in the econometric analysis above. As the success of the SOI program has been extensively covered by other studies, ${ }^{10}$ I will limit my discussion to the surprising finding between development assistance and insurgent attacks.

\subsubsection{The cost-benefit mechanism}

The cost-benefit explanation claims that aid will induce a higher level of violence when the relative returns on rebellion increase with respect to other economic activities (Grossman, 1992; Hirshleifer, 1991). One can also apply the general equilibrium model of Grossman (1992) directly to the case of Iraq and then infer that Sunni insurgents would remain active because CERP provides a better employment opportunity that otherwise would not have been available to them.

Several observations render this explanation unlikely. First, although it sounds plausible, the theory assumes that the employed local Iraqis were indifferent to the stay of the Coalition forces, an assumption difficult to be substantiated. In their analysis of the security situation in Iraq, the US Department of Defense (2007) stated that violent oppositions came from various political, religious, and ethnic groups. The common, primary goal of the destabilizing forces in Iraq was to expel the Coalition forces from Iraq (US Department of Defense, 2007). These forces included Sunni insurgents, AQI, and Jaysh al-Mahdi (JAM), all of which recruited both Sunni and Shiite fighters from Iraq and foreign countries.

Different researchers also observe and agree that the local people did not want the Coalition forces to have a foothold on their land, even though the protection offered by the Coalition forces against AQI was an important element of the short-term alliance (e.g. Biddle, Friedman, and Shapiro (2012). Yet, for the tribal leaders, the alliance was no more than

10 For example, Biddle (2008), Long (2008), McCary (2009), and Marten (2012), and Biddle, Friedman, and Shapiro (2012), among others. 
a "convenient marriage" and a means to protect their interests from the prey of AQI. Furthermore, this exchange was not cost-less to the tribal leaders who had cooperated with the US as they became obvious targets of AQI's attacks (Long, 2008; Marten, 2012). And as McCary (2009) pointed out, the perception that the US forces would leave the country was a major determinant of the alliance decision. In short, though we cannot completely eliminate the hypothesis that the short-term interest of employment is still present, the above observations weaken the hypothesis by challenging the underlying assumption of the hypothesis on the willingness of the local Iraqis to compromise their security concern and nationalist sentiment in exchange for short-term economic interests.

Statistical analysis by Berman et al. (2011) provides more decisive evidence against the explanation. Using data from Iraq, Afghanistan, and the Philippines, the study finds a negative relationship between unemployment and insurgent attacks (Berman et al., 2011) — that is, a higher unemployment rate is correlated with less violence. They ascribe the rather surprising result to the success of the Anbar Awakening and argue (1) that the insurgents may be less interested in the economically less advantaged region, or (2) that improved security measures may suppress economic activity, or (3) that a lower cost of obtaining information (intelligence) for counterinsurgency is due to a higher unemployment rate. The last two explanations are not particularly applicable in our case as CERP is a program that aims to engage local people to local economic activities (i.e. to improve employment). CERP is not a program that rewards civilians for information either; the Department of Defense had a separate program for that (Martins, 2005). In short, the above discussion suggests that the positive relationship between development assistance and violence is more likely to be due to other competing theories.

\subsubsection{The capacity explanation}

A large body of research emphasizes that aid may strengthen an armed group (Dube and Naidu, 2015; Nunn and Qian, 2014; Wood and Sullivan, 2015). Presenting a slightly different argument using the bargaining framework, Narang (2014) considers that aid may encourage a group to renegotiate. But they both predict that aid can strengthen the position of an armed group, enabling it to fight against the authority. Similar to the cost-benefit mechanism examined before, this explanation claims that 
aid will induce more violence after some cost-benefit calculations. While the cost-benefit explanation emphasizes the outside options available to the rebels (i.e. the cost side) and considers rebellion as yet another economic activity, the capacity explanation speaks to the revenue side of the calculation and is more open to other motivations of rebellion. Aid can either improve the odds of winning (e.g. more financial resources to buy weapons) or increase the gains by using some violence (e.g. looting), or both. As I will show, among the three theories tested in this study, this capacity explanation is the most promising one.

The first test looks at the nature of the assistance. Development assistance can be captured by rebel groups to improve their (military) capacity. According to Martins (2004), though a portion of the spending was on water, food production, and purchase of vehicles, the assistance was also spent on infrastructure (e.g. sanitation, transportation, repair of cultural facilities), services (e.g. health care, education, civil cleaning), and institution-building (e.g. rule of law). While the first category of items can be looted, thus contributing to the military strength of insurgents directly, the second category cannot be. An inspection of the dataset reveals that a portion of the loot could be particularly valuable to insurgents: communication equipment, food production, health equipment, military facilities, police facilities, spare part replenishment, and water resources. All these supplies were valuable to foreign fighters, especially those lonewolf terrorists, who, unlike the local people, fell outside of any command structure and did not receive material assistance from a local organization. However, the test also reveals a potential weakness of the theory - it suggests only one necessary but insufficient factor to the positive relationship between development assistance and violent conflict.

Furthermore, an independent report by the Office of the Special Inspector General for Iraq Reconstruction (SIGIR), a federal agency created by the Congress to oversee the use of CERP funds, lends some support to the hypothesis. Between 2011 and 2012, SIGIR surveyed 390 Army and Marine battalion commanders and civilian personnel and engineers serving in the US Army Corps of Engineers (USACE), the Department of State, and the US Agency for International Development (USAID). According to the report, both military and civilian personnel (76 per cent) acknowledged that part of the funds may have been misused or lost to fraud and corruption. Over 70 per cent of respondents believed that the amount lost to fraud and corruption was larger than 10 per cent. Moreover, 35 per 
cent estimated that the loss was in the range of 10 to 25 per cent (SIGIR, 2012, p. 14).

According to the SIGIR report, there was a general agreement among respondents that corruption is endemic in Iraq. Corruption was used by local contractors to gain access, protection, and to get the projects done without being attacked by the local people. As a respondent asserted, it is a hidden cost of the program (SIGIR, 2012, p. 15). Tellingly, a respondent who was stationed in Baghdad between 2005 and 2006 observed that "[m]oney was paid to insurgents for protection - some of the money (usually new US $\$ 100$ dollar bills) was found during raids on insurgents [along with] admission from contractors that they paid money 'for protection" " (SIGIR, 2012, p. 19).

A point particularly relevant to the capacity explanation is that looting is not the only factor that made insurgents stronger. An additional factor is that part of the aid money was transferred to insurgents indirectly. As noted earlier, transfers can take different forms; for example, fraud, corruption, and security payments from contractors. An engineer from the SIGIR survey stated that some contractors conspired with the insurgents and/or paid them to ensure their own security (SIGIR, 2012, p. 32). A commander, who had served in Kirkuk, also pointed out that they were well-aware that part of the funding would be reinvested in the insurgency and paid to local leaders susceptible to insurgent support (SIGIR, 2012, p. 32). A quote from a Marine officer, stationed in Anbar, made this point clear, "the better we were at leveraging CERP, we saw a corresponding increase in the sophistication of enemy equipment and training" (SIGIR, 2012, p. 32). While losses due to fraud and corruption were expected, the drippings from disgruntled leaders to insurgents, possibly foreign fighters, who did not directly benefit from the aid, were unanticipated, eventually spoiling the fruits of the counterinsurgency efforts.

In sum, the explanatory power of the capacity argument is better supported by some of the anecdotal evidence. Also, the finding informs us that the increase in capacity can pass through different channels. Apart from looting, fraud and corruption can also link aid, capacity, and increased level of violence in the whole causal chain. 


\subsubsection{The sabotage explanation}

The sabotage argument posits that it is the pre-emptive motive of insurgents that drives them to attack the authority (Crost, Felter, and Johnston, 2014). Expecting that the assistance is going to win the hearts and minds of the population, insurgents will try to undermine those projects proactively, preventing aid programs to be undertaken in the first place. If the public support does not sway to the aid providers, the number of attacks should not increase because the plan of attack is contingent on the (expected) effectiveness of the assistance to win the hearts and minds of the locals, according to the argument. Once the reason of attack disappears, the number of attacks should not rise because there is nothing left for the insurgents to pre-empt. Therefore, the existence of the motive is a necessary condition that the theory needs to satisfy.

An examination of the public opinion of the Iraqi people towards the US and the Coalition forces, however, shows that the motive of pre-emption is rather weak in the present case. After analyzing the polling data from Iraqi conducted in February 2008, ${ }^{11}$ Cohen (2014) considered public opinion as less malleable than the proponents of the theory think it should be. According to the poll data, ${ }^{12}$ The proportion of Iraqis who expressed "a great deal" and "quite a lot" of confidence in the US occupation forces had changed from 19 per cent (2003), to 25 per cent (2004), to 18 per cent (2005), to 18 per cent (2007), to 15 per cent (2007), and to 20 per cent (2008). There was an up in 2004 and a down in 2007, but the general attitude is quite stable at around 18 per cent. How does the number correlate with CERP? Figure 2.2 puts the above poll data along with the (annual) CERP data with the SOI component removed. It clearly shows that the two series are negatively correlated, with the correlation coefficient equal to -o.83. The relationship, in sharp contrast to what the theory predicts, could be due to the long-held discontent of the Iraqis, especially the Sunni, towards the invasion and occupation, explained earlier. As the construction works may recreate and vividly enhance the image of occupation, the CERP program may further fuel the negative view towards

11 The survey was conducted by the $\mathrm{D}_{3}$ Systems (Vienna, Virginia) and KA Research Ltd (Istanbul) on behalf of three major media outlets in the US (ABC News), Britain (the BBC), and Japan (NHK).

12 Global Policy Forum. 2016. Iraq Opinion Poll (March 2008). Available at: https://www. globalpolicy.org/invasion-and-war/iraqi-public-opinion-and-polls.html. Access 9 May, 2016. 
the occupation forces, at least in the short run. This explanation finds some support from the same poll data: CERP spending peaked in 2007 . In that year, when asked how long the US and other Coalition forces should remain in Iraq, a record-high 47 per cent of Iraqis indicated that they should "leave now". Project spending also increased within 2007 (see Figure 2.I). And during that period, the percentage corresponding to the poll question increased from 35 per cent to 47 per cent. By contrast, when the project subsided between 2007 and 2008, the share of people holding the same opinion dropped to 38 per cent.

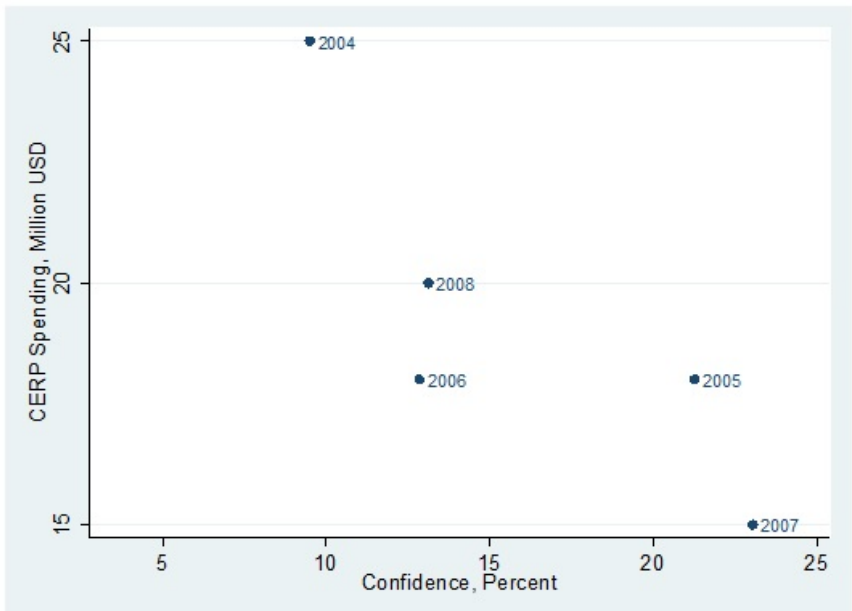

Figure 2.2: Iraqis' confidence in the US occupation forces and CERP spending

A weakness of the test is that the public opinion data refers to the entire Iraqi population, not necessarily populations in areas affected by the program. But given that most of the development programs were concentrated in populated areas, the sabotage explanation is unlikely to explain the positive relationship between development assistance and attack in Iraq based on the econometric analysis.

\subsection{CONCLUSION}

What does the Iraqi case tell us about the effectiveness of foreign assistance on counterinsurgency? First, local politics shape the relationship between aid and conflict. As a result, reverse causality, selection effect, and common third factor are likely to exist and influence the causal relationship. Second, similar to what is reported in other studies, in the 
short-run, development assistance sometimes may induce more violence and not reduce it. Finally, some existing theories are unable to explain the positive association between aid and conflict completely in the case of Iraq. Both the opportunity costs theory and the sabotage argument seem to have little role to play. By contrast, the capacity explanation offers the most promising explanation. Yet, contrary to the usual proposition that insurgents will loot the aid and equip themselves, insurgents in Iraq were better than that. They connected with the local leaders who had allied with their common enemies and extracted rents from the contractors. By doing so, the insurgents avoided crossfires, reducing the risks associated with looting and pocketing the money for reinvestment in their attacks. Ironically, while the US military brought down violence against them by allying with local tribes, some of the tribal leaders adopting the same alliance strategy to contract violence out to insurgents, most likely the foreign fighters who were not direct beneficiaries of the development assistance. In this light, future counterinsurgency efforts should bear in mind the ties between aid recipients and other actors, provide better security to contractors, or allocate aid more strategically. Similarly, development agencies should be more selective in choosing their partners. Whenever possible, they should also provide assistance that is less likely to be looted (e.g. projects aiming at building institutions), so that it can be handed over to the needed. 


\section{SPILLOVER}

Money has been used as a weapon in the counterinsurgency warfare in Iraq. It has been argued that development assistance has produced a hearts and minds effect, dampening Iraqis' discontent with the US and bringing violence against the Coalition forces to an end. Previous studies, however, commonly assume that insurgency is a local phenomenon, not reproducible in other areas. But the violation of this spatial independence assumption can bias towards the positive result. Using a spatial dynamic panel data model, this chapter shows that spatial dependence exists and cannot be assumed away. Estimation results based on the new model also reveal that the acclaimed Commander's Emergency Reconstruction Program (CERP) produced a positive neighborhood effect by inducing more attacks in adjacent areas. By contrast, the alliance strategy is a more compelling factor to explain the dwindling of insurgent attacks in Iraq.

This chapter is based on Wong, Pui-Hang. 2014. Insurgents in motion: Counterinsurgency and insurgency relocation in Iraq. UNU-MERIT Working Paper 2014-045. 
Violence did not end with US's decisive military victory and has persisted in Iraq since 2003. Although the US-Iraq war was ended in 2003, insurgent attacks against the Coalition forces mounted. Hundreds of insurgent attacks against the Coalition forces were recorded every week in the subsequent four years. To reverse the trend, in January 2007, the Bush administration announced the deployment of an additional 20,000 soldiers to the existing 150,00o troops in Iraq, mainly in Baghdad. The upward trend of violence eventually slowed down and reached the peak of about 1,800 attacks per week in mid-2007. Since then, the number of insurgent attacks against the Coalition forces subsided.

Several arguments have been advanced to explain the decrease in the level of violence. One explanation puts forward about the success of the troop surge. According to this explanation, the enhanced military power effectively combated the insurgents and deterred future violence (e.g. Sky, 2011). However, some studies found that troop size has no apparent effect on counterinsurgency (e.g. Friedman, 2011). Some critiques also state that domestic political factors were far more important than the change in the counterinsurgency doctrines and policies (e.g. Hagan et al., 2013; Lindsay and Long, 2013). For instance, Long (2008) ascribed the change in the number of insurgent attacks to the strategic alliance between the US military and the local tribes-particularly, the Anbar Awakening and the subsequent Sons of Iraq. He contended that the role of troop surge is secondary as occupying forces have to rely on the local people to restore security and political order. The role of the US military, at most, was to facilitate the restoration process by offering the necessary protection to the peace brokers. Similarly, Lynch (2011) also argued that financial incentives to informers would only be accepted and hence take an effect when the stigma against working with the US military is reduced. The true effect of the surge can only be realized with a transformed relationship between the US military and the Iraqi people. So the drop in the level of violence is neither caused by the troop surge nor the alliance but the US military's social engagement with the local people. Some further added that the change in military doctrines was the most decisive factor in explaining the number of attacks. For example, Berman, Shapiro, and Felter (2011) proposed that the hearts and minds effect produced by the reconstruction projects is the most decisive factor in explaining the decreasing number of attacks. They reasoned that improved provision of public goods was able to induce public support from local communities to cooperate with the military force. More specifically, they evaluated the effectiveness of the 
Commanders' Emergency Reconstruction Program (CERP) in Iraq and found that the policy had a significant effect in reversing the trend of violence. Finally, Biddle, Friedman, and Shapiro (2012) proposed a synergy hypothesis, which states that troop surge and alliance are jointly responsible for the reduction in the level of violence. Their analysis found that areas treated with both policies showed the most significant reduction in the number of attacks.

This chapter argues that previous findings can be stemmed from a rather problematic assumption-that insurgents are insensitive to counterinsurgency policies, and hence attacks are geographically confined. This spatial independence assumption is proved to be disputable. For instance, in the terrorism literature, it has been constantly found that terrorists are reactive to anti-terrorism measures and swift in adjusting their target choices and attack modes (e.g. Crenshaw, 1998). Admittedly, the success of insurgent attacks does hinge on a myriad of local factors such as the knowledge of a geographical region. But the local barrier is far from insurmountable and can be overcome by hiring the locals. In other words, contrary to what people think, insurgent attacks could be easily reproduced, especially in areas where nationalist sentiment is shared across communities. Consequently, if this kind of spatial dependence prevails, analyses that fail to incorporate this dependence would overstate the true policy effect and lead to erroneous policy recommendations.

This chapter contributes to the literature by introducing a statistical tool to the field of conflict studies and applying it to inform the debate over the true cause of the decline of the violence against the Coalition forces after taking the spatial dependence concern into consideration. Findings based on the proposed method suggest that CERP is likely to induce more violence in the neighboring region. By contrast, the alliance strategy reduced violence in Iraq more effectively than the CERP did. Given my use of the Iraqi data, the findings are likely to be specific to the human-geographical context of the country, which is elaborated in the next section. However, I will provide a more general framework in the following section by listing some relevant factors. In this way, I hope the analysis will remain relevant at both theoretical and practical levels.

In the rest of the chapter, I will first introduce the target selection framework and list some factors that are related to the question of insurgent mobility. I will then explain the significance and relevance of the argument and demonstrate the empirical consequences of ignoring the issue of spatial substitution. An econometric model encompassing spatial de- 
pendence will be introduced in the subsequent section, followed by the discussion of the empirical results and conclusion.

\subsection{THE LOCAL ROOT OF VIOLENCE}

Many studies have shown that terrorists are highly calculative and selective in choosing their targets (Crenshaw, 1998; Drake, 1998; Faria, 2006; McCartan et al., 2008). Insurgents are sensitive to the costs of launching an attack and tend to choose targets in less well-guarded locations. The same also holds regarding strategy choices and attack modes (Jenkins, 1986; Enders and Sandler, 1993). For example, the analysis by Enders and Sandler (1993) indicates that counter-terrorism measures designed to reduce one type of attack usually induce other types of attack. Their analysis, for example, showed that the installation of metal detectors in airports concomitantly leads to more kidnappings and assassinations. This finding raises the question of whether counterinsurgency creates only a balloon-squeezing effect. This concern is sometimes acknowledged and recognized but has not been addressed empirically (e.g. Malkasian, 2006, p. 383; Hughes, 2010, p. 167; Biddle, Friedman, and Shapiro, 2012, p. 22).

Instead of viewing a country as a disconnected set of districts, insurgents are likely to consider a region as a whole and see neighboring districts as (spatial) substitutes of a military stronghold. Insurgents usually have the choice to move to other lightly guarded locations to achieve similar outcomes by incurring some costs. The strategic concern poses an empirical challenge to empirical analyses as they usually assume away this dependence by concentrating only on indicators of the targeted regions. The research assumption and practice certainly do not reflect what happens in reality. Worse still, sticking to the local indicators may lead to operations that actually spread violence to other regions and create multiple fronts. As the objectives of an operation usually involve several dimensions, which may include, for example, the size of the affected area and the ease of control, analysts should assess a situation with a more holistic view and take the issue of spatial substitution into consideration.

The above logic suggests that the validity of the previous findings hinges on the degree of substitutability between locations according to the calculus of insurgents. Based on an actor-centered approach, one may conduct an analysis by enumerating a set of target selection criteria to determine the degree of substitutability between different targets and hence 
the mobility of insurgents. Some relevant questions include: How important are the local human geographical factors to the insurgents in planning an attack? How swift are the insurgents in adjusting their plans and seeding violence in other places? Since it is easier for researchers to obtain regional characteristics than to get genuine answers from insurgents, one may consider reproducibility of violence as a function of various geographical and human-related factors specific to insurgents and the nature of an insurgency. These factors include but are not limited to geography, socio-economic characteristics, custom, and human relations between the insurgents and the inhabited groups. These factors, however, can carry different weights in the insurgents' calculus. As the weights of factors vary from case to case, the net effect is usually ambiguous and ultimately an empirical question. Generally speaking, if a local factor is deemed essential, one would expect that violence is more difficult to be bred. On the other hand, if a location-specific factor is inessential, substitution is more likely to be seen. Furthermore, a single factor may channel through multiple mechanisms and interacts with other factors, as I will explain below.

In the Iraqi context, a number of factors are particularly relevant. The first is the economic well-being of the local people. Destitution, income inequality, and poor living conditions may create grievances in local communities (Cederman, Weidmann, and Gleditsch, 2011). Furthermore, economic deprivation is also found to reduce the opportunity costs of recruiting a rebel (Fearon and Laitin, 2003; Humphreys and Weinstein, 2008). The change of living conditions due to conflicts may motivate Iraqis to take revenge by attacking the Coalition forces. For example, Hughes (2010, p. 159) indicated that many attacks against the Coalition forces were initiated by the humiliated and impoverished ex-officers of the demobilized Iraqi army. The perceived failure to reconstruct the country was also used to inspire resentment among Shias and Sunnis alike. If this view is widely shared among Iraqis, insurgents would have a wider base to breed violence. Insurgent attacks would also be less likely to be geographically confined. On the other hand, if poverty is confined to a certain area, or income inequality is the factor to be blamed, insurgents may find it more difficult to reproduce violence in regions where people are more satisfied with their lives.

Another factor is natural resources. Oil, gas, and pipelines are unequally distributed in Iraq. If the resource revenue is critical to the survival and activities of the insurgents (Ross, 2004; Buhaug and Rød, 2006), 
they are more likely to stay close to the resources. In that case, insurgents are less likely to move beyond their control zones to launch attacks in regions where they have no immediate interests. In regions where insurgents do not have control, if attacks are inevitable, they are more likely to find the resource-rich regions attractive. Hughes (2010, p. 165), for instance, documented that Sunni insurgents targeted the power grid and the oil industry, with the intention to sabotage reconstruction and to intensify discontent among the public. In this case, the latter intention may interact with the economic factor discussed before.

The third possible factor is ethno-political relations. Whether or not an ethnic group has motivations to rebel is linked to the shift of power positions and the configuration of the power relations in a polity (Cederman, Wimmer, and Min, 2010). In the Iraqi case, more attacks in Sunnidominated regions should be observed because the Sunnis lost their privileged position because of their attachment to the Ba'ath regime before the 2003 Iraq War. This factor is indeed strongly associated with the attacks, at least in the early years of the invasion (Berman, Shapiro, and Felter, 2011). Public opinion surveys carried out in 2006 and 2007 reveal that over 90 per cent of Sunnis had a negative opinion towards the presence of the US. They generally felt that the US was responsible for the situation in Iraq and hence emotionally supported the attacks (Lynch, 2011, pp. 49-50). If this is the main reason behind the attacks, Sunnis may find it difficult to export violence to Kurdish-dominated areas. On the other hand, the nationalist resentment may be shared by the Iraqi diaspora and Sunnis outside Iraq and become a reason to join the insurgency. Power struggles within and among different religious groups can also lead violent outbidding to appear as a viable strategy to gain public support (Hughes, 2010, pp. 159-161). In this way, nationalism and political competition may lead insurgent attacks not to be bounded locally.

Problems due to the lack of information is universal to all kinds of insurgent attacks, but information is usually location-specific. Although insurgents are highly mobile-for example, they can install improvised explosive devices (IEDs) in other localities—the lack of local knowledge may prevent insurgents from organizing attacks effectively if they do not receive some help from the local people. Information related to the routes for logistics and retreats, and locations that can maximize casualties are some examples of the strategic parameters which insurgents may care about. In fact, the new doctrine of counterinsurgency is deemed to be effective because it engages the locals to provide intelligence that helps 
security forces to identify outsiders and expel them from the regions (Biddle, Friedman, and Shapiro, 2012; Lyall, 2010; Lynch, 2011). In short, if the information problem is a major constraint in an insurgent attack, the likelihood of spatial substitution will be reduced substantially.

Tribal politics and networks among local elites and political leaders can prevent violence from spreading. For instance, Long (2008) considered that Al-Qaeda's violent coercion against Sunnis in Anbar provided the US military an opportunity to ally with the Anbar Salvation Council. Anger and insecurity catalyzed cooperation, laying down a foundation for the alliance and contributing to the success of the US tribal strategy. Also related are ethnic and tribal relations and social norms. If the social group of concern is in enmity with potential insurgents, insurgents would become more reluctant or find it difficult to cross a region or buy-off people of other groups, even though the social labels in some cases can be fluid and multi-layered. If enmity is sufficiently low, diplomacy or political exchanges among tribes will help insurgents to overcome the information constraint. However, inter-tribal cooperation can take different forms: outsourcing, providing necessary resources or intelligence, simply turning a blind eye to an attack, and refusing to share intelligence with the military. A neutral local group may not want to be involved and become a scapegoat, thereby refusing to cooperate with insurgents and reporting the plot to local security forces. On the other hand, groups in constant conflict, for example, such as Sunnis and Shias, would find cooperation or alliance more difficult.

Finally, some locations possess a higher strategic or symbolic value than others. Controlling these locations sometimes can lend the holders some powers. Examples include Baghdad and Kirkuk, where the Kirkuk oilfield is located. To seize the control of these places, insurgents may be more willing to tolerate losses to defend them or be less likely to replace them with substitutes of lower values to them.

\subsection{EMPIRICAL CONSEQUENCES OF SPILLOVER}

Whether target substitution is real or not, why should analysts care about it? When relocation is common, the reduction of violence in one district means a rise of violence in neighboring districts. Focusing on the temporal pattern of violence in one region and ignoring the possibility of spatial spillovers would paint an overly optimistic picture regarding the 
effectiveness of the counterinsurgency strategy under consideration, because a conclusion is usually drawn based on the comparisons across two supposedly independent units. Usual comparison methods, be they qualitative or quantitative, assume that the pattern observed in the control group is independent of the one in the treatment group. If relocation is widespread, this form of cross-unit interdependence will violate the independence assumption mentioned above, which renders results even obtained from an experimental setting biased (Franzese and Hays, 2008, p. 760). Subject to interdependence, an analysis risks incurring the omitted variable bias by exaggerating the true effect of the policy under evaluation. And this bias cannot be corrected by simply clustering the standard errors (Franzese and Hays, 2007; Franzese and Hays, 2008, pp. 754-757).

The logic suggests that we cannot simply compare, for example, the change in the levels of violence in Baghdad and Baladrooz, a district bordering Mada'in in Baghdad, and draw conclusions based on the comparison, as the trend in Baladrooz is 'contaminated' when relocation occurs. The rise in the level of violence in the control region, Baladrooz in the present example, will lead to an overestimation of the effectiveness of the counterinsurgency programs. This is true even if the violence was unabated in the presence of a counterinsurgency program because the level of violence was, in fact, higher in the 'control' district.

An examination of the SIGACT data reveals that the relocation that we worry about is likely to take place. Figure 3.I plots the (weekly) number of attacks in Baladrooz and Mada'in between 2004 and the first half of 2009. ${ }^{1}$ In the beginning, the numbers of attacks in the two districts share a similar trend. But the trends diverge shortly after 2007 when different counterinsurgency policies were put in place. More importantly, the number of attacks in Baladrooz increased shortly after a drop in Mada'in in late 2007; a pattern consistent with the displacement hypothesis. Furthermore, a naive extrapolation of the trend in Baladrooz will suggest that the number of attacks would have been around 270 attacks per week in the second half of 2008, instead of over 400 that were actually observed. This implies that if violence spilled over to Baladrooz, the effectiveness of the counterinsurgency program could be exaggerated. The widened gap due to relocation would lead analysts to wrongly conclude that the program was highly effective. In the present case, as Figure 3.1 shows,

1 The data are based on the Multi-National Forces Iraq (MNF-I) SIGACT III database. 'Significant activities', or SIGACT, is the count number of attacks targeting the Coalition forces. 
the size of the bias could be as large as the size of the true policy effect. The illustration does not aim to state that the increase must be due to the counterinsurgency efforts in 2007. Rather, it is used to illustrate the theoretical and empirical concerns that have been discussed and should be addressed properly. ${ }^{2}$

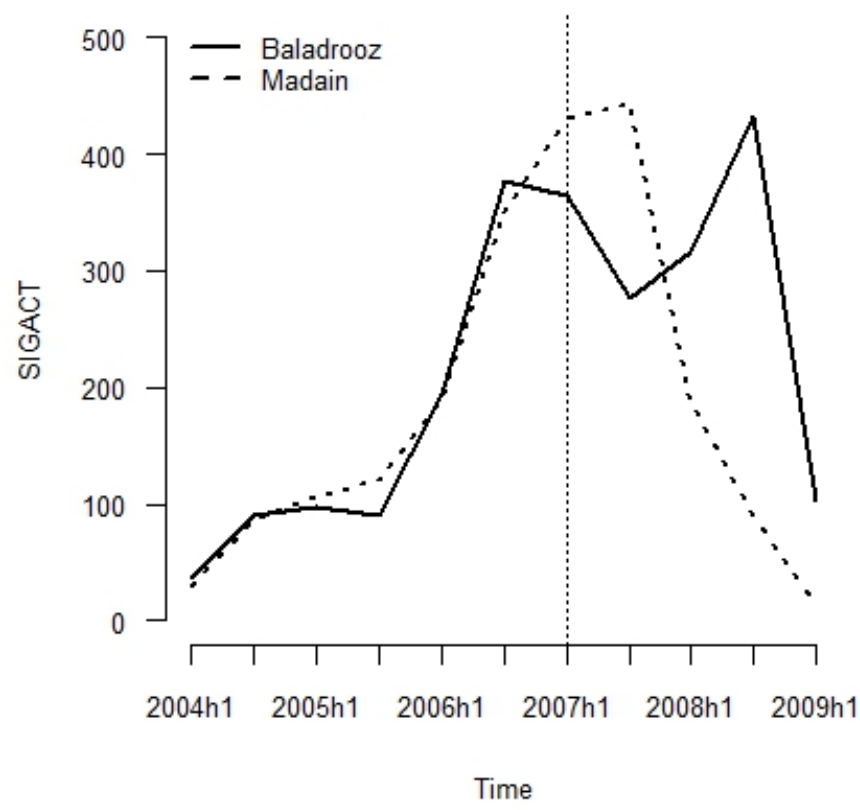

(a)

Figure 3.1: Shift of insurgency from Madain to Baladrooz

In sum, the interplay among the factors discussed in the previous section would make it hard for us to predict the extent to which displacement may bias a policy evaluation. While data availability does not allow me to disentangle the effect of each individual factor discussed before, three questions of particular interest are answerable:

2 A recent study by Romano, Calfano, and Phelps (2015) assesses the impacts using timeseries analysis by pooling all districts together. It has the effect of avoiding the interdependence problem mentioned here. But the design of the study does not allow them to test and gauge the spillover effect that this chapter addresses. 
1. Is spatial interdependence in the Iraqi case an issue severe enough to revise the conclusions drawn from the previous analyses?

2. What are the marginal contributions of each individual counterinsurgency policy?

3. Is there a synergy effect between the troop surge and the alliance strategy?

The following section will introduce the econometric model used to answer the above questions.

\section{$3 \cdot 3$ DATA}

Data for the analysis are based on Berman, Shapiro, and Felter (2011). The dependent variable is the number of attacks against the Coalition forces. The measure is by no means perfect, ${ }^{3}$ but it is one of the most detailed and consistent measures available and widely used in other quantitative studies such as Berman, Shapiro, and Felter (2011), Biddle, Friedman, and Shapiro (2012) and Romano, Calfano, and Phelps (2015). I do not distinguish various types of attacks to allow substitution between attack modes. There are three independent variables of particular interest. The first is the change in the number of troops between the second half of 2004 and the second half of 2008, which aims to capture the effect of the troop surge.

The other two independent variables are expenditures in two projects: the Commander's Emergency Response Program (CERP) and the payments to militias, resembling the Sons of Iraq (SOI) program. Data for the CERP projects records non-SOI related expenditures on reconstruction in Iraq. Project money was mainly used in areas such as education, health, and transportation. Given the public goods nature, the variables are adjusted for the sizes of the population. I also include four other similar development assistance funds as controls. The cross-sectional unit is district (104 districts) and the time unit is half-year (10 periods). As most projects last for several months, the six-month window allows the projects to be completed and to reap benefits perceivable to the local communities (Berman, Shapiro, and Felter, 2011). Other control variables include an approximated number of population, an index of satisfaction with local public goods provision (at 2004, shortly after the war), income change

3 For example, see Berman, Shapiro, and Felter (2011, p. 790) for discussion. 
between 2002 and 2004 (i.e. before and after the invasion), and pipeline volume (weighted by the prices of oil and gas adjusted for inflation), and the share of Sunni citizens in the population. A spatial contiguity matrix is used in the analysis.

\section{$3 \cdot 4$ MODELS}

The basic model, which does not contain the spatial weight, was first estimated using OLS. Estimation then was extended to the fixed-effect model. The fixed-effect model is able to control for effects due to any timeinvariant, district-specific characteristics, such as custom and distance to the capital. The model is also able to control for most of the immobile human-geographical factors, which are likely to be time-invariant.

I will then proceed by estimating the following spatial model using maximum likelihood estimation with a modified likelihood function (Ord, 1975).

$$
y_{i t}=\delta \sum_{j=1, i \neq j}^{N} w_{i j} y_{j t}+\theta \sum_{j=1, i \neq j}^{N} w_{i j} x_{j t}+\gamma x_{i t}+\beta z_{i t}+\mu_{i}+\varepsilon_{i t}
$$

In the above model, $y$ is the dependent variable, $w$ the spatial weight, $x$ the explanatory variable hypothesized to exert both spatial and nonspatial effects to $y, z$ the control variables, and $\mu_{i}$ the district-specific fixed effect. 4 The significance of the spatial effect can be evaluated based on the Wald test (Anselin, Le Gallo, and Jayet, 2008). The spatial Durbin model, rather than the more common spatial lag or spatial error models, is estimated as it is more general (Elhorst, 2012) and generates results that better match our research interests. Spatial substitution exists when $\theta>0$. Literally, it says that the violence level in district $i$ (i.e. $y_{i t}$ ) would increase as the intensity of counterinsurgency policy $x$ in the neighboring district js (i.e. $x_{j t}$ ) increases. If $\theta<0$, one may interpret the counterinsurgency

4 To avoid burdening the equation, the case where there is only one $x$ and $z$ variable is shown. This spatial Durbin model can be reduced to the more common spatial lags or spatial error models if certain restrictions on the parameters are imposed (LeSage and Pace, 2009). Since the research interest is the significance of the spatially lagged explanatory variables, I estimate the full model without imposing any parameter restrictions in my investigation. 
has an eradicating effect; counterinsurgency in that case helps reduce violence not only in the operated regions but also the neighboring areas.

The model above is restrictive in the sense that only time-invariant effects are controlled for. To better capture the omitted time-varying effects, I also estimated the corresponding dynamic panel model, which includes a lagged dependent variable that summarizes the recent history of violence in an evaluating unit (Angrist and Pischke, 2009).

$$
y_{i t}=\tau y_{i, t-1}+\delta \sum_{j=1, i \neq j}^{N} w_{i j} y_{j t}+\theta \sum_{j=1, i \neq j}^{N} w_{i j} x_{j t}+\gamma x_{i t}+\beta z_{i t}+\mu_{i}+\varepsilon_{i t}
$$

To estimate the spatial dynamic panel model, the quasi-maximum likelihood estimator for spatial panel models is employed (Yu, de Jong, and Lee, 2008). The estimator is used to account for the endogeneity related to the spatial term and the lagged dependent variable. To account for the Nickell bias associated with the dynamic panel data model, I use the formula in Lee and $\mathrm{Yu}$ (2010) to correct for the bias. A follow-up Monte Carlo study by Elhorst (2010a) found that this estimation procedure outperforms the GMM estimator in terms of bias-ness when $\mathrm{T}$ is small, a situation we are presently in. One may advocate for the use of an alternative model such as Poisson or negative binomial for the count data, but the property of those estimators is yet to be established in a spatial dynamic setting using panel data.

One has to proceed with care when evaluating the marginal effect of an explanatory variable as the dependent variable now appears on both sides of equations $I$ and 2 with the presence of a spatial lag. A statistically significant coefficient does not necessarily mean that the explanatory variable has a statistically significant marginal effect (Franzese and Hays, 2007; Franzese and Hays, 2008). 5 To see this, one can rewrite equation 1 in matrix form and evaluate the marginal effects as

5 The following discussion is based on Elhorst (2012). 


$$
\begin{aligned}
\frac{\partial Y}{\partial X_{k}}=\left[\frac{\partial Y}{\partial x_{1 k}} \cdot \frac{\partial Y}{\partial x_{N k}}\right]=\left[\begin{array}{ccc}
\frac{\partial y_{1}}{\partial x_{1 k}} & \cdot \frac{\partial y_{1}}{\partial x_{N k}} \\
\cdot & \cdot & \cdot \\
\frac{\partial y_{N}}{\partial x_{1 k}} & \cdot \frac{\partial y_{N}}{\partial x_{N k}}
\end{array}\right] \\
=\left(I_{N}-\delta W\right)^{-1}\left[\begin{array}{cccc}
\gamma_{k} & w_{12} \theta_{k} & \cdot & w_{1 N} \theta_{k} \\
w_{21} \theta_{k} & \gamma_{k} & \cdot & w_{2 N} \theta_{k} \\
\cdot & \cdot & \cdot & \cdot \\
w_{N 1} \theta_{k} & w_{N 2} \theta_{k} & \cdot & \gamma_{k}
\end{array}\right]
\end{aligned}
$$

The resulting matrix is a square matrix with dimensions $\mathrm{N}$ by $\mathrm{N}$, where $\mathrm{N}$ is equal to the number of districts. The matrix summarizes the marginal effects of the explanatory variable $X_{k}$ to $Y$. Each element in it represents the marginal effect of the explanatory variable $X_{k}$ in district $j$ (row) on the dependent variable in district $i$ (column). For example, consider the square matrix corresponding to the variable CERP spending. The element in row 10 and column 5 of the matrix tells us the marginal effect of CERP spending in district 10 on the violence level in district 5, after taking into account the possible feedback, which is picked up by the term $\left(\mathrm{I}_{\mathrm{N}}-\right.$ $\delta W)^{-1}$. Feedback here means the spillover effect of violence in district $i$ to district $j$ (first-round), and from $j$ back to $i$, and from $i$ to $j$ (secondround), and so on. The diagonal elements in the matrix represent the direct effect of the explanatory variable (i.e. policy in district $i$ on violence in the same district), whereas the off-diagonal elements are the indirect effects or the spillover effects. As each element in the matrix is districtspecific, it is rather inconvenient to report the district-by-district effect. 6 Consequently, I will only report the average marginal effects in the later section. To compute this average marginal effect, one can simply take the average of the corresponding elements (Elhorst, 2010b). That is, the average of all diagonal elements for the average direct marginal effect, and the average of either the row sums or the column sums of the offdiagonal elements for the average indirect marginal effect (LeSage and Pace, 2009).

The last equality in equation 3 clearly shows that the direct marginal effect of $X_{k}$ on $Y$ is determined by the parameters $\delta$ and $\gamma_{k}$ which inter-

6 For example, with 104 districts in our case, there are $104 \times 104=10,816$ marginal effects for each variable $X_{k}$ per period. 
act non-linearly. Given the interaction, care also has to be taken to draw statistical inferences concerning the marginal effects, as the standard error of the estimated coefficient is different from the standard error of the marginal effect, which depends on both $\delta$ and $\gamma_{k}$. To evaluate the statistical significance of the marginal effect, I employed the simulation method to construct the empirical distributions of the simulated marginal effects using the estimates and the information matrix (Greene, 2011). ${ }^{7}$ The simulation exercise is functionally akin to the familiar $\mathrm{t}$-test in usual regression analysis. The complication here is necessary because the marginal effects of the explanatory variables are not identical to their corresponding coefficients in a model with a spatially lagged dependent variable on the right-hand side of the equation.

\section{$3 \cdot 5$ EMPIRICAL FINDINGS}

The estimation results are reported in Table 3.1. Results based on OLS estimation, which is contained in column 1 , are somewhat consistent with our expectations. Sunni-dominated areas have a higher number of attacks. Some counterinsurgency efforts are effective in reducing the level of violence. Findings based on the OLS estimation, however, are likely to be affected by the selection effect. For this reason, I also estimated the fixedeffect model which better controls for the selection effect due to timeinvariant factors (e.g. being the capital of the country). ${ }^{8}$ Most of the funds were found to have a negative effect on the level of violence, but only the coefficient corresponding to the Development Funds Iraq (DFI) is statistically significant.

Added to the benchmark is the static spatial panel with the districtlevel fixed-effect (see Table 3.2). Statistical significance of the coefficient corresponding to the spatial term suggests that spatial interaction has a significant role to play in the process. It suggests that violence in district $j$ can spill over to district $i$. This also validates our worry about the bias induced by the spatial effects. Estimation results further confirm that

7 In brief, random values are first drawn from a standard normal distribution with mean zero and standard deviation of one. These random values are then multiplied with the upper-triangular Cholesky decomposition of the variances-covariance matrix derived from the information matrix. Next, these simulated random noises are added to the estimates to produce simulated parameters. The whole procedure is repeated 1,0oo times. The simulated values form the empirical distributions are reported in the results section.

8 Sunni share and income change data for four districts were not available. This explains why we had more observations with the fixed-effect than with the OLS model. 
Table 3.1: Effect of counterinsurgency policies in Iraq: Benchmark

\begin{tabular}{lrlr}
\hline & \multicolumn{1}{c}{ OLS } & & \multicolumn{1}{c}{ F 12} \\
\hline Pop & 246.564 & $* * *$ & 97.008 \\
Troop & $(37.364)$ & & $(70.189)$ \\
& 57.120 & $* * *$ & 26.557 \\
Resource & $(13.219)$ & & $(19.040)$ \\
& -2.320 & $* * *$ & -0.211 \\
Unemploy & $(0.487)$ & & $(1.160)$ \\
& -7.193 & $* * *$ & -2.898 \\
SOI & $(1.750)$ & & $(1.856)$ \\
& -0.001 & & -0.054 \\
ISFF & $(0.008)$ & & $(0.034)$ \\
& -6.781 & $* * *$ & -3.813 \\
CERP & $(1.972)$ & & $(2.921)$ \\
& 144.112 & $* * *$ & 1.670 \\
ESF & $(38.894)$ & & $(1.418)$ \\
& 0.049 & & 0.008 \\
DFI & $(0.056)$ & & $(0.040)$ \\
& -29.942 & $*$ & -2.119 \\
IRRF & $(15.608)$ & & $(1.090)$ \\
& -2.823 & & -1.234 \\
Sunni & $(3.252)$ & & $(1.684)$ \\
Services & 4.417 & $* * * *$ & \\
& $(0.659)$ & & \\
Income(2004) & 4.039 & & \\
& $(6.681)$ & & \\
Constant & 0.000 & & \\
& $(0.001)$ & $* * *$ & $-1,006.224$ \\
No. districts & $-2,962.262$ & $* * *$ & $(889.604)$ \\
\hline Observations & $(476.809)$ & & 104 \\
& 100 & & 936 \\
\hline
\end{tabular}

Note: Robust clustered standard errors in parentheses.

${ }^{* * *} \mathrm{p}<0.01,{ }^{* *} \mathrm{p}<0.05,{ }^{*} \mathrm{p}<0.1$.

the ethnic alliance strategy, SOI, has a pacifying effect on violence. By contrast, I did not find strong evidence for the pacifying effect of CERP. What is more, as hypothesized, the coefficient corresponding to the spatially weighted variable W.CERP shows that CERP has a positive spillover effect column (3), meaning that a higher level of CERP spending at district $j$ may increase the level of violence in district $i$ as well. This can happen when, for instance, people in district $i$ also want to benefit from aid by mimicking some attacks locally. But this spillover effect is not found in the case of SOI. 
One limitation of the static models is that it fails to account for the short-term effects of policies, which interests policy makers the most, as counterinsurgency is likely to be a response to recent changes in the level of violence and hence is not time-invariant. Adding a lagged dependent variable, which summarizes the immediate history of a region, to the right-hand side of a model allows me to better account for the short-run adjustment dynamics of violence in response to counterinsurgency policy.

The estimation results of the dynamic models are summarized in column (4) in Table 3.2. The coefficients of the lagged dependent variable and of the spatial terms are highly significant. Furthermore, results are similar to what we found before. While SOI reduced the number of attacks locally, we do not find a significant spillover effect associated with it. By contrast, CERP seems to induce more violence in both local and neighboring districts, though the neighborhood effect is statistically weaker in this case.

What is also of interest is whether there is a synergy effect between SOI and troop surge. For example, Biddle, Friedman, and Shapiro (2012) hypothesized that troop surge and alliance are jointly responsible for the reduction in the number of insurgent attacks. To investigate this synergy hypothesis, I also estimated the spatial model with interaction terms. The estimation results of a dynamic model are reported in columns (5) and (6) of Table 3.3. The coefficient corresponding to the interaction term is positive and statistically significant in the model. 
Table 3.2: Spatial effect

\begin{tabular}{|c|c|c|c|c|}
\hline & $\begin{array}{c}(3) \\
\text { STATIC }\end{array}$ & & $\begin{array}{c}(4) \\
\text { DYNAMIC }\end{array}$ & \\
\hline$y_{t-1}$ & & & $\begin{array}{r}0.74 \\
(0.03)\end{array}$ & $* * *$ \\
\hline w.y & $\begin{array}{r}0.53 \\
(0.07)\end{array}$ & $* * *$ & $\begin{array}{r}0.21 \\
(0.04)\end{array}$ & $* * *$ \\
\hline Pop & $\begin{array}{r}72.09 \\
(63.89)\end{array}$ & & $\begin{array}{r}-46.48 \\
(39.97)\end{array}$ & \\
\hline Troop & $\begin{array}{r}11.12 \\
(14.50)\end{array}$ & & $\begin{array}{r}-10.82 \\
(12.63)\end{array}$ & \\
\hline Resource & $\begin{array}{r}-0.24 \\
(1.24)\end{array}$ & & $\begin{array}{r}-0.01 \\
(0.51)\end{array}$ & \\
\hline Unemploy & $\begin{array}{l}-4.51 \\
(2.34)\end{array}$ & * & $\begin{array}{l}-0.27 \\
(0.71)\end{array}$ & \\
\hline SOI & $\begin{array}{r}-0.04 \\
(0.02)\end{array}$ & * & $\begin{array}{c}-0.04 \\
(0.01)\end{array}$ & *** \\
\hline ISFF & $\begin{array}{r}0.53 \\
(1.82)\end{array}$ & & $\begin{array}{r}-1.88 \\
(1.76)\end{array}$ & \\
\hline CERP & $\begin{array}{r}-0.25 \\
(1.51)\end{array}$ & & $\begin{array}{r}3.66 \\
(1.26)\end{array}$ & *** \\
\hline ESF & $\begin{array}{r}0.02 \\
(0.04)\end{array}$ & & $\begin{array}{l}-0.01 \\
(0.01)\end{array}$ & \\
\hline DFI & $\begin{array}{r}1.02 \\
(0.81)\end{array}$ & & $\begin{array}{r}2.54 \\
(1.29)\end{array}$ & $* *$ \\
\hline IRRF & $\begin{array}{r}-0.14 \\
(1.21)\end{array}$ & & $\begin{array}{r}0.45 \\
(1.28)\end{array}$ & \\
\hline w.Troop & $\begin{array}{r}9.66 \\
(28.35)\end{array}$ & & $\begin{array}{r}-3.33 \\
(13.28)\end{array}$ & \\
\hline w.Resource & $\begin{array}{r}1.90 \\
(1.09)\end{array}$ & * & $\begin{array}{r}0.24 \\
(0.68)\end{array}$ & \\
\hline w.Unemploy & $\begin{array}{r}0.38 \\
(1.68)\end{array}$ & & $\begin{array}{r}-0.45 \\
(1.28)\end{array}$ & \\
\hline w.SOI & $\begin{array}{r}0.00 \\
(0.02)\end{array}$ & * & $\begin{array}{r}-0.01 \\
(0.01)\end{array}$ & * \\
\hline w.ISFF & $\begin{array}{r}-9.25 \\
(5.98)\end{array}$ & & $\begin{array}{r}-0.79 \\
(2.56)\end{array}$ & \\
\hline w.CERP & $\begin{array}{r}9.71 \\
(4.30)\end{array}$ & $* *$ & $\begin{array}{r}3.52 \\
(1.85)\end{array}$ & * \\
\hline w.ESF & $\begin{array}{l}-0.12 \\
(0.05)\end{array}$ & $* * *$ & $\begin{array}{r}-0.06 \\
(0.03)\end{array}$ & \\
\hline w.DFI & $\begin{array}{l}-6.74 \\
(8.14)\end{array}$ & & $\begin{array}{r}3.65 \\
(1.83)\end{array}$ & * \\
\hline w.IRRF & $\begin{array}{r}4.00 \\
(7 \cdot 38) \\
\end{array}$ & & $\begin{array}{r}0.54 \\
(2.43) \\
\end{array}$ & \\
\hline No. districts & 104 & & 104 & \\
\hline Observations & 832 & & 832 & \\
\hline
\end{tabular}

Note: Robust clustered standard errors in parentheses.

${ }^{* * *} \mathrm{p}<0.01,{ }^{* *} \mathrm{p}<0.05,{ }^{*} \mathrm{p}<0.1$.

However, as discussed in the previous section, with the multiplier effect, coefficients interact with one another non-linearly in a spatial model. Consequently, one cannot easily read the marginal effect from the tables. For illustration purposes, consider the marginal effect of the surge in the 
Table 3.3: Synergy effect

\begin{tabular}{|c|c|c|c|c|}
\hline & $\begin{array}{c}(5) \\
\text { DYNAMIC }\end{array}$ & & $\begin{array}{c}(6) \\
\text { DYNAMIC }\end{array}$ & \\
\hline$y_{t-1}$ & $\begin{array}{r}0.74 \\
(0.03)\end{array}$ & $* * *$ & $\begin{array}{r}0.74 \\
(0.03)\end{array}$ & $* * *$ \\
\hline w.y & $\begin{array}{r}0.19 \\
(0.04)\end{array}$ & $* * *$ & $\begin{array}{r}0.21 \\
(0.04)\end{array}$ & $* * *$ \\
\hline Pop & $\begin{array}{r}-37.27 \\
(40.32)\end{array}$ & & $\begin{array}{r}-39.67 \\
(40.29)\end{array}$ & \\
\hline Synergy & $\begin{array}{r}21.32 \\
(9.41)\end{array}$ & $* * *$ & $\begin{array}{r}27.83 \\
(12.15)\end{array}$ & ** \\
\hline Troop & $\begin{array}{r}-11.15 \\
(12.90)\end{array}$ & & $\begin{array}{r}-10.93 \\
(12.72)\end{array}$ & \\
\hline Resource & $\begin{array}{r}-0.04 \\
(0.52)\end{array}$ & & $\begin{array}{r}0.04 \\
(0.52)\end{array}$ & \\
\hline Unemploy & $\begin{array}{c}-0.31 \\
(0.71)\end{array}$ & & $\begin{array}{r}-0.29 \\
(0.71)\end{array}$ & \\
\hline SOI & $\begin{array}{l}-0.11 \\
(0.03)\end{array}$ & $* * *$ & $\begin{array}{l}-0.13 \\
(0.04)\end{array}$ & $* * *$ \\
\hline ISFF & $\begin{array}{r}-1.95 \\
(1.77)\end{array}$ & & $\begin{array}{r}-1.92 \\
(1.77)\end{array}$ & \\
\hline CERP & $\begin{array}{r}3.73 \\
(1.26)\end{array}$ & $* * *$ & $\begin{array}{r}3.68 \\
(1.26)\end{array}$ & $* * *$ \\
\hline ESF & $\begin{array}{r}0.00 \\
(0.01)\end{array}$ & & $\begin{array}{r}0.00 \\
(0.01)\end{array}$ & \\
\hline DFI & $\begin{array}{r}2.48 \\
(1.29)\end{array}$ & * & $\begin{array}{r}2.54 \\
(1.29)\end{array}$ & ** \\
\hline IRRF & $\begin{array}{r}0.48 \\
(1.29)\end{array}$ & & $\begin{array}{r}0.49 \\
(1.28)\end{array}$ & \\
\hline w.Synergy & $\begin{array}{r}38.98 \\
(20.47)\end{array}$ & * & $\begin{array}{r}24.78 \\
(25.17)\end{array}$ & \\
\hline w.Troop & $\begin{array}{r}-3.33 \\
(13.28)\end{array}$ & & $\begin{array}{r}-1.13 \\
(13.32)\end{array}$ & \\
\hline w.Resource & $\begin{array}{r}0.24 \\
(0.68)\end{array}$ & & $\begin{array}{r}0.09 \\
(0.68)\end{array}$ & \\
\hline w.Unemploy & $\begin{array}{r}-0.45 \\
(1.28)\end{array}$ & & $\begin{array}{r}-0.66 \\
(1.29)\end{array}$ & \\
\hline w.SOI & $\begin{array}{l}-0.01 \\
\text { (0.01) }\end{array}$ & * & $\begin{array}{r}-0.09 \\
(0.08)\end{array}$ & \\
\hline w.ISFF & $\begin{array}{r}-0.79 \\
(2.56)\end{array}$ & & $\begin{array}{r}-0.86 \\
(2.57)\end{array}$ & \\
\hline w.CERP & $\begin{array}{r}3.52 \\
(1.85)\end{array}$ & * & $\begin{array}{r}3.60 \\
(1.85)\end{array}$ & * \\
\hline w.ESF & $\begin{array}{r}-0.06 \\
(0.03)\end{array}$ & & $\begin{array}{c}-0.04 \\
(0.03)\end{array}$ & \\
\hline w.DFI & $\begin{array}{r}3.65 \\
(1.83)\end{array}$ & * & $\begin{array}{r}3.54 \\
(1.83)\end{array}$ & * \\
\hline w.IRRF & $\begin{array}{r}0.54 \\
(2.43)\end{array}$ & & $\begin{array}{r}0.42 \\
(2.47)\end{array}$ & \\
\hline No. districts & 104 & & 104 & \\
\hline Observations & 832 & & 832 & \\
\hline
\end{tabular}

Note: Robust clustered standard errors in parentheses.

$$
\text { *** } \mathrm{p}<0.01,{ }^{* *} \mathrm{p}<0.05,{ }^{*} \mathrm{p}<0.1 \text {. }
$$


interaction model. Based on equation 3, the marginal effect of the surge on SIGACT at time $t$ is:

$$
\frac{\partial \operatorname{SIGACT}_{\mathrm{t}}}{\partial \mathrm{TSS}_{\mathrm{i}, \mathrm{t}}}=\underbrace{\left(\mathrm{I}_{\mathrm{N}}-\delta \mathrm{W}\right)^{-1}}_{\text {multiplier effect }}\left[\begin{array}{cccc}
\Gamma_{i, \mathrm{t}} & w_{12} \Theta_{j, \mathrm{t}} & \cdot & w_{1 \mathrm{~N}} \Theta_{\mathrm{j}, \mathrm{t}} \\
w_{21} \Theta_{j, \mathrm{t}} & \Gamma_{i, \mathrm{t}} & \cdot & w_{2 \mathrm{~N}} \Theta_{j, \mathrm{t}} \\
\cdot & \cdot & \cdot & \cdot \\
w_{\mathrm{N} 1} \Theta_{j, \mathrm{t}} & w_{\mathrm{N} 2} \Theta_{j, t} & \cdot & \Gamma_{i, \mathrm{t}}
\end{array}\right]
$$

where

$$
\begin{aligned}
& \Gamma_{i, t} \equiv \underbrace{\underbrace{\gamma_{\mathrm{TS}}}_{\text {direct effect }}+\underbrace{\mathrm{SOI}_{i, t} \times \gamma_{\mathrm{SrN}}}_{\text {interact with the surge }}}_{\text {own }} \\
& \Theta_{j, \mathrm{t}} \equiv \underbrace{\underbrace{\theta_{\mathrm{TS}}}_{\text {own }}+\underbrace{\mathrm{SOI_{j,t } \times \theta _ { \mathrm { SrN } }}}_{\text {interact with the surge }}}_{\text {indirect effect }}
\end{aligned}
$$

with SOI denoting Sons of Iraq, TS troop surge, and SYN synergy.

Three observations about the expressions follow. First, the total marginal effect is the product of the multiplier effect times the direct effect and indirect effect. The direct effect indicates the policy effect in the implemented region whereas the indirect effect shows the spillover effect. Each of the direct and indirect effects has two components, one associated with the surge itself and an interaction term associated with SOI. Second, there is a time subscript attached to the policy variable corresponding to the surge. This means that the marginal contribution of a policy in the presence of the synergy effect is time-varying. Finally, the marginal effect of a counterinsurgency strategy is asymmetric in the presence of the synergy effect. This means that with synergy, the marginal contribution of the surge depends on the prevailing status of SOI. In parallel, the marginal contribution of SOI depends on the prevailing status of the surge in a district as well. Though we are evaluating the same synergy effect between the surge and SOI, the marginal effects are different, depending on which other policy variable is held fixed (and at what value). The asymmetry implies that if the synergy effect between the surge and SOI exists, policy makers should think carefully about which strategies they want to adjust, 
as the effect of lowering the troop size (and holding SOI spending fixed) and of lowering the spending on SOI (and holding troop size fixed) may not have the same sign and size, depending on the estimates and other variables.

Figures 3.2(a)-(f) illustrate the marginal effects of three policy variables based on the dynamic model with the synergy effect. ${ }^{9}$ Since the marginal effects are time-varying, here I report the marginal effect based on the period-average of the estimates, with the 95 per cent confidence interval shown. The tails are trimmed and not shown in the diagrams. Therefore, if a distribution covers zero, shown by a vertical dotted line, it signifies that the marginal effect is statistically insignificant at the 5 per cent level.

Figure 3.2(a) informs us that by slightly reinforcing CERP in a district, the average effect on the implemented district is likely to be violenceenhancing. Furthermore, the policy also induces more attacks to the neighboring regions, though the effect is slightly below the 5 per cent level (Figure 3.2(b)). On the other hand, SOI is found to be violence-reducing locally (Figure 3.2(c)) but has no obvious spillover effect associated with it (Figure 3.2(d)). Finally, troop surge has a mild effect in countering with insurgencies but the effect is rather ambiguous (Figures 3.2(e) and 3.2(f)). The above findings suggest that SOI is the only policy that carries the intended effects.

However, different synergy effects may have marginal effects opposite in sign. For this reason, we would also want to see the conditional policy effect. Again, the period averages and confidence intervals are displayed. Overall, if a district has both policies active, increasing the intensity of a policy is likely to induce more violence, though the effects are not statistically significant at the 5 per cent level (Figures 3.3(a)-(d)). In other words, the synergy effect, if there is any, is more likely to be harmful in the short run. Though this finding sounds counter-intuitive, Biddle, Friedman, and Shapiro (2012) and Lindsay and Long (2013) invariably pointed to the spike in violence shortly after the surge; so do Romano, Calfano, and Phelps (2015). All of these studies stated that troop surge in the short run causes more confrontations and backfires.

Two observations follow from the above findings. First, it is obvious that the marginal effects of the same policy can be different, depending on the status of the other policies. Second, the danger of generalizing the policy effect without specifying the conditions of the other policies

9 A similar conclusion can be reached based on estimation results from the static model. 
becomes clear. For example, in evaluating the synergy effect, while the net effect of SOI is to reduce violent attacks, it may spread violence to the neighboring regions when combined with troop surge. All in all, spatial spillover in the examined cases is real and considerable. Some policy mixes are also found to have opposite effects in the implemented and neighboring regions. More importantly, while the claims in the previous studies are usually unconditional, my findings show that the effects are far from universal. Disregarding the interaction effect could lead to undesirable policy outcomes. The effects of different strategies are nonadditive, and no counterinsurgency strategy (or its mix) is perfect and works unconditionally.

The SOI measure in the dataset can be noisy as it also includes payments to local armed force. As a robustness check, I also used the data in Biddle, Friedman, and Shapiro (2012) to identify the SOI operation areas. As the areas identified in the article were based on interviewees recorded in a different dataset, this new source of data provides an alternative and less noisy measure about the status of the project. The estimation results based on this new measure are reported in column (6) of Table 3.3 and they are consistent with the findings reported earlier.

\subsection{CONCLUSION}

Previous sub-national analyses in counterinsurgency in Iraq usually make an implicit assumption that different units are isolated islands. When the assumption is violated, the assessments can be biased towards the positive findings. This issue is common in sub-national level analyses as the barriers to trans-administrative unit activities are almost nonexistent. This study introduces a target selection approach to the insurgent mobility problem. While the net effect of a counterinsurgency strategy is always context-dependent, this study discusses a number of factors relevant to the problem and a tool portable to similar kinds of analyses. Applying the framework and method to the Iraqi data, I found evidence supporting the hypothesis of spatial interdependence. The effects of a counterinsurgency strategy also vary considerably across space when mixed with another strategy. This finding is especially important as similar strategies have been adopted in Afghanistan. Yet, the findings here are not to suggest abandoning the strategy altogether in spite of the spillover effect in the short run; the costs may be a necessary one to enhance security in 


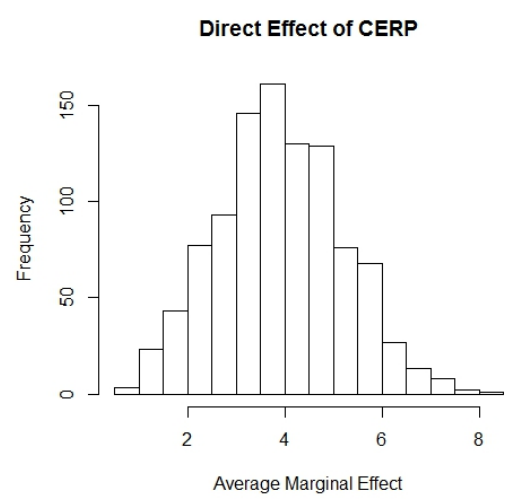

(a)

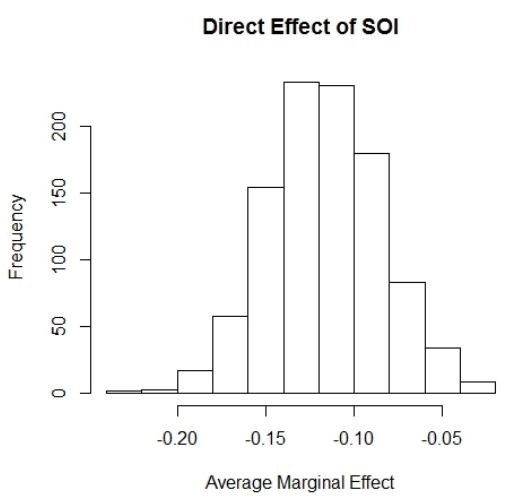

(c)

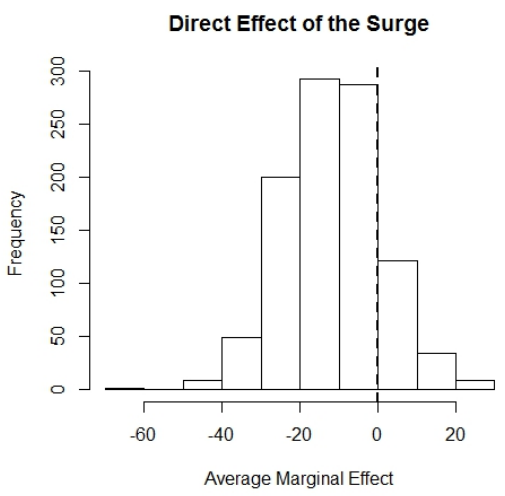

(e)

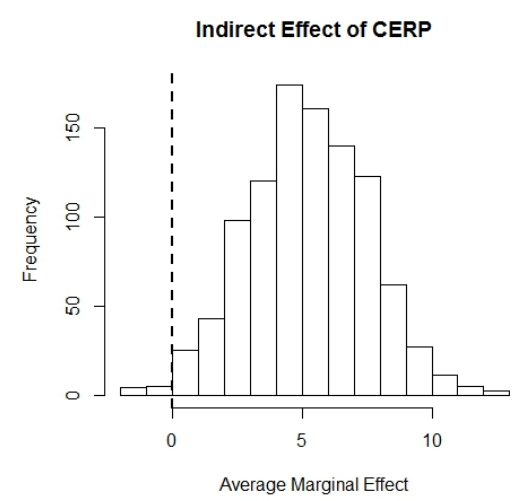

(b)

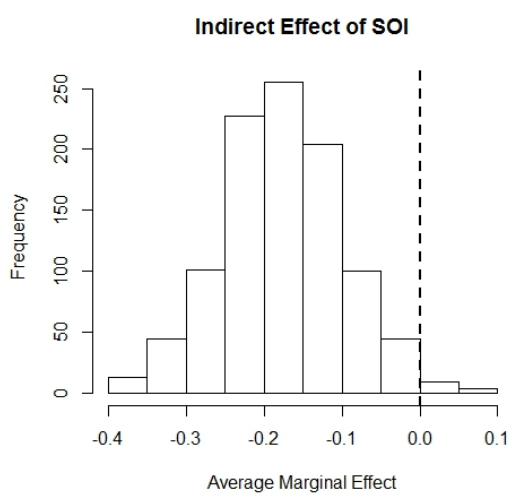

(d)

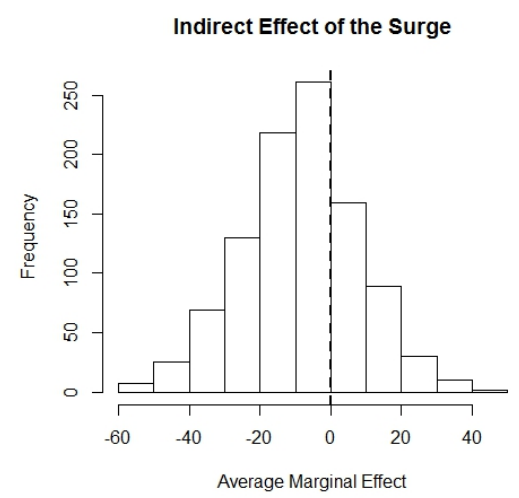

(f)

Figure 3.2: Spatial effects of three counterinsurgency policies, with the synergy effects 


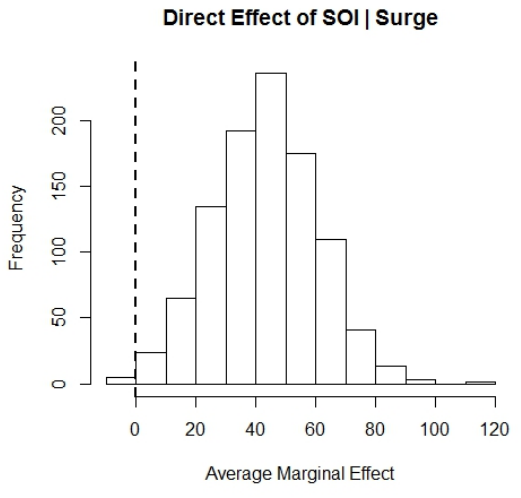

(a)

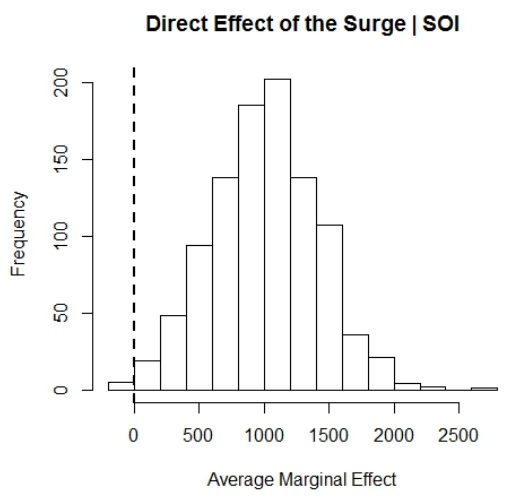

(c)

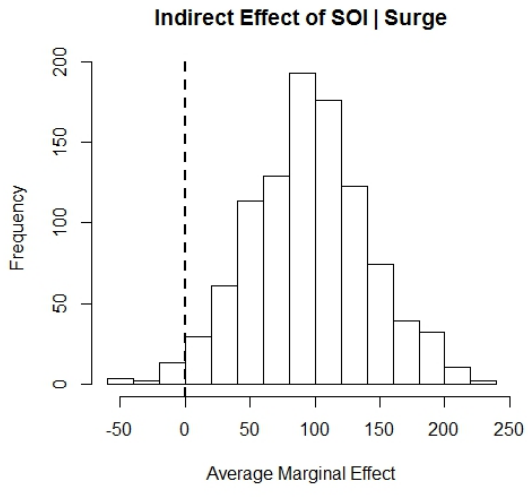

(b)

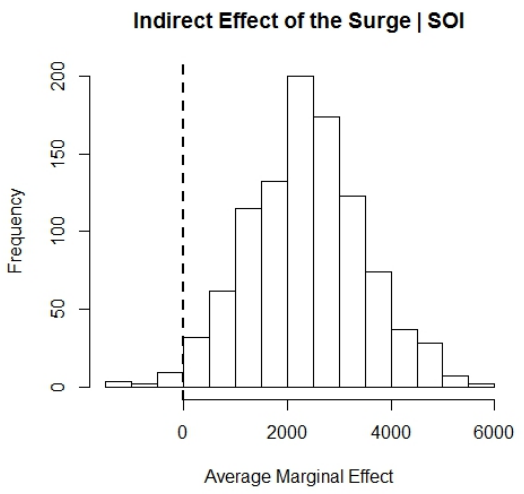

(d)

Figure 3.3: Synergy effects of SOI and troop surge, with synergy 
the country. Instead, the findings suggest that policy makers should take the spillover effect into account when devising and assessing their strategies. A more fruitful approach should be attentive to the human and geographical factors of a region and its neighborhoods. In general, a similar strategy in areas that disfavors violence substitution is more likely to be cost-efficient and effective, as it minimizes the harm due to the likely spillover effects. The findings based on the Iraqi case suggest that strategies that are less likely to create rents are more likely to minimize the spillover effect.

This chapter contributes to the counterinsurgency literature by offering a framework and a tool to analyze impacts of counterinsurgency efforts. It also provides new empirical findings based on an improved method for further theorization. Many qualitative studies inform us that the local political context also plays a significant role in explaining insurgency (e.g. Long, 2008; Hagan et al., 2013). Though some of the effects are geographically limited in scope and hence not likely to substantially affect the argument regarding relocation and conditionality, a more elaborated assessment is needed in the future when data of higher resolution in both time and spatial dimensions are available. Given the scarcity of data and my research objective, which is to assess the sensitivity of previous findings to the spatial consideration, future studies should test which of the proposed factors are generally relevant in the target selection process, so that a complete theory can be built.

My findings have important implications for the emerging conflict diffusion literature. A basic notion of the literature is that the spread of violence is neither random nor directionless. Different scholars have advanced the research agenda and ask why conflicts cluster in space (Midlarsky, Crenshaw, and Yoshida, 1980; Gleditsch, 2007; Buhaug and Gleditsch, 2008). Is the clustering a result of diffusion or attribute clustering? What are the underlying mechanisms of diffusion? ${ }^{10}$ The proposed target selection framework could be understood as a mechanism through which violence travels across space. ${ }^{11}$ The proposed framework also provides a foundation to integrate agency with structural characteristics: violence could be a deliberate strategy of insurgents subject to geographical constraints, be the strategy a result of the counterinsurgency efforts or not.

10 See also Wood (2013, p. 238). Braithwaite and Johnson (2012) found evidence of clustering in the Iraqi case.

11 See Baudains, Braithwaite, and Johnson (2013), which studies the 2011 riots in London using a similar framework. But they hypothesized that the rioters were far less rational. 
Thus, the framework avoids the dichotomy that overwhelmingly emphasizes either agency or geography. In short, the findings in this study bring social scientists' attention to the mobility issue and provide insights and tools that help both academicians and policy makers to better address and conceptualize the target selection problem associated with violent conflicts. 


\section{$3 \cdot 7$ APPENDIX}

This appendix provides further details of the bias-corrected least square dummy variable (BCLSDV) estimator of the fixed effect model that I used to obtain the estimates in Table 3.3. In this appendix, the vector $\beta$ includes what I separately indicated as $\beta$ and $\gamma$ in the main text. I made the separation in text to make equation 4 clearer for exposition purpose. The description is largely reproduced from Elhorst (2010a, pp. 273-274). The details are provided here for the sake of completeness.

1. The variables, $y_{i t}, y_{i t-1}, \sum w_{i j} y_{j t}$, and $x_{i t}$ are demeaned. For example,

$$
y_{i t}^{*}=y_{i t}-\frac{1}{T} \sum_{t=1}^{T} y_{i t} .
$$

2. The endogeneity of $\sum_{j} w_{i j} y_{j t}$ is taken account by concentrating out the fixed effects (e.g. Yu, de Jong, and Lee (2008) and Elhorst (2010b)). Consequently, we estimate the demeaned version of equation 2 using maximum likelihood. The log-likelihood function is

$$
\begin{aligned}
& \mathrm{L}=\mathrm{C}-\frac{\mathrm{NT}}{2} \log \left[\left(e_{0}-\delta e_{1}\right)^{\top}\left(e_{0}-\delta e_{1}\right)\right] \\
&+T \log \left|\mathrm{I}_{\mathrm{N}}-\delta \mathrm{W}\right|
\end{aligned}
$$

where $C$ is a constant and $e_{0}$ and $e_{1}$ are, respectively, residuals of regressing $Y^{*}$ and $\left(I_{\mathrm{T}} \otimes W\right) Y^{*}$ on $\widetilde{X}^{*}$, with $\widetilde{X}^{*}=\left[\begin{array}{ll}Y_{-1}^{*} & X^{*}\end{array}\right]$.

3. Since there is only one unknown $\delta$ in the likelihood function, which is concave in it, the maximization can be solved easily using numerical method.

4. Other parameters can be obtained by substituting back the estimated $\widehat{\delta}$ obtained above using the following expressions.

$$
\left[\begin{array}{c}
\widehat{\tau} \\
\widehat{\beta}
\end{array}\right]=\left(\widetilde{X}^{* \top} \widetilde{X}^{*}\right)^{-1} \widetilde{X}^{* \top}\left[Y^{*}-\delta\left(I_{\mathrm{T}} \otimes W\right) Y^{*}\right]
$$




$$
\begin{aligned}
\widehat{\delta}^{2}=\frac{1}{N T}\left(Y^{*}-\delta\left(I_{\mathrm{T}} \otimes W\right) Y^{*}-\widetilde{X}^{*}\left[\begin{array}{ll}
\widehat{\tau} & \widehat{\beta}^{\top}
\end{array}\right]^{\top}\right)^{\top} \\
\left(Y^{*}-\delta\left(I_{T} \otimes W\right) Y^{*}-\widetilde{X}^{*}\left[\begin{array}{ll}
\widehat{\tau} & \widehat{\beta}^{\top}
\end{array}\right]^{\top}\right)
\end{aligned}
$$

5. The estimates obtained above are biased because the model includes the lagged dependent variable. Extending the LSDV estimator to a spatial setting, Yu, de Jong, and Lee (2008) derived the analytic solutions to correct for the size of the bias. One can obtain the BCLSDV using the formula

$$
\left[\begin{array}{c}
\widehat{\tau} \\
\widehat{\delta} \\
\widehat{\beta} \\
\widehat{\sigma}^{2}
\end{array}\right]_{\text {BCLSDV }}=\left[\begin{array}{c}
\widehat{\tau} \\
\widehat{\delta} \\
\widehat{\beta} \\
\widehat{\sigma}^{2}
\end{array}\right]_{\text {LSDV }}-\left(\frac{-\Sigma}{N T}\right)^{-1} \frac{1}{T} \text { bias }\left[\begin{array}{c}
\widehat{\tau} \\
\widehat{\delta} \\
\widehat{\beta} \\
\widehat{\sigma}^{2}
\end{array}\right]_{\text {LSDV }}
$$

where

$$
\begin{aligned}
& \operatorname{bias}\left[\begin{array}{c}
\widehat{\tau} \\
\widehat{\delta} \\
\widehat{\beta} \\
\widehat{\sigma}^{2}
\end{array}\right]_{\mathrm{LSDV}}= \\
& {\left[\begin{array}{c}
\frac{1}{N} \operatorname{tr}\left\{\left[(1-\widehat{\tau}) I_{N}-\widehat{\delta} W\right]^{-1}\right\} \\
\frac{1}{N} \operatorname{tr}\left\{W\left(I_{N}-\widehat{\delta} W\right)\left[(1-\widehat{\tau}) I_{N}-\widehat{\delta} W\right]^{-1}\right\} \\
+\frac{1}{N} \operatorname{tr}\left\{W\left(I_{N}-\widehat{\delta} W\right)\right\} \\
0 \\
\frac{1}{2 \widehat{\sigma}^{2}}
\end{array}\right]}
\end{aligned}
$$


and the lower diagonal elements of the information matrix $\Sigma$ is equal to

$$
\left[\begin{array}{cccc}
\frac{1}{\widehat{\sigma}^{2}} Y_{-1}^{* \top} Y_{-1}^{*} & & \\
\frac{1}{\widehat{\sigma}^{2}} Y_{-1}^{* \top}\left(\mathrm{I}_{\mathrm{T}} \otimes \widetilde{W}\right) Y_{-1}^{*} \widehat{\tau} & \Psi & \\
\frac{1}{\widehat{\sigma}^{2}} X_{-1}^{* \top} Y_{-1}^{*} & \frac{1}{\hat{\sigma}^{2}} X^{* \top}\left(\mathrm{I}_{\mathrm{T}} \otimes \widetilde{W}\right) X^{*} \widehat{\beta} & \frac{1}{\widehat{\sigma}^{2}} X^{* \top} X^{*} \\
0 & \frac{T}{\widehat{\sigma}^{2}} \operatorname{tr}(\widetilde{W}) & 0 & \frac{N T}{2 \widehat{\sigma}^{4}}
\end{array}\right]
$$

where

$\Psi=T^{*} \operatorname{tr}\left(\widetilde{W} \widetilde{W}+\widetilde{W}^{\top} \widetilde{W}\right)+\frac{1}{\widehat{\sigma}^{2}}\left[\begin{array}{ll}\widehat{\tau} & \widehat{\beta}\end{array}\right]^{\top} \widetilde{X}^{* \top}\left(\mathrm{I}_{\mathrm{T}} \otimes \widetilde{W}^{\top} \widetilde{W}\right) \widetilde{X}^{*}\left[\begin{array}{ll}\widehat{\tau} & \widehat{\beta}\end{array}\right]$ and

$$
\widetilde{W}=W\left(I_{N}-\widehat{\delta} W\right)^{-1}
$$


Part II

THE PSYCHOLOGY OF RECONSTRUCTION 

Existing studies in the disarmament, demobilization, and reintegration (DDR) literature predominantly concern the impacts of a program. However, survey data show that a large number of ex-combatants chose not to join the program. And till now, there is little systematic analysis studying the participation decision. This chapter tries to address this knowledge gap. Using data from a reintegration program in Liberia, this analysis finds that besides economic conditions, the psychological well-being of an ex-combatant is a strong predictor of non-participation and dropout. When comparing with the graduates of reintegration program, non-participants and dropouts also display greater interests in re-entering the battlefield. In short, mental health is not only a public health issue that affects ex-combatants' quality of life. It can embroil reintegration efforts and endanger regional security.

This chapter is based on Wong, Pui-Hang. 2017b. Paper prepared for the Research School on Peace and Conflict Symposium, Oslo, 20-21 April, 2017. 
Disarmament, demobilization, and reintegration (DDR) is an integral part of peace-building projects in many post-conflict societies today. Reintegration, however, has remained a policy challenge to practitioners such as the United Nations, foreign donors, and local non-government organizations. A seldom addressed challenge is that of non-participation or dropout. Although the true number of non-participants is not known, based on a survey on former combatants of the Liberian civil war, it is estimated that about 12 per cent of former combatants had not registered with the National Commission on Disarmament, Demobilization, Rehabilitation and Reintegration (Pugel, 2007; Pugel, 2009). ${ }^{1}$ There is no official statistic on the size of dropout either. But according to Pugel (2007), two years after the reintegration process had commenced, there were only about 28 per cent of ex-fighters who had either entered or completed the reintegration phase of the disarmament, demobilization, rehabilitation, and reintegration (DDRR) process outside of Monrovia, the capital of Liberia. While in the Greater Monrovia region, the figure was as high as 63 per cent.

One assumption adopted by the United Nations Mission in Liberia (UNMIL) about the 'disappeared' claimants-people who registered at the DD (disarmament and demobilization) phases but disappeared in the RR (rehabilitation and reintegration) phases of the program, estimated at two per cent-is that they were well-integrated and did not require assistance (Paes, 2005, p. 285). This implicit assumption, however, is not grounded and can be dangerous. In fact, data show that the dropouts in a vocational training program in Liberia demonstrated greater interests in mercenary activities than people who completed the program (see Appendix I for the results). Given this worrisome trend, it is important to gain a better understanding of the dropout behaviors in order to improve future design of similar programs in other post-conflict settings.

This chapter addresses this knowledge gap and seeks to improve our understanding about the non-participation and drop-out decision of excombatants. A survey by Pugel (2007) reveals that the majority of nonparticipants did not join the DDRR program in Liberia because they did not want to be identified as ex-combatants. Yet, the relevance and role of

I This figure covers only all those aged 18 or above but not the child soldiers who fought in the Liberian civil war. Neither does it include foreign fighters which were excluded from the national DDRR program in Liberia. The Joint Implementation Unit (2003), the unit that took charge of the DDRR program in Liberia, estimated that there were over 11,000 child soldiers involved in the civil war. 
different social, economic, and psychological factors underlying the decision remain a topic to be further explored. While this study encompasses all three dimensions at the same time, it concentrates on the psychological factor. More specifically, this chapter finds supportive evidence to the argument that past wrongdoing of former fighters may develop the moral emotion of shame once the former fighters withdraw from a value system drastically different from the one they experienced during the wartime (Singer, 2004). In some cases, the emotion can further develop into psychological distress (Lee, Scragg, and Turner, 2001). As a part of the adaptive strategy, the psychologically distressed individuals may choose to escape from stimuli associated with their war memory, social rejection, or both, and display the symptoms of avoidance and social withdrawal. While this constitutes a necessary part of the recovery process, the behavioral responses may sustain and further develop into post-traumatic stress disorders (PTSD) and hinder future reintegration. Using data from a reintegration program in Liberia, my analysis finds that the dropouts from the program exhibited greater interest in engaging in mercenary activities than the graduates of the program. Furthermore, after accounting for other factors such as perceived social rejection and economic hardships, which left some of the potential participants no choice but to continue working, my analysis finds supportive evidence to the relevance of the psychological factors discussed above. More specifically, showing symptoms of social avoidance predicts an increase of the odds of dropout by 21 per cent. Further analysis also shows that the development of symptoms is partially shaped by the wartime experience of an ex-fighter. While the development of symptoms is only weakly correlated with the time that an ex-combatant spent in warring factions, the number of violent acts that the respondents were forced to commit has a strong predictive power on the incidence of avoidance. And consistent with the theory of trauma membrane, which states that people suffering from psychological distress may want to create a comfort zone surrounded by the entrusted 'insiders' (Lindy, Grace, and Green, 1981), this study also finds that individuals showing symptoms of avoidance were also more embedded in friendship networks with other ex-combatants. This finding comes in contrast to what de Vries and Wiegink (2011) hypothesize, that maintaining a relationship with other ex-combatants after a war may contribute to the rehabilitation of former combatants.

In the following, I will first review what existing literature suggests about non-participation and the behavior of dropouts, then move on to 
discuss the challenges of reintegration in Liberia and explain how the psychological conditions of former combatants can play a role in the reintegration process. After introducing the data and method, I will report the empirical findings before offering a few concluding remarks.

\subsection{BARRIERS TO PARTICIPATION}

A large part of the literature in DDR, and reintegration in particular, concentrates on program evaluation (Blattman and Annan, 2016; Blattman, Fiala, and Martinez, 2014; Gilligan, Mvukiyehe, and Samii, 2013; Humphreys and Weinstein, 2007; Kaplan and Nussio, 2015; Pugel, 2007). Though the issue of non-participation is acknowledged in some of these impact analyses, it has not been treated as a subject of interest in itself. For instance, non-participation is only considered as a source of potential bias in Humphreys and Weinstein (2007) and a statistical nuance to be avoided in Gilligan, Mvukiyehe, and Samii (2013). Though some practitioners are aware of the issue, we still lack corresponding policies targeting nonparticipants. In fact, some of the practitioners just assumed that some ex-combatants were well-integrated and hence let them fall outside the policy net. Overall, while the literature pays sufficient attention to excombatants, ex-combatants are usually viewed as a homogeneous group and we still know relatively little about why some ex-combatants choose not to engage in reintegration and what the potential consequences of ignoring the issue are.

Major contributions to the topic of non-participation are mainly from studies in other disciplines: medicine, psychology, and social works. For example, Saunders, Zygowicz, and D'Angelo (2006) found that barriers to treatment-seeking in the case of substance abuse are mostly treatmentrelated (e.g. availability of treatment, costs) and person-related (e.g. fear of being stigmatized). In a study on veterans of the Iraq and Afghanistan wars, Stecker et al. (2013) found that person-related barriers are more relevant than treatment-related barriers in explaining treatment-seeking behavior. Focusing on ex-combatants, Betancourt et al. (2008) examined the barriers to returning to school among child soldiers in Sierra Leone. They hypothesized that affordability, quality of facilities, age, social norms, and mental health can be potential barriers of reintegration. Another prominent factor is program design. McKay and Mazurana (2004) noticed that educational aid was only made available to children who had gone 
through a formal DDR process. And because female former child soldiers were usually sent back to villages without formally entering any DDR program, they were usually excluded from receiving further education. More recently, Kaplan and Nussio (2015) argue that social acceptance is another key factor explaining former combatants' participation in social organizations, an important dimension of reintegration.

Similar to the above studies, this chapter looks at various barriers to reintegration encountered by ex-combatants after civil wars. But rather than stressing the social and economic environment that an ex-combatant is embedded in, this study addresses the potential psychological factors that drive some ex-fighters to drop out from reintegration programs even when they are available. The phenomenon is particularly surprising when taking into account that the demand for DDR was high because of the adverse economic situation of the war-torn country and the room for opportunistic behaviors given by the design of a program (more on this below). In the following, after introducing the general background of the DDRR program in Liberia and taken constraints related to economic background and social acceptance into consideration, I will explain how the psychological state of former ex-combatants can impede the reintegration process.

\subsection{DDRR IN POST-CONFLICT LIBERIA}

About four months after the signing of the Comprehensive Peace Agreement in Accra in August, the DDRR program in Liberia was launched in December $2003 .^{2}$ UNMIL originally estimated that the number of combatants would be about 40,000, but it turned out that 102,193 ex-combatants showed up and registered for the DDRR program (United Nations Department of Peacekeeping Operations, 2010b, p. 25). The difference in number may lead one to conclude that non-participation is a non-issue in

2 According to Paes (2005), the DDRR process in Liberia consists of two distinct phases: a DD phase in 2004 and an RR phase starting in the same year. During the DD process, former combatants first handed in their fire arms at the Di cantonment ran by UNMIL. They then encamped in the D2 site to receive medical attention, peace training, and career counseling. Upon completion of this phase, they relocated to the destination of their choices and were entitled to a cash stipend of US\$150 per person. The RR period began shortly after their arrival at the destination. During the period, participants would receive formal education and vocational training. The second installment of US\$150 would also be distributed as a sustenance allowance. 
Liberia. But there are good reasons to believe that that is not necessarily the case.

First, only 27,804 weapons and 7,129,198 rounds of small arms ammunition were collected by October 2004, the time when the DD phase was concluded. This weapon-to-fighter ratio of 0.27 , however, is relatively low when compared with the ratio of 0.58 in the case of Sierra Leone (Kilroy, 2015 , p. 5). Furthermore, heavy weapons like mortars were largely absent (Paes, 2005, p. 256). Many of the handed-in weapons were also found to have an extremely low quality, which led some UNMIL officials to consider that the applicants should not have been qualified for entry into the DDRR program (Nichols, 2005). All these issues reveal not only a serious arms retention problem but also a potential non-participation problem. It is hard to tell the actual scale of the problem as the true number of nonparticipants will never be known. But the discussed problems warn us that the DDRR program is far from comprehensive. In fact, other studies also show that the DDRR program had left many ex-combatants behind. For instance, Paes (2005) reported that some faction leaders confiscated weapons from fighters prior to DDRR. This caused many ex-combatants not to be qualified to participate in the DDRR program. ${ }^{3}$

Second, many registered participants to the DDRR program in Liberia had only been disarmed and demobilized but were yet to start or complete the RR phase of the program. By 2006, about two years after the commencement of the RR process, it is estimated that about 6o per cent of registered demobilized ex-fighters who lived outside Monrovia had not entered the RR phase. The corresponding figure for the people living in Monrovia is over 35 per cent (Pugel, 2007). According to a survey study by Pugel (2007), these dropouts were also the most vulnerable. They were the least educated and the poorest among the ex-combatants who had already completed or enrolled in a reintegration training program. However, what remains unclear is whether and to what extent the low completion rate is due to the socio-economic background or psychological health of the participants, or both. In the following, I will explain how participation can be related to the war experience and psychological health of an ex-combatant.

3 Apart from the issues discussed above, Jennings (2007) also documented that many noncombatants obtained arms from other channels in order to profit from the program. 


\section{$4 \cdot 3$}

Apart from economic hardship, rejection from family and community members is one of the major and most common challenges faced by ex-combatants. According to Hill, Taylor, and Temin (2008), only 11 per cent of surveyed ex-combatants in Liberia stated that they gained acceptance from their neighbors. Qualitative studies uncover a similar pattern as well. For example, in a discourse analysis based on interviews with ex-combatants, DDR practitioners, community leaders, and civil representatives, McMullin (2013) contended that the practices of the DDR program in Liberia were heavily built on the assumption and perception that the existence of ex-combatants would pose a severe security threat to the country and the communities that they lived in. In another study, Podder (2012) reported that tension between communities and ex-combatants in the Lofa region were often intense and required NGOs to intervene. As an ex-combatant youth in Voinjama said, people in the community 'don't think we [combatants] are a human being, they feel we are rogues' (Podder, 2012, p. 196). They usually had no jobs and no family simply because of the ex-combatant label.

Probably because some combatants chose to fight in order to protect their families and communities (Humphreys and Weinstein, 2008; Pugel, 2007), ex-combatants were not always stigmatized (Paes, 2005, p. 257). Yet, self-judging and fear of being stigmatized can influence ex-combatants' perception on others' reactions and hence the level of psychological distress (Shelton and Richeson, 2006; van Vliet, 2010). For example, Griffin et al. (2016) indicated that perpetrators may feel ashamed when they consider themselves responsible for their wrongdoing. Especially in the case where forced violence is used as an induction or socialization process, 4 this self-blame can be particularly pronounced among former fighters who were abducted and forced to commit violence against others, including family, neighbors, and friends (Boothby and Knudsen, 2000).

Be the rejections real or imaginary, they often evoke shame, an emotional state in which one's self-image would come under serious attack (van Vliet, 2010). ${ }^{5}$ Indeed, many studies have found a positive relation-

4 See Cohen (2013) on forced violence and socialization.

5 Psychologists often distinguish shame from guilt. While shame involves negative judgment about the concept of self (i.e. I am bad), guilt is about one's behaviors (i.e. what I did was bad), which can leave one's self-image intact (Tangney and Dearing, 2002). In some cases, the attack provoked by the moral emotion can become so strong that it will 
ship between shame and symptoms of post-traumatic stress disorder, or PTSD. ${ }^{6}$ As Singer (2004) pointed out, the development of disorders can be due to the clash between values on the combat fields and at home. When former fighters attribute their wrongdoings to their own faults and condemn themselves, the emotion of shame usually arises (Richman and Leary, 2009).

Psychologists also find that shame can induce psychological pain when the entire self is seen as flawed (van Vliet, 2010). As an adaptive strategy to escape from mental distress, the person who suffers from emotional pain may want to hide or escape from other people to minimize the negative experience associated with rejection (Elliot, Gable, and Mapes, 2006; Gramzow and Tangney, 1992; Tangney et al., 1996; van Vliet, 2010). This type of avoidance can take different forms: denial, social withdrawal, and numbing, to name but a few (van Vliet, 2010). For this reason, avoidance is classified as one of three major symptoms clusters in the Diagnostic and Statistical Manual of Mental Disorders (DSM-IV-TR) criteria for PTSD. 7

Though originated as a coping strategy, ex-combatants usually do not limit avoidance to those who rejected them but often extend it to other people (Vangelisti et al., 2005). This leads people who are ashamed of what they did to withdraw from social contact (Richman and Leary, 2009). This strategy is chosen not only because it is effortless but also because it allows a person to accumulate the necessary psychological resources to recover (Richman and Leary, 2009; Zeidner and Saklofske, 1996). Therefore, the display of avoidance is not necessary an indication of psychological disorders but a signal of a recovery process. However, avoidance can come with a psychological cost and may sustain post-traumatic symptoms such as depression (Ehlers and Steil, 1995; Holahan et al., 2005; van Vliet, 2010). Furthermore, a study on Vietnam combat veteran psychiatric inpatients with PTSD shows that symptoms of avoidance were significantly associated with violent behavior (McFall et al., 1999). Although there is no evidence on the causal relationship between mental health condition and conflict relapse, studies in other disciplines such as social work and criminology also find that PTSD often has links to recidivism (Kubiak, 2004; Tangney, Stuewig, and Martinez, 2014).

induce hostility. And it is shame proneness, not guilt proneness, that positively predicted recidivism (Tangney, Stuewig, and Martinez, 2014).

6 For example, see Leskela, Dieperink, and Thuras (2002) and Wong and Cook (1992).

7 Published by the American Psychiatric Association, the Manual is and used by clinicians to help diagnose mental disorders. 
All in all, former combatants who face or perceive rejection have a higher risk of developing psychological symptoms of avoidance and social withdrawal, which may form a barrier to their resumption of civilian life. This leads to the following hypotheses:

Hypothesis 1: Ex-combatants who exhibit social avoidance behaviors are more likely to drop out from a reintegration program.

Hypothesis 2: The past wrongdoing of an ex-combatant is associated with social avoidance.

\subsection{DATA AND MODEL}

The data come from a survey of 916 ex-combatants in Liberia (Blattman and Annan, 2016). ${ }^{8}$ These ex-combatants were recruited in two regions populated by ex-fighters, one in Central Bong County and one in eastern Sinoe County. Potential recruits from these areas, mainly rubber plantations and border areas, were identified by UNMIL as economically vulnerable.

There are two limitations regarding the use of the dataset. First, given the geographical coverage and self-selected nature of the training program, the sample excludes those who did not reside close enough to the recruitment sites and those who had no interest in agricultural activities. Second, there is no data on those who registered but were screened out by the recruiters. These people, however, are less relevant in terms of policy interest. They are mainly low-risk people, minors, non-Liberians, or well-integrated ex-fighters (Blattman and Annan, 2016).

In the program, participating ex-combatants were offered an opportunity to take part in a training program that lasted for three (Sinoe) or four (Bong) months. The program had two components: agricultural training and life-skill class with counseling. Like many other reintegration programs, upon graduation, participants would receive assistance and an initial capital for relocation and farming. Training offers were randomized. The sample includes 916 participants and 48 per cent of them were offered the opportunity to participate in the program. Among them, 27 per cent either declined the offers, or accepted the offers but did not show

8 Given my research interest, I include only ex-combatants in this analysis. And because the dataset comes from Blattman and Annan (2016), the description about the dataset below largely came from the study. 
up, or failed to complete the program. These people are the focus of this analysis.

The key dependent variable, Dropout, is a dummy variable that denotes whether or not the respondent either declined the offers, or accepted the offers but did not show up for training, or failed to complete the program. The respondents are similar in the sense that they chose to quit the program at a different point of time, with or without letting the organizer know in advance. The small sample size and diversity also inhibits a separate analysis for different groups of people.

The main independent variable here is Avoidance. It is a four-item selfreport measure based on the post-traumatic stress disorder (PTSD) subscale checklist. The checklist includes the following four questions: (1) In the last four weeks, have you sometimes tried to stay away from places or certain people or talk about things because it makes you think about bad things that happened to you? (2) In the last four weeks, do you not feel like doing the things you usually like to do with friends? (3) In the last four weeks, did you feel that you don't want to share ideas or feelings with other people? (4) In the last four weeks, did you ever not want to plan for your future or lose hope?

The analysis also includes some other controls. The economic situation of a respondent may affect the propensity of a respondent to drop out from the program. To capture the effects of opportunity costs and unemployment (Berman et al., 2011; Collier and Hoeffler, 1998), I include the variable Employment to record the number of days that the respondent worked in the seven days prior to the baseline survey. The variable Income indicates the typical monthly income that the respondent earned at the time of the baseline survey. I use another variable called Debt, to measure the stock of debt that the respondent owed to a third-party. All in all, the financial constraint of the respondent (and the household) may forbid an ex-combatant to participate in the training that lasts for three to four months. However, some people may farm instead of being employed. For this reason, I include the variable, Farmland (amount of land owned by the family of the respondent) as well.

I also include variables which capture the effects of the social environment on the respondent. They are Family, Neighbors, Community, and Friends. Family and Neighbors are ordinal variables (o-3) which measure to what extent the respondent experienced problems in gaining acceptance from family and neighbors: none (o); small (1); some (2); plenty (3). Community is an index that measures the degree to which the respondent 
contributed to community works. 9 Since Kaplan and Nussio (2015) argue that high rates of social participation can help an ex-combatant to better reintegrate into civilian life, the variable is included as a further control. Similarly, people who kept contacts with other ex-combatants may affect reintegration outcome (de Vries and Wiegink, 2011). To control for this network effect, I also include a variable, called Friends, to capture this effect. It is an ordinal variable (o-4), measuring the portion of friends who are ex-combatants as well: none (0); less than half (1); half (2); more than half (3); all of them (4). ${ }^{10}$ Finally, I also included Age and Education (years of schooling) as demographic controls.

The dependent variable in the model that tests Hypothesis 2 is Avoidance, described above. For the independent variables, in addition to the demographic controls (Education and Age) and the social relations variables discussed before (i.e. Family, Neighbors, and Friends), I include the following key independent variables: Violent Acts, Time in faction, and Safety. The variable Violent Acts indicate how much (none, few, some, plenty) violence that the respondents were forced to do during the time that they spent in the factions. ${ }^{11}$ Time in faction measures how long the respondent stayed in warring factions. Safety, a dummy variable, is an indicator that shows whether or not while the respondent felt safe living in the community. ${ }^{12}$ While some people, as a coping strategy, may deny that they encountered any acceptance problem in the community, this variable can be used as an alternative indicator of the perceived social acceptance. For example, Nussio (2011) documented that ex-combatants often worry about whether they would experience acts of revenge once their identity as an ex-combatant would be known.

Given that the dependent variable Dropout is dichotomous, I employ a logit regression model to assess the effects of the key independent variables. I also use a logit model with random-effect to control for unobserved heterogeneity among respondents from different geographical lo-

9 Note that a comparable community measure is not available in the baseline survey. The variable Community, contained in the original dataset, is based on questions in the end line survey.

10 The ordinal construct of the variables imposes the linearity assumption between the measures and the dependent variable. For example, the assumption says that an increase from 1 to 2 has the same effect on the dependent variable as an increase from 2 to 3 . However, my results are not sensitive to the linearity assumption.

11 This is based on the responses to the survey questions: Were you forced to commit a violent act? How many violent acts were you forced to commit: Plenty, some, or few?

12 This is based on the responses to the survey question: Do you feel safe in this community? 
cations (7o strata). Since only a small percentage of people gave a positive response, to avoid dropping observations due to the lack of variations within a stratum, I use the random-effect instead of the fixed-effect model as a robust check. ${ }^{13}$ Noting that Avoidance is an ordinal variable, I use an ordinal logit model in the analysis testing Hypothesis 2. One potential issue with the model is that it imposes the assumption that the cut-off points are parallel. This may or may not be true. As an additional check, I also dichotomize the measure and estimate with a logit and randomeffect logit model.

\section{$4 \cdot 5$ EMPIRICAL FINDINGS}

We first look at whether and how the dropouts are different from the graduates. The means and standard deviations of different variables, organized by group, are reported in Table 4.I. From Table 4.1, it is clear that ex-combatants in the graduate group are different from the ones in the dropout group in several ways. First, the dropouts on average earned and worked more than the graduates but were less educated. Note also that the standard deviation of the variables Hours and Earnings are higher in the dropout group than in the graduate group. This suggests that the reasons for dropout can be quite diverse. The diversity may be due to the fact that some people quit or do not join the program in the first place because the expected returns from investing in human capital are rather low, whereas some people may leave the program involuntarily because they have a higher opportunity costs of leaving their work and household behind to join and complete the program.

There are other differences too. For example, the dropouts exhibited greater difficulties in reintegration. They were much less involved in community works and perceived to have more problems with family and neighbors. Most of them had gone through DDR but expressed less sympathy towards people in Côte d'Ivoire. This latter finding is interesting and consistent with the hypothesis that the dropouts may display more avoidance behaviors and be relatively numb to other people but, at the same time, show greater interest in joining mercenary groups. This suggests that the interest in mercenary activities may be partially due to their psychological conditions. However, given the size of the standard devia-

13 In fact, more than half of the observations can be dropped given the data structure. 
Table 4.1: Sample characteristics

\begin{tabular}{lrrrr}
\hline & \multicolumn{1}{c}{ ALL } & GRAD. & DROPOUTS & NON-ASSIGNED \\
\hline Mercenary & 0.065 & 0.037 & 0.095 & 0.075 \\
& $(0.246)$ & $(0.189)$ & $(0.295)$ & $(0.264)$ \\
Hours & 50.63 & 48.11 & 52.63 & 51.80 \\
& $(41.29)$ & $(40.55)$ & $(44.39)$ & $(40.94)$ \\
Earnings & 68.29 & 60.52 & 74.70 & 71.85 \\
& $(94.94)$ & $(82.95)$ & $(98.16)$ & $(101.30)$ \\
Age & 30.13 & 29.68 & 29.99 & 30.46 \\
& $(7.56)$ & $(8.01)$ & $(7.22)$ & $(7.34)$ \\
Education & 5.41 & 5.97 & 5.79 & 5.58 \\
& $(3.80)$ & $(3.85)$ & $(4.00)$ & $(3.71)$ \\
Community & 0.026 & 0.120 & -0.129 & 0.002 \\
& $(0.982)$ & $(0.958)$ & $(1.03)$ & $(0.980)$ \\
Farmland & 9.24 & 8.92 & 8.82 & 9.57 \\
& $(10.07)$ & $(9.32)$ & $(9.20)$ & $(10.75)$ \\
Avoidance & 1.39 & 1.33 & 1.57 & 1.39 \\
& $(1.31)$ & $(1.27)$ & $(1.32)$ & $(1.32)$ \\
Family & 0.213 & 0.199 & 0.162 & 0.235 \\
& $(0.725)$ & $(0.691)$ & $(0.647)$ & $(0.765)$ \\
Neighbors & 0.157 & 0.161 & 0.096 & 0.170 \\
& $(0.617)$ & $(0.611)$ & $(0.500)$ & $(0.648)$ \\
DDR & 0.272 & 0.239 & 0.353 & 0.273 \\
& $(0.445)$ & $(0.427)$ & $(0.480)$ & $(0.446)$ \\
Sympathy & 0.433 & 0.413 & 0.325 & 0.475 \\
Friends & $(0.496)$ & $(0.493)$ & $(0.470)$ & $(0.500)$ \\
& 1.92 & 1.90 & 1.97 & 1.91 \\
& $(1.07)$ & $(1.09)$ & $(1.00)$ & $(1.08)$ \\
\hline
\end{tabular}

tion, we need more observations to conclude, statistically, whether these two groups of people are really different.

To what extent can the phenomenon of dropout be explained by the hypothesized effect of psychological avoidance? Results from the logit analysis, summarized in Table 4.2, tell us that the effect is likely to be present. Furthermore, among different types of social relations, we have slightly stronger supportive evidence indicating that acceptance from neighbors is more important than acceptance from family. While economic plight (proxy by the variable Debt) is also relevant, the factor does not fully explain the hypothesized psychological origin of the dropout problem. Exhibiting symptoms of avoidance is a strong and statistically significant predictor of dropout. According to the estimate from Model (4), having an additional symptom of avoidance behavior predicts an increase of the odds of dropout by 25 per cent. Results from a random-effect model are also similar. All in all, ex-combatants who exhibit social avoidance behav- 
Table 4.2: Avoidance and dropout

\begin{tabular}{|c|c|c|c|c|c|c|c|c|}
\hline & LOGIT & & LOGIT & & RE & & RE & \\
\hline Avoidance & $\begin{array}{r}0.228 \\
(0.061)\end{array}$ & $* * *$ & $\begin{array}{r}0.218 \\
(0.064)\end{array}$ & $* * *$ & $\begin{array}{r}0.173 \\
(0.064)\end{array}$ & $* * *$ & $\begin{array}{r}0.172 \\
(0.065)\end{array}$ & $* *$ \\
\hline Family & $\begin{array}{r}0.351 \\
(0.243)\end{array}$ & & $\begin{array}{r}0.343 \\
(0.233)\end{array}$ & & $\begin{array}{r}0.340 \\
(0.254)\end{array}$ & & $\begin{array}{r}0.310 \\
(0.246)\end{array}$ & \\
\hline Neighbors & $\begin{array}{r}-0.625 \\
(0.355)\end{array}$ & * & $\begin{array}{r}-0.597 \\
(0.333)\end{array}$ & * & $\begin{array}{r}-0.647 \\
(0.357)\end{array}$ & * & $\begin{array}{r}-0.586 \\
(0.335)\end{array}$ & * \\
\hline Community & $\begin{array}{r}-0.306 \\
(0.112)\end{array}$ & $* * *$ & $\begin{array}{r}-0.309 \\
(0.110)\end{array}$ & $* * *$ & $\begin{array}{r}-0.349 \\
(0.105)\end{array}$ & $* * *$ & $\begin{array}{r}-0.316 \\
(0.119)\end{array}$ & $* * *$ \\
\hline Friends & $\begin{array}{r}0.023 \\
(0.120)\end{array}$ & & $\begin{array}{r}0.026 \\
(0.124)\end{array}$ & & $\begin{array}{r}0.003 \\
(0.109)\end{array}$ & & $\begin{array}{r}0.076 \\
(0.119)\end{array}$ & \\
\hline Income & & & $\begin{array}{r}0.000 \\
(0.000)\end{array}$ & & & & $\begin{array}{r}0.000 \\
(0.000)\end{array}$ & * \\
\hline Employment & & & $\begin{array}{r}-0.021 \\
(0.057)\end{array}$ & & & & $\begin{array}{r}-0.04 \\
(0.066)\end{array}$ & \\
\hline Debt & & & $\begin{array}{r}0.011 \\
(0.005)\end{array}$ & * & & & $\begin{array}{r}0.010 \\
(0.006)\end{array}$ & * \\
\hline Farmland & & & $\begin{array}{r}-0.004 \\
(0.013)\end{array}$ & & & & $\begin{array}{r}-0.002 \\
(0.014)\end{array}$ & \\
\hline Education & $\begin{array}{r}0.004 \\
(0.025)\end{array}$ & & $\begin{array}{r}-0.002 \\
(0.024)\end{array}$ & & $\begin{array}{r}0.007 \\
(0.022)\end{array}$ & & $\begin{array}{r}-0.002 \\
(0.025)\end{array}$ & \\
\hline Age & $\begin{array}{r}0.019 \\
(0.015)\end{array}$ & & $\begin{array}{r}0.015 \\
(0.016)\end{array}$ & & $\begin{array}{r}0.029 \\
(0.016)\end{array}$ & * & $\begin{array}{r}0.017 \\
(0.018)\end{array}$ & \\
\hline Constant & $\begin{array}{r}-1.929 \\
(0.580)\end{array}$ & $* * *$ & $\begin{array}{r}-1.790 \\
(0.747)\end{array}$ & $* *$ & $\begin{array}{r}-2.255 \\
(0.559)\end{array}$ & $* * *$ & $\begin{array}{l}-2.218 \\
(0.830)\end{array}$ & $* * *$ \\
\hline $\begin{array}{l}\text { Random } \\
\text { effect }\end{array}$ & & & & & $\begin{array}{r}-0.484 \\
(0.507)\end{array}$ & & $\begin{array}{l}-0.429 \\
(0.572)\end{array}$ & \\
\hline $\begin{array}{l}\text { Observations } \\
\text { Strata }\end{array}$ & 443 & & 443 & & $\begin{array}{r}500 \\
70\end{array}$ & & $\begin{array}{r}443 \\
70\end{array}$ & \\
\hline
\end{tabular}

Note: Robust clustered standard errors in parentheses.

$$
{ }^{* * *} \mathrm{p}<0.01,{ }^{* *} \mathrm{p}<0.05,^{*} \mathrm{p}<0.1
$$

iors are more likely not to participate in or to drop out from an reintegration program, consistent with Hypothesis 1 .

What are the risk factors that are associated with psychological avoidance? Which group of people potentially needs more attention from policy makers? As suggested in the existing literature, those who committed more violence towards other people during the conflict are found to be more likely to display avoidance behaviors. This hypothesis is supported by regression results reported in Table 4.3. Time spent in faction seems to be another relevant factor as the coefficients corresponding to the variable carry the expected sign. But we do not have sufficient evidence for it. Furthermore, the friendship network appears to be the most important 
social relations in predicting avoidance behavior. This finding is intuitive. Conceivably, ex-fighters who are less integrated are more likely to withdraw themselves and find comfort within their private ex-combatant networks. This forms an enclave, which may potentially contribute to recidivism. Also important but less certain is the effect of gaining acceptance from neighbors. However, note that evidence regarding different types of social relations is less decisive as a different pattern is observed in a robustness check model that makes use of dichotomous dependent variable. However, findings based on different models provide similar supportive evidence to Hypothesis 2.

In short, the dropouts come from fairly diverse backgrounds. But in common, they demonstrated a greater interest in fighting in Côte d'Ivoire if a reasonably high monetary incentive was offered (see Appendix I for the results). Furthermore, apart from economic and social factors, the psychological state of an individual also plays a crucial role in the reintegration process. More specifically, symptoms of avoidance are associated with the dropout behavior. The identified symptoms of avoidance are also consistent with what has been proposed in the psychological literature, that both social rejection and wartime violence can evoke emotional distress and lead to social avoidance that is correlated to poorer reintegration outcome.

\subsection{CONCLUSION}

Reintegration, a process that tries to bring ex-combatants back into society, remains a major policy challenge to practitioners today. The challenges do not only stem from the lack of resources to cover the needs of the vast number of former combatants and their families in the medium term, it also involves the repair of the social fabric torn by past violence. People working in the policy world would have realized that reintegration programs that emphasize only the economic well-being is insufficient to meet the challenges. As a result, most of the DDR programs today contain some psychological components, including trauma counseling, traditional ceremonies, community-based support network, and reconciliation (Maedl et al., 2010). Though the psychological needs of the ex-combatants have been better recognized, and many reintegration programs have been designed to address their needs, this article underscores that many former combatants cannot benefit from the program. 
Table 4.3: Determinants of avoidance

\begin{tabular}{|c|c|c|c|c|c|c|}
\hline & $\begin{array}{l}\text { ORDINAL } \\
\text { LOGIT }\end{array}$ & & LOGIT & & RE & \\
\hline Violent acts & $\begin{array}{r}0.276 \\
(0.078)\end{array}$ & $* * *$ & $\begin{array}{r}0.255 \\
(0.093)\end{array}$ & $* * *$ & $\begin{array}{r}0.270 \\
(0.093)\end{array}$ & $* * *$ \\
\hline Time in faction & $\begin{array}{r}0.001 \\
(0.002)\end{array}$ & & $\begin{array}{r}0.000 \\
(0.002)\end{array}$ & & $\begin{array}{r}-0.000 \\
(0.002)\end{array}$ & \\
\hline Safety & $\begin{array}{r}0.009 \\
(0.248)\end{array}$ & & $\begin{array}{r}-0.123 \\
(0.305)\end{array}$ & & $\begin{array}{r}-0.132 \\
(0.295)\end{array}$ & \\
\hline Family & $\begin{array}{r}-0.078 \\
(0.177)\end{array}$ & & $\begin{array}{r}-0.247 \\
(0.144)\end{array}$ & * & $\begin{array}{r}-0.293 \\
(0.155)\end{array}$ & * \\
\hline Neighbors & $\begin{array}{r}0.183 \\
(0.194)\end{array}$ & & $\begin{array}{r}0.331 \\
(0.162)\end{array}$ & $* *$ & $\begin{array}{r}0.354 \\
(0.176)\end{array}$ & ** \\
\hline Friends & $\begin{array}{r}0.141 \\
(0.065)\end{array}$ & $* *$ & $\begin{array}{r}0.109 \\
(0.071)\end{array}$ & & $\begin{array}{r}0.103 \\
(0.069)\end{array}$ & \\
\hline Education & $\begin{array}{r}-0.035 \\
(0.022)\end{array}$ & & $\begin{array}{r}-0.048 \\
(0.022)\end{array}$ & $* *$ & $\begin{array}{r}-0.044 \\
(0.023)\end{array}$ & * \\
\hline Age & $\begin{array}{r}0.003 \\
(0.007)\end{array}$ & & $\begin{array}{r}0.000 \\
(0.009)\end{array}$ & & $\begin{array}{c}0.002 \\
(0.010)\end{array}$ & \\
\hline Constant & & & $\begin{array}{r}0.728 \\
(0.471)\end{array}$ & & $\begin{array}{r}0.687 \\
(0.467)\end{array}$ & \\
\hline Cutoff 1 & $\begin{array}{r}-0.348 \\
(0.421)\end{array}$ & & & & & \\
\hline Cutoff 2 & $\begin{array}{r}0.658 \\
(0.407)\end{array}$ & & & & & \\
\hline Cutoff 3 & $\begin{array}{r}1.551 \\
(0.429)\end{array}$ & $* * *$ & & & & \\
\hline Cutoff 4 & $\begin{array}{r}2.862 \\
(0.495) \\
\end{array}$ & $* * *$ & & & & \\
\hline $\begin{array}{l}\text { Observations } \\
\text { Strata }\end{array}$ & 977 & & 977 & & $\begin{array}{r}977 \\
70\end{array}$ & \\
\hline
\end{tabular}

Note: Robust clustered standard errors in parentheses.

$$
\text { *** } \mathrm{p}<0.01,{ }^{* *} \mathrm{p}<0.05,{ }^{*} \mathrm{p}<0.1 \text {. }
$$

One may be tempted to conclude that there should be more (psychiatric) interventions directed towards the silent ex-fighters. Yet, at this stage, it is still premature to conclude that more intervention is always better. We still lack a good rehabilitation policy solution at this point because there is no consensus over what actions are appropriate to those showing early symptoms of psychological distress. More research is needed to find out whether further intervention is required to provide assistance to people displaying withdrawal behaviors. As discussed earlier, withdrawal and avoidance can be a part of a healthy recovery process, and there are chances that forced integration may do more harm than good by pushing an individual beyond his or her psychological limit, contributing to 
further mental breakdown. Apart from the highly-contested ethical and legal issues, there is no consensus over the effectiveness of involuntary treatment (Kallert, Glöckner, and Schützwohl, 2008; Seed, Fox, and Berry, 2016).

The psychological health issue is not only relevant to ex-combatants of civil wars but also returnees from conflict regions or potential homegrown extremists. For example, research shows that mental illness is one of the key risk factors associated with lone-terrorism (Corner and Gill, 2015). This research suggests that perhaps a stronger social support can be a good alternative to stronger psychiatric attention because this avoids adding a stigmatized label to the people at risk of radicalization. A stronger social network can also prevent isolation, build social resilience and reduce the risks of influenced by radicals to become extremists (Bhui, 2015). Nevertheless, many questions remain unresolved in this area and more studies should be put in place to target non-participants and dropouts, a rather invisible group of people, to safeguard a better reintegration outcome. 


\subsection{APPENDIX I}

One claim in this study is that the dropouts may pose a security threat to the nearby regions. The analysis in this appendix substantiates the claim. Given that the claim is tangential to the participation decision of ex-combatants, the focus of the chapter, I include the analysis only in the appendix. The dependent variable, Mercenary, is a binary variable and is coded as equal to one if the respondent indicated that he would 'take part in the confusion in Côte d'Ivoire' for a stated amount (US\$250/500/1000). It is based on the questions, if you were given 500 USD to take part in the confusion in Côte d'Ivoire, would you go? What if you were given 1,000 USD to take part in the confusion? What if you were given 250 USD to take part in the confusion? The key independent variable, Dropout, is a dummy variable which denotes whether or not the respondent either declined the offers, or accepted the offers but did not show up for training (treatment day $=0$ ), or failed to complete the program. They are similar in the sense that whether one chooses to quit the program earlier or later, with or without informing the organizer in advance.

People who had more sympathy for the people in Côte d'Ivoire may be more willing to fight. The dummy variable, Sympathy, is equal to 1 if the respondent answered yes to the question, 'Is there any tribe in Côte d'Ivoire that you feel sorry for?' People who went through some parts of the DDR program may be less likely to become mercenaries. The binary variable DDR indicates whether the respondent participated in either 1996/97 or 2004/o5 DDRR programs before. Furthermore, people who kept contacts with other ex-combatants or ex-commanders may be more likely to go back to the battlefield (de Vries and Wiegink, 2011). To control for the network effect, I also include in my analysis another variable, Friends. The economic situation of a respondent may also affect the propensity of a respondent to engage in mercenary work. For this reason, I include the variables Earnings (net cash earnings in the past four weeks) and Hours (number of hours worked in the past four weeks) to capture the effects of opportunity costs and unemployment (Berman et al., 2011; Collier and Hoeffler, 1998). However, some people may farm instead of being employed. For this reason, I included the variable, Farmland (amount of land owned by the family of the respondent), as well.

The results of the logit analysis are contained in Table 4.4. The estimated coefficient of the Dropout variable is sizable and statistically significant. Based on the estimate obtained from Model (1), the odds for the 
dropout to engage in mercenary work are 191 per cent higher than those remained in the program. The odds are even higher (i.e. 256 per cent) after controlling for other factors. Yet, we do not have solid evidence for the effects of other covariates. Though employment (Hours) have an expected negative effect on the risks of joining a mercenary group, the effect is not statistically significant at the 5 per cent level. The same also holds for the embeddedness of a person in ex-combatant friendship networks. Results based on a random-effect model also reveal a similar pattern. 
Table 4.4: Propensity to engage in mercenary activities of the dropouts

\begin{tabular}{|c|c|c|c|c|c|c|c|c|}
\hline & LOGIT & & LOGIT & & RE & & $\mathrm{RE}$ & \\
\hline Dropout & $\begin{array}{r}1.007 \\
(0.378)\end{array}$ & $* * *$ & $\begin{array}{r}1.264 \\
(0.395)\end{array}$ & $* * *$ & $\begin{array}{r}0.929 \\
(0.339)\end{array}$ & $* * *$ & $\begin{array}{r}1.264 \\
(0.398)\end{array}$ & $* * *$ \\
\hline Education & & & $\begin{array}{l}-0.040 \\
(0.058)\end{array}$ & & & & $\begin{array}{l}-0.037 \\
(0.055)\end{array}$ & \\
\hline Age & & & $\begin{array}{l}-0.050 \\
(0.041)\end{array}$ & & & & $\begin{array}{l}-0.050 \\
(0.040)\end{array}$ & \\
\hline Earnings & & & $\begin{array}{r}0.002 \\
(0.002)\end{array}$ & & & & $\begin{array}{r}0.002 \\
(0.002)\end{array}$ & \\
\hline Hours & & & $\begin{array}{r}-0.005 \\
(0.004)\end{array}$ & & & & $\begin{array}{r}-0.005 \\
(0.004)\end{array}$ & \\
\hline Farmland & & & $\begin{array}{r}-0.051 \\
(0.023)\end{array}$ & $* *$ & & & $\begin{array}{r}-0.052 \\
(0.024)\end{array}$ & $* *$ \\
\hline DDR & & & $\begin{array}{r}-0.355 \\
(0.563)\end{array}$ & & & & $\begin{array}{r}-0.337 \\
(0.547)\end{array}$ & \\
\hline Sympathy & & & $\begin{array}{r}0.372 \\
(0.387)\end{array}$ & & & & $\begin{array}{r}0.389 \\
(0.381)\end{array}$ & \\
\hline Friends & & & $\begin{array}{r}0.251 \\
(0.232)\end{array}$ & & & & $\begin{array}{r}0.254 \\
(0.234)\end{array}$ & \\
\hline Constant & $\begin{array}{r}-3.258 \\
(0.280)\end{array}$ & $* * *$ & $\begin{array}{r}-1.866 \\
(0.964)\end{array}$ & * & $\begin{array}{r}-3.446 \\
(0.390)\end{array}$ & $* * *$ & $\begin{array}{l}-1.942 \\
(1.120)\end{array}$ & $*$ \\
\hline Random Effect & & & & & $\begin{array}{r}-1.795 \\
(2.777)\end{array}$ & & $\begin{array}{r}-2.098 \\
(2.860)\end{array}$ & \\
\hline $\begin{array}{l}\text { Observations } \\
\text { Strata }\end{array}$ & 450 & & 433 & & $\begin{array}{r}558 \\
70\end{array}$ & & $\begin{array}{r}433 \\
70\end{array}$ & \\
\hline
\end{tabular}

Note: Robust clustered standard errors in parentheses.

*** $\mathrm{p}<0.01,{ }^{* *} \mathrm{p}<0.05,{ }^{*} \mathrm{p}<0.1$. 


\subsection{APPENDIX II}

Table 4.5: Summary statistics

\begin{tabular}{|c|c|c|c|c|c|}
\hline VARIABLE & $\mathbf{N}$ & MEAN & SD & MIN & MAX \\
\hline Hours & 842 & 50.36 & 40.10 & $\mathrm{o}$ & 304.5 \\
\hline Earnings & 841 & 68.81 & 95.02 & o & $714 \cdot 3$ \\
\hline Age & 916 & 30.23 & $7 \cdot 595$ & 18 & 57 \\
\hline Education & 916 & 5.865 & 3.770 & o & 14 \\
\hline Community & 842 & 0.059 & 0.969 & -2.623 & 2.653 \\
\hline Employment & 916 & 6.004 & 1.886 & $\mathrm{o}$ & 7 \\
\hline Debt & 916 & 7.985 & 26.17 & o & $429 \cdot 3$ \\
\hline Farmland & 916 & 9.218 & 9.905 & o & 50 \\
\hline Income & 916 & 3,782 & 9,279 & o & 200,000 \\
\hline Avoidance & 915 & 1.339 & 1.275 & o & 4 \\
\hline Violent acts & 902 & 0.612 & 0.990 & o & 3 \\
\hline Time in faction & 916 & 31.46 & 31.35 & o & 192 \\
\hline Family & 916 & 0.212 & 0.725 & o & 3 \\
\hline Neighbors & 916 & 0.155 & 0.617 & o & 3 \\
\hline Dropout & 916 & 0.121 & 0.323 & $\mathrm{O}$ & 1 \\
\hline Treat & 916 & 0.358 & 0.480 & o & 1 \\
\hline Non-assigned & 916 & 0.521 & 0.500 & o & 1 \\
\hline DDR & 916 & 0.274 & 0.446 & $\mathrm{o}$ & 1 \\
\hline Mercenary & 842 & 0.064 & 0.245 & o & $\begin{array}{llllllll} & & & & & \end{array}$ \\
\hline Sympathy & 822 & 0.423 & 0.494 & o & 1 \\
\hline Safety & 914 & 0.952 & 0.214 & o & 1 \\
\hline Friends & 907 & 1.961 & 1.051 & o & 4 \\
\hline
\end{tabular}



As a fundamental concept in peace research, trust, or the lack of it, has shown to be associated with the onset of violent conflict, the instability of negotiated settlement, and the sustainability of peace. Despite its proven importance, the question of how political trust can be built after civil conflicts has only received limited attention and remains unanswered. While previous studies demonstrated that improved provision of public services plays a significant role in a trust-building process, the present article shows a more nuanced picture, namely that service enhancement only works if it reflects the needs of people. Projects that do not properly mirror the needs of people, however, have no direct effect on building political trust. Using micro-level data from Sierra Leone, I found that people are more likely to trust governments that are willing to listen and respond to their needs and demands. Though government performance carries the previously hypothesized effect, its explanatory power reduces substantively once responsiveness is introduced into the analysis. This finding also holds when potential biases due to endogeneity and sample selection are considered. Results from a mediation analysis also indicate that if government performance has any effect, it is transmitted through the responsiveness mechanism. Overall, this article contributes to the literature by clarifying the mechanism of trust-building in post-conflict societies.

This chapter is reprinted from Wong, Pui-Hang. 2016. How can political trust be built after civil wars? Evidence from post-conflict Sierra Leone, Journal of Peace Research, Vol. 53, No. 6, pp. 772-785 under the Creative Commons Attribution-Non-Commercial 3.o License (CC-BY-NC). 
Many scholars have argued that in developed countries government performance is one of the major determinants of trust in government (Hetherington, 1998; Levi, Sacks, and Tyler, 2009; Rothstein, 2009). They reasoned that satisfactory performance renders government legitimacy, which in turn enhances government's trustworthiness. This relationship, however, may not hold in post-conflict states for two reasons. Firstly, for these countries high levels of political legitimacy, stability, and state capacity are usually out of their reach. Secondly, due to the war experiences, critical security situation, and economic hardship, people living in postconflict countries are likely to have different preferences and priorities than those living in stable democracies. For these reasons, it remains to be seen to what extent the relationship between government performance and trust in the government can be generalized to post-conflict societies.

Existing studies in post-conflict states commonly found that exposure to violence is a strong determinant of social trust (e.g. Cassar, Grosjean, and Whitt (2013), Cuesta and Alda (2012), Luca and Verpoorten (2015), and Rohner, Thoenig, and Zilibotti (2013), yet there is only a handful of studies devoted to the topic of trust in government. These studies found that satisfaction with government services is a strong predictor of trust in government (Askvik, Jamil, and Dhakal, 2011; Hutchison and Johnson, 2011; Sacks and Larizza, 2012; Stoyan et al., 2016), a finding consistent with studies in developed countries.

This article shows that demonstration of concern by governments is an important but overlooked factor that mediates the relationship between government performance and political trust. Trust development is an evolutionary process that involves constant evaluation and learning about the behaviors of the trustees. For this reason, responding to the needs and demands of local people is a necessary move to generate positive experiences that support attitude change. As trust is also an affective attitude (Jones, 1996) and positive emotions enhance trust (Kenworthy et al., 2016; Pettigrew, 1998), demonstration of concern plays a decisive role in a trust-building process as well. This mechanism is particularly relevant in post-conflict states, as trust building is a path-dependent process. People living in stable democracies usually already hold a certain, relatively stable belief towards government institutions. In contrast, people living in post-conflict societies might be more willing to revise their beliefs to- 
wards the new government. ${ }^{1}$ This makes civil-government interaction a decisive factor moderating political trust in a post-conflict society.

Some authors have argued that preventing politicians from exploiting a trust relationship is a key to successful trust-building (e.g. James (2002)). To achieve this, politicians bind their hands and devolve power to people by building up more inclusive institutions that allow citizens to participate in the policy making process. This article also tests this hypothesis. Yet, I found only weak support for the argument. If institutions have any positive effect on trust, the effect is mediated by government responsiveness. In other words, the power of inclusive institutions hinges on their role as a platform to gather voices to show responsiveness rather than as a way to guard against potential exploitation. Activating the latter mechanism requires at least a moderate sense of empowerment which citizens in a new democracy may not be aware of and may not have the capability to actualize.

Extant studies do no more than show the presence of a relationship between the level of political trust and various indicators of public services or government performance (e.g. Sacks and Larizza (2012). Whether or not this relationship works through the channels they describe remains unclear and unproven. This form of causal ambiguity poses challenges for political scientists because the exact mechanism through which the variable exerts its effect remains unknown. For this reason, there is an increasing demand in the field of political science for research focusing more on the causal mechanism (e.g. Bennett and Checkel (2014), Gerring (2008), and Imai et al. (2011). In light of this development, the second part of my analysis tries to unpack the mechanism of trust building. To do so, I performed a mediation analysis investigating the mediated effects of the factor, demonstration of concern. My result shows that both government performance and institution have no direct effect on trust building once government responsiveness is introduced as a mediating factor. All in all, these findings imply that in post-conflict states, political trust is less likely to be built based on exchange or protection. In contrast, it is more likely to be determined by the level of care that a government demonstrates towards its citizens, the degree to which a government engages its people in the policy making process, and how responsive a government is to the demands of its citizens.

1 For example, Mishler and Rose, 2001 explored the effect of regime change on political trust. 
This article contributes to the literature in two ways. First, I found that the role of public services in trust building has probably been misunderstood. While this is not to say that government performance is unimportant, my findings hint that the causal mechanism in post-conflict states can be quite different and need to be analyzed more. Second, most of the previous research has only relied on basic estimation methods such as OLS and multilevel analysis, which are incapable of addressing the empirical challenges of endogeneity and selection bias (e.g. see Askvik, Jamil, and Dhakal (2011), Juan and Pierskalla (2016), Hutchison and Johnson (2011), Sacks and Larizza (2012), and Stoyan et al. (2016). This article engages these challenges by applying the instrumental variable method and Heckman's selection model to deal with the potential endogeneity bias and the data attrition problem commonly encountered in studies using survey data.

In the following section, I will explain why the issue of political trust is crucial in a post-conflict environment and elaborates on different trustbuilding mechanisms.

\subsection{BUILDING POLITICAL TRUST AFTER CIVIL WAR}

Trust is a fundamental concept in the field of peace research. It is referred to as the foundation of social cooperation and positive peace (Galtung, 1969, p. 190). The concept is also embedded in the classical theories of war and conflict resolution. For example, in the negotiated settlement literature, based on the model of the security dilemma, Walter (1997) showed that the possibility of opponents eventually exploiting trust forms a critical barrier to civil war settlement. Similarly, based on the bargaining model of war, Walter (1999) also theorized that because establishing trustworthiness and credibility is the key to solving the commitment problem, trust can be regarded as a precondition of peace. Furthermore, trust in government also determines the success of a peace-building process. Recently, Juan and Pierskalla (2016) argued that a low level of political trust can undermine the implementation of peace agreements and reduce citizens' compliance with law, which in turn increases the risk of conflict recurrence. The issue of political trust is crucial for financial reasons as well. Levi and Stoker (2000) pointed out that low trust in government can decrease tax compliance and hinder the progress of reconstruction. If a new government is unable to secure a stable stream of income to restore 
public services, people are more likely to withdraw their support for the government and restart a new phase of violence. For example, based on the case of post-apartheid South Africa, Fjeldstad (2004) showed that tax compliance mirrors people's perception of the trustworthiness of their government. In short, because the capacity of a state to raise revenues determines security, development, and political stability of a country in the long run (Besley and Persson, 2010), any agenda of post-conflict statebuilding should give priority to the issue of political trust.

The importance of the issue begs the question of how political trust can be built after widespread political violence which has often destroyed the social fabric of a society. Multiple theories have been proposed. In the following, I will discuss three channels that highlight different aspects of a trust-building process.

\subsubsection{Exchange}

According to the social exchange theory (Blau, 1964), trust building can be seen as a social exchange process, in which one side of the relation provides benefits to the other and to invoke reciprocation. A key difference between economic exchanges and social exchanges is that the latter may involve benefits without intrinsic economic values (Whitener et al., 1998).

This view is consistent with a popular empirical finding in the political science literature: the level of political trust is associated with the performance of a government (e.g. Hetherington (1998) and Levi, Sacks, and Tyler (2009)). Following Hetherington (1998), these studies define political trust as an evaluative orientation and consider satisfaction with government services a factor contributing to legitimacy. When a government dutifully performs its functions, it is considered as legitimate. Therefore, it is argued, improvements in public services should induce citizens' confidence in government (Hutchison and Johnson, 2011). Further to the argument, Sacks and Larizza (2012) highlighted the behavioral mechanism that underlies this exchange relationship. Focusing on public service quality, they posited that citizens tend to 'reward relative improvements or sanction deteriorations in services' (Sacks and Larizza, 2012 , p. 5). In other words, a trust relationship is developed gradually when a government provides quality services to its citizens and gains legitimacy for governance. When it fails to meet its citizens' expectations, they withdraw their trust and view the government as untrustworthy. 
Hypothesis 1: People will be more likely to develop trust in government if they have benefited from improved public services or development projects.

\subsubsection{Institutional protection}

Trust also involves the risks of incurring losses because it can potentially be exploited (Hardin, 1996; Hoffman, 2002; James, 2002). Thus, trust depends on the trustworthiness of a trustee (Hardin, 1996; James, 2002; Lewis and Weigert, 1985). Therefore, trust building and establishing trustworthiness are two sides of the same coin. This reasoning suggests that if a government wants to enhance its citizens' trust in it, it needs to establish trustworthiness.

Social scientists often use the game of the prisoner's dilemma to model trust, which is usually defined as the cooperative equilibrium of the game (e.g. Deutsch (1960), James (2002), and McGillivray and Smith (2000)). Whereas a history of dishonesty triggers noncooperation and punishment, a history of trustworthiness reinforces the credibility of the trustees. And it is this virtuous cycle that supports the strategy of trust and making trust self-enforcing in the long run.

Although cooperation is a more desirable outcome in the prisoner's dilemma game, it is unsustainable in the short run. This implies that though gains from exchange exist, cooperation is never guaranteed. In this case, an institutional device is required to render the strategy of 'no exploitation' self-enforcing and the equilibrium of cooperation sustainable (James, 2002; McGillivray and Smith, 2000). One good example of such an institutional device is an inclusive decision-making institution that is able to protect people's interests. By being given a chance to influence and to deliberate in the policy process, the public feels that their interests are more likely to be taken into account. If citizens have an opportunity to fight against proposals that might harm their interests, they are more likely to trust their government on the whole as they have a means to oversee development issues and limit government predation.

Hypothesis 2: Having a consensus-based decision-making institution is more likely to induce citizens' trust. 


\subsubsection{Engagement}

The above approaches emphasize that trust is based on interests. But as Jones (1996) argued, trust is also an affective attitude. Social psychologists have long argued that constant contact can reduce anxiety and prejudices (Pettigrew and Tropp, 2006). Consequently, having citizens engaged in the policy making process not only enhances knowledge about the other party, it also reduces anxiety and increases empathy, thus generating a positive emotion towards the actors (Pettigrew and Tropp, 2008). As Kenworthy et al. (2016) showed, these positive emotions play an important role in a trust-building process. Consequently, governments can build trust by creating positive experience in their contacts with their citizens.

How can these positive experiences be generated? Governments can achieve this by engaging citizens through communications and showing their concerns. Engagement through communication can help people establish mutual expectation and shape preferences (Lynch, 2002). Experiments by Fehr and List (2004) showed that trustworthiness depends on whether or not power is employed. If the threat to punish is available but not used, trustworthiness is highest. On the other hand, if the threat to punish is used, trustworthiness is lowest. In other words, the diplomatic strategy of engagement has the advantage of minimizing the direct application of power and therefore inducing trust. Similarly, different authors have argued that demonstrating concern and sensitivity to the needs of other people leads others to perceive trustworthiness (McAllister, 1995; Ruokonen, 2013; Sacks and Larizza, 2012; Whitener et al., 1998). Accordingly, what a government could do to establish trustworthiness is to listen and respond to people's needs and demands. By doing so, the government initiates a positive feedback loop that supports positive evaluation.

In contrast to the exchange view discussed before, this cognitive process is not contingent upon the realization of benefits (e.g. public services) and can be activated by gestures, such as respect and willingness to communicate. Such small gestures have the power to shape people's perception of an actor and an organization Greenberg (1994). In this way, trust building can be understood as a perception management process instead of an exchange process.

A good example of this trust-building process can be found in Sierra Leone. To improve accountability and policy responsiveness, international donors such as the World Bank and the United Nations Development Pro- 
gramme (UNDP) proposed a decentralization reform to the Sierra Leone central government in 2004. In brief, the reform called for a change of political structure that can shorten the distance between the state and the local people and promote good governance. They reasoned that decentralization can create more space for the local authority and community to interact and provides more access points to politicians so that the authority can respond to the needs of people. The reform in the agriculture sector can serve as an example of the decentralization reform. As a part of the reform, the government introduced the Agricultural Business Unit (ABU) initiative. The objective of the initiative was to devolve more power related to planning and decision-making to the local people, by creating more community-based farmer groups to manage agricultural issues such as labor and land use at the grassroots level (Maconachie, 2008). According to Maconachie (2008), ABU farmers were given greater power to decide on issues that had been out of their control. For instance, because of the reform, they can now decide when to increase the size of land for cultivation, how much harvest to save for investment, and how much they should contribute to the local council. Farmers were also given more power to monitor activities of the local government. In contrast, the role of the central government was reduced to mainly providing training and initial capital such as loans and credit.

The experience of the ABU initiative offers a good example to illustrate the importance of engagement in the trust-building process. Maconachie (2008) found that the initiative did not reach the desired outcomes because there was a lack of meaningful engagement and contacts between farmers and local politicians. For instance, farmers often complained that local councilors were not interested in going to the field to learn about the local conditions. Local staff also felt that they were being excluded from the process as they were never asked to join meetings. This lack of meaningful engagement and communications induced grievances and skepticism towards the purposes of the initiative among farmers (Maconachie, 2008). The distrust even led some of the stakeholders to question whether or not there was a hidden agenda behind the program, ultimately leading to more exclusion. High levels of distrust were reported among all involved, including farmers, local staff, and the central government. And allegations of power abuse, misuse of funds, and corruption were frequently reported. Conceivably, if all parties had been more engaged in communications and more responsive to the needs of other people, a higher level of trust could have been cultivated. 
Hypothesis 3: A local government that is more willing to listen and respond to the needs of people is more likely to be trusted.

\subsection{DATA}

Most of the existing studies rely on data from developed regions (e.g. Levi, Sacks, and Tyler (2009) and Kenworthy et al. (2016)) or relatively peaceful societies (e.g. Hutchison and Johnson (2011). However, traumatized by the experience of violence, people living in a post-conflict environment are likely to have different preferences and concerns than citizens living in stable democracies. For this reason, Sierra Leone, a developing country which experienced civil war, was chosen as a case in this analysis. Data were drawn from the 2007 and 2008 National Public Services (NPS) surveys conducted by the Evaluations Unit of the Institutional Reform and Capacity Building Project (IRCBP) administered by the Government of Sierra Leone and the World Bank. NPS is a nationally representative survey, with households randomly sampled from all 19 local councils of the country. In total 6,424 households participated in the survey.

Given the focus of this article on trust-building mechanisms, I only included respondents that participated in both waves of the survey, to allow for a comparison of responses across time. To ensure data quality, I excluded observations in which the interviewers considered that (1) the overall truthfulness of the responses is low; (2) the respondents had serious problems speaking or understanding them; and (3) the respondents were not willing to answer some of the questions because some people (e.g. government officials) were present during the interviews. In total, 2,422 observations satisfied these three criteria and were included in the analysis. The difference in number can be explained by several additional factors: district change, targeted respondents who were not at home or had moved out of the neighborhood, and missing responses to one or more questions. The missing data problem is common in analyses using survey data. To address this issue, I used the Heckman selection model to check against potential bias in my analysis (see the Method section below).

Given limited space, I will only discuss the dependent variable and the key independent variables below. The details of the control variables, 
including the descriptive statistics, original survey questions, and coding can be found in the appendix.

The coding of the dependent variable, Trust, is based on responses to the following question: 'In your opinion, do you believe local councilors or do you have to be careful dealing with them?' The dependent variable is a binary variable and is equal to 1 when a respondent stated that he or she had not trusted the local councilor in 2007 but did so in 2008. It should be noted that responses were recorded only when a respondent indicated that he or she knew about the local councils. To cope with this data issue, I generated a dummy variable, Aware, to differentiate this type of response. The dichotomization of the variable, however, treats other possibilities (e.g. consistent distrust and steady trust) as the same. I still rely on the logit model because it allows me to take care of other methodological issues (see the Models section below), which required modeling techniques not easily incorporated into a multinomial logit model. This at first may raise concern about the validity of the findings, but as I will show in the robustness check section, this assumption does not affect the findings in any major ways.

To test Hypothesis 1, I include a variable, Benefit, in the analysis. It is a binary variable and is equal to 1 when the respondent indicated that he or she had benefited from development projects that a local councilor had been doing in 2008 but not 2007. The coding is based on the following two questions: 'Do you know of any projects the Local Council is doing or has done?' and 'Have you benefited from any of these projects?' As a robustness check, I also produced a new set of indicators to measure if respondents perceived improvements in five different kinds of public services (education, health care, road, water, and market) as alternative measures of benefit.

To test Hypothesis 2, I include a variable, Consensus, in the analysis. The variable denotes the percentage of respondents in the region who considered that the whole neighborhood had made the decision at a public meeting through consensus or voting. The coding is based on the question: 'When there is a decision to be made in the community/neighborhood on an issue that affects you, such as deciding between building a new school or a road, how does this decision usually get made?'

The independent variable, Listen, indicates whether or not a respondent perceived that the local councilors had been attentive to his or her needs. This dummy variable is coded based on the responses to the question: 'Do you think the Local Council listens to what people in this town 
/neighborhood say or what they need?' The variable is equal to 1 when the respondent stated that he or she did think so in 2008 but not 2007. If active listening has anything to do with trust building, as Hypothesis 3 suggests, people who perceived politicians differently over time should be more likely to change their attitudes towards the politicians. The reverse, however, can also be true. For this reason, I used a simultaneous probit model to account for potential bias.

Other than the dependent and independent variables introduced above, I also included a set of socio-economic variables as controls. Youths, migrants, and women are three underprivileged groups in Sierra Leone (Fanthorpe, 2005; Labonte, 2012). For this reason, the war experience may lead them to have greater difficulties in developing trust towards political authority. The same also holds true for those that were exposed to violence during the war period (Juan and Pierskalla, 2016). Moreover, social capital and community relations are found to be correlated with political trust as they tend to reinforce citizens' experiences with their governments (Nannestad, 2008; Putnam, 1993; Rothstein, 2000). To control for the effects of social capital and community relations, I also include the variables Member (the number of social groups that the household joined) and Community (perception of how easy it is for people in the community to work together) into my analysis.

\subsection{MODELS}

In addition to the logit model, I also utilized a multilevel logistic regression, a probit model with sample selection, and a simultaneous probit model to accommodate various empirical issues in my analysis. I will explain each of them below.

The multilevel logistic regression model was used due to the hierarchical structure of the data. As individuals are influenced by similar contextual factors, observations in the same unit are not completely independent. If the dependence is strong, the usual logit model will give smaller standard errors and misleading results (Steenbergen and Jones, 2002). The multilevel model becomes a better choice because it is able to correct for the dependence. Essentially, I estimated the following two-level model:

$$
\ln \left(\frac{\pi_{i j}}{1-\pi_{i j}}\right)=\gamma_{0 j}+\beta x_{i j}+\epsilon_{i j}
$$




$$
\gamma_{0 j}=\beta_{0}+u_{j}
$$

The model is similar to the usual logit model, with the difference that the constant term now contains a random component $u_{j}$, which may vary across cluster $j$ in which individual i resided. The random component has mean o and its variance will be estimated explicitly. ${ }^{2}$

The regular logit model may incur a selection bias since only respondents that were repeatedly interviewed would enter my analysis. As people who trusted the local government less might have a higher likelihood of migrating and might therefore not be interviewed for the second time, this will inflate the size of the estimates obtained from models that do not take this selection effect into consideration. I used the probit model (with sample selection) proposed by van de Ven and Van Praag (1981) to tackle this problem. The model regresses attitude change and migration decision at the same time and assumes that the error terms in the equations are correlated. Consequently, joint estimation enables me to correct for the bias associated with the selection effect. The additional variables that I used to model migration decisions include a set of socio-economic variables found to be associated with the decision to migrate: education level, age, economic well-being, and whether or not the person has a history of migration (e.g. see Strauss and Thomas (1995)).

The single equation model discussed thus far may suffer from simultaneity bias if trust attitude reversely affects perception on responsiveness. To account for the potential bias, I applied the two-step estimator by Rivers and Vuong (1988) to estimate the simultaneous probit equations. The instruments that I used in the first stage are two variables: Listen $_{j}$ (the proportion of respondents in cluster $j$ that considered local councilors responsive) and Visit (whether or not a local politician had visited the community between the two sampling periods). The use of the community-average as an instrument is based on the idea that social capital usually affects an individual's perception through socialization (Putnam, 1993). This community-level variable is exogenous to individuals because a random person is usually not powerful enough to influence the perception of the leaders at the community level (Cuesta and Alda,

2 Readers who are interested in the details are referred to Steenbergen and Jones (2002) for further discussion. 
2012). I also included the variable Visit as a part of my over-identification strategy. The variable may correlate with trust attitude because it affects the variable Trust through the endogenous variable. For this reason, the variable can still be qualified as an instrument (Cameron and Trivedi, 2005). However, one should note that given the non-experimental nature of the study, this modeling exercise should be read as an attempt to provide identification. The finding based on this model is better treated as a robustness check than as conclusive evidence.

\subsection{EMPIRICAL FINDINGS}

Estimation results are summarized in Table 5.1. Results based on Models 1,2 , and 3 demonstrate that people who perceive that a politician is more attentive to their needs and demands are more likely to change their attitudes from mistrusting to trusting, consistent with Hypothesis 3. In other words, being responsive has a strong and significant effect on trust building. As Figure 5.I shows, respondents that had less than two items in their households (i.e. over 75 per cent of all households) are about 20 per cent (in probability) more likely to start trusting their local councilors if they think that the councilors listen to their needs. When compared with Model 3, the model with the multilevel specification (Model 4) gives similar results.

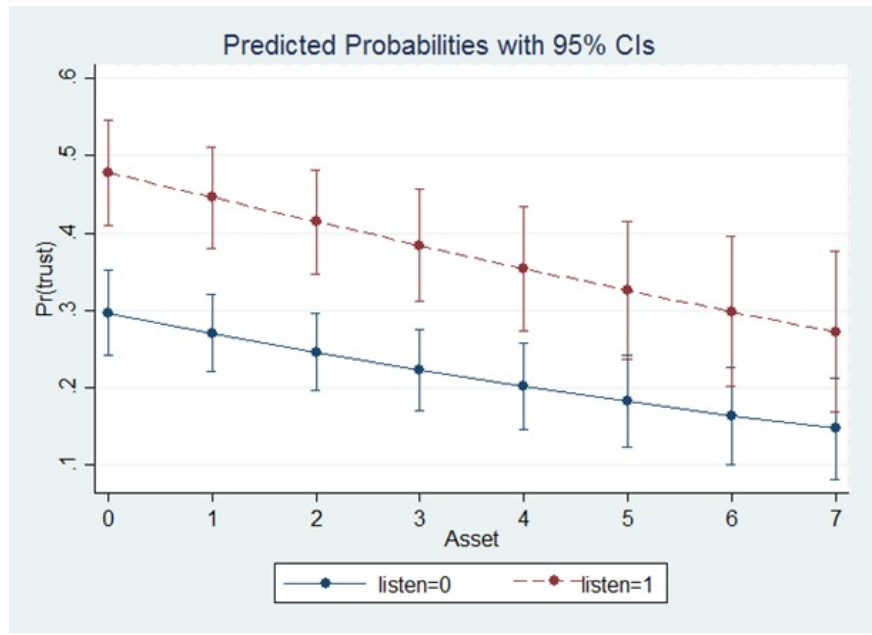

Figure 5.1: Marginal effect of the variable listen 
Table 5.1: Determinants of change in trust attitude

\begin{tabular}{|c|c|c|c|c|c|c|c|c|}
\hline & LOGIT & & LOGIT & & LOGIT & & $\begin{array}{l}\text { M.LV } \\
\text { LOGIT }\end{array}$ & \\
\hline Listen & $\begin{array}{r}0.775 \\
(0.108)\end{array}$ & $* * *$ & & & $\begin{array}{r}0.775 \\
(0.124)\end{array}$ & $* * *$ & $\begin{array}{r}0.794 \\
(0.132)\end{array}$ & $* * *$ \\
\hline Aware (2008) & & & $\begin{array}{r}0.026 \\
(0.180)\end{array}$ & & $\begin{array}{l}-0.374 \\
(0.191)\end{array}$ & & $\begin{array}{r}-0.349 \\
(0.199)\end{array}$ & \\
\hline Aware (2007) & & & $\begin{array}{r}-0.283 \\
(0.120)\end{array}$ & * & $\begin{array}{l}-0.127 \\
(0.125)\end{array}$ & & $\begin{array}{l}-0.135 \\
(0.132)\end{array}$ & \\
\hline Benefit & & & $\begin{array}{r}0.425 \\
(0.183)\end{array}$ & & $\begin{array}{r}0.274 \\
(0.181)\end{array}$ & & $\begin{array}{r}0.256 \\
(0.187)\end{array}$ & \\
\hline Victimization & & & $\begin{array}{r}0.038 \\
(0.061)\end{array}$ & & $\begin{array}{r}0.026 \\
(0.061)\end{array}$ & & $\begin{array}{r}0.030 \\
(0.064)\end{array}$ & \\
\hline Female & & & $\begin{array}{r}-0.058 \\
(0.116)\end{array}$ & & $\begin{array}{r}-0.091 \\
(0.117)\end{array}$ & & $\begin{array}{r}-0.090 \\
(0.123)\end{array}$ & \\
\hline Asset & & & $\begin{array}{l}-0.121 \\
(0.039)\end{array}$ & $* *$ & $\begin{array}{r}-0.128 \\
(0.038)\end{array}$ & $* * *$ & $\begin{array}{l}-0.132 \\
(0.039)\end{array}$ & $* * *$ \\
\hline Community & & & $\begin{array}{r}2.085 \\
(0.201)\end{array}$ & $* * *$ & $\begin{array}{r}2.067 \\
(0.202)\end{array}$ & $* * *$ & $\begin{array}{r}2.145 \\
(0.214)\end{array}$ & $* * *$ \\
\hline Age & & & $\begin{array}{r}-0.000 \\
(0.004)\end{array}$ & & $\begin{array}{r}-0.001 \\
(0.004)\end{array}$ & & $\begin{array}{l}-0.001 \\
(0.004)\end{array}$ & \\
\hline Migrant & & & $\begin{array}{r}-0.072 \\
(0.130)\end{array}$ & & $\begin{array}{r}-0.074 \\
(0.131)\end{array}$ & & $\begin{array}{l}-0.070 \\
(0.138)\end{array}$ & \\
\hline Member & & & $\begin{array}{r}0.094 \\
(0.047)\end{array}$ & * & $\begin{array}{r}0.089 \\
(0.047)\end{array}$ & & $\begin{array}{r}0.088 \\
(0.049)\end{array}$ & \\
\hline Consensus $_{j}$ & & & $\begin{array}{r}-0.623 \\
(0.220)\end{array}$ & $* *$ & $\begin{array}{l}-0.703 \\
(0.220)\end{array}$ & $* *$ & $\begin{array}{l}-0.724 \\
(0.233)\end{array}$ & $* *$ \\
\hline Constant & $\begin{array}{r}-1.080 \\
(0.077)\end{array}$ & $* * *$ & $\begin{array}{l}-1.822 \\
(0.355)\end{array}$ & $* * *$ & $\begin{array}{l}-1.820 \\
(0.356)\end{array}$ & $* * *$ & $\begin{array}{l}-1.925 \\
(0.380)\end{array}$ & $* * *$ \\
\hline $\begin{array}{l}\text { Random compo- } \\
\text { nent }\end{array}$ & & & & & & & $\begin{array}{r}0.254 \\
(0.136)\end{array}$ & \\
\hline $\begin{array}{l}\text { No. of EA } \\
\text { Observations }\end{array}$ & 1,899 & & 1,769 & & 1,769 & & $\begin{array}{r}564 \\
1,769\end{array}$ & \\
\hline
\end{tabular}

Note: Robust clustered standard errors in parentheses.

$$
\text { *** } \mathrm{p}<0.001,{ }^{* *} \mathrm{p}<0.01,{ }^{*} \mathrm{p}<0.05
$$

In contrast, in Model 2, though Benefit is a strong determinant of positive attitude change, its effect is short of statistical significance once the variable Listen is added to the model (Model 3). The substantive effect of project benefits also becomes much smaller. It drops from a 53 per cent increase (Model 2) to a 31 per cent increase (Model 3), both in terms of the odds ratio.

This finding is different from what has been reported in studies that do not control for the effect of responsiveness or engagement. The difference can potentially be explained by the civil war history of the country, 
a background factor which is absent from previous studies (e.g. Hetherington (1998), which propose that improved public services can create political trust by enhancing political legitimacy. While we might expect political legitimacy to be enhanced in this way in relatively peaceful societies, this mechanism is unlikely to work in societies with a recent history of violence as victimization tends to undermine political trust (Juan and Pierskalla, 2016). Another possible explanation for the difference in findings is that while the existing studies model the level of political trust (e.g. Askvik, Jamil, and Dhakal (2011), Hutchison and Johnson (2011), Sacks and Larizza (2012), and Stoyan et al. (2016), I model the change in the level of political trust. The nuances between the two appear to be trivial but are empirically distinct because they are determined by different processes. It should also be noted that the transformation between level and change is often only assumed and not automatic. For example, the well-established negative relationship between income (level) and civil war does not mean that recessions will trigger civil wars spontaneously. As another example, the positive relationship between income and democracy does not imply that economic growth will prompt democratization. Quite the opposite, it is recession, not growth, that usually triggers democratization (Haggard and Kaufman, 1995).

Estimates based on Models 1 to 4 suggest that people living in areas with a consensus-based decision-making system are less likely to change their evaluations of the government positively, contrasting to Hypothesis 2. This pattern appears to be surprising but can potentially be explained by the social capital argument of Putnam (1993), which states that civil experience is a strong determinant of political trust. Studies have shown that people who are better connected with their neighbors tend to trust their governments more (Nannestad, 2008). In Sierra Leone, political patronage is a defining feature of local politics (Jackson, 2007). This political structure often induces favoritism and political fragmentation, making consensus sometimes a disguised form of violence, creating tension in the community rather than reducing it (Ferme, 1998). Because this structural feature can lead to negative civil experience that spoils political trust, it may explain why a consensus-based decision-making system could be related to a negative change in trust attitude.

Estimates from Models 1 to 4 may suffer from the sample selection problem because only respondents that were repeatedly interviewed would enter the analysis. As people who trust the local government less may have higher chances of moving away, dropping these observations is 
likely to inflate the size of the estimates obtained from models that do not take this selection effect into account. I applied the selection model to re-estimate the effect of perceived responsiveness on positive change in trust attitude. The result confirms that there is a selection bias. Nevertheless, the estimate corresponding to the coefficient of the variable Listen remains statistically significant at the o.1 per cent level. The odds ratio obtained from the selection model is equal to a 46 per cent increase, which is still sizable.

Finally, one may argue that the previous models may incur simultaneous bias because people that trust the government more may be more likely to view the local government as responsive. I utilized the simultaneous probit model to account for potential simultaneity. The results are reported in the last two columns of Table 5.3. As the reliability of the results hinges on the strength of the instruments, it is necessary to check the bias due to the weak instrument problem. Various statistical tests suggest that the instruments are strong enough. The F-statistic from the first stage estimation is equal to 67.48 , which is larger than the threshold of ten, meaning that the instruments are sufficiently strong to ensure that the estimates are not biased (Staiger and Stock, 1997). Statistical tests that are robust to weak instrument (Finlay and Magnusson, 2009) also indicate that the estimated coefficient of the variable Listen is positive and statistically significant $(\mathrm{p}<\mathrm{0.01})$. As another check, by adopting the linear probability model, I re-estimated the model using two-stage least-square and performed some additional tests. The F-statistic, again, passes the weakinstrument test. I also performed the Sargan test of over-identification. The null hypothesis of having valid instruments cannot be rejected at the 5 per cent significance level. A similar result was also obtained from the Wooldridge's score test. Again, the model yields comparable results and the estimate corresponding to the Listen variable remains statistically significant.

All in all, findings based on different models provide strong support for Hypothesis 3, which states that government responsiveness is a strong determinant of trust building. On the other hand, I only found weak supportive evidence for Hypothesis $\mathrm{I}$ and no supportive evidence for $\mathrm{Hy}$ pothesis 2 as the estimated coefficient corresponding to the variable Benefit is statistically insignificant and the coefficient corresponding to the variable Consensus has an opposite sign.

Instead of using an all-encompassing term to measure the effect of project benefits, I also created a set of indicators to measure the improve- 
Table 5.2: Robustness checks

\begin{tabular}{|c|c|c|c|c|c|c|c|c|}
\hline & TRUST & & STAY & & TRUST & & $\begin{array}{l}\text { LISTEN } \\
\text { LOGIT }\end{array}$ & \\
\hline Listen & $\begin{array}{r}0.381 \\
(0.085)\end{array}$ & $* * *$ & & & $\begin{array}{r}0.692 \\
(0.161)\end{array}$ & $* * *$ & & \\
\hline Aware (2008) & $\begin{array}{r}-0.127 \\
(0.106)\end{array}$ & & & & $\begin{array}{r}-0.371 \\
(0.141)\end{array}$ & $* *$ & $\begin{array}{r}0.339 \\
(0.035)\end{array}$ & $* * *$ \\
\hline Aware (2007) & $\begin{array}{r}-0.060 \\
(0.067)\end{array}$ & & & & $\begin{array}{r}-0.022 \\
(0.088)\end{array}$ & & $\begin{array}{r}-0.160 \\
(0.024)\end{array}$ & $* * *$ \\
\hline Benefit & $\begin{array}{r}0.086 \\
(0.093)\end{array}$ & & & & $\begin{array}{r}0.140 \\
(0.115)\end{array}$ & & $\begin{array}{r}0.134 \\
(0.032)\end{array}$ & $* * *$ \\
\hline Victimization & $\begin{array}{r}0.024 \\
(0.031)\end{array}$ & & & & $\begin{array}{r}0.017 \\
(0.041)\end{array}$ & & $\begin{array}{r}0.002 \\
(0.012)\end{array}$ & \\
\hline Female & $\begin{array}{r}-0.035 \\
(0.057)\end{array}$ & & & & $\begin{array}{r}-0.066 \\
(0.073)\end{array}$ & & $\begin{array}{r}0.015 \\
(0.021)\end{array}$ & \\
\hline Asset & $\begin{array}{r}-0.038 \\
(0.028)\end{array}$ & & $\begin{array}{r}-0.043 \\
(0.020)\end{array}$ & * & $\begin{array}{r}-0.089 \\
(0.024)\end{array}$ & $* * *$ & $\begin{array}{r}-0.001 \\
(0.006)\end{array}$ & \\
\hline Community & $\begin{array}{r}0.911 \\
(0.214)\end{array}$ & $* * *$ & & & $\begin{array}{r}1.144 \\
(0.101)\end{array}$ & $* * *$ & $\begin{array}{r}0.032 \\
(0.024)\end{array}$ & \\
\hline Age & $\begin{array}{r}-0.003 \\
(0.002)\end{array}$ & & $\begin{array}{r}0.009 \\
(0.002)\end{array}$ & $* * *$ & $\begin{array}{r}-0.001 \\
(0.002)\end{array}$ & & $\begin{array}{r}-0.000 \\
(0.001)\end{array}$ & \\
\hline Migrant & $\begin{array}{r}0.096 \\
(0.091)\end{array}$ & & $\begin{array}{r}-0.383 \\
(0.072)\end{array}$ & $* * *$ & $\begin{array}{r}-0.033 \\
(0.082)\end{array}$ & & $\begin{array}{r}-0.016 \\
(0.024)\end{array}$ & \\
\hline Member & $\begin{array}{r}0.048 \\
(0.024)\end{array}$ & * & & & $\begin{array}{r}0.042 \\
(0.029)\end{array}$ & & $\begin{array}{r}-0.018 \\
(0.009)\end{array}$ & * \\
\hline Consensus $_{j}$ & $\begin{array}{l}-0.387 \\
(0.114)\end{array}$ & $* * *$ & & & $\begin{array}{l}-0.385 \\
(0.133)\end{array}$ & $* *$ & $\begin{array}{r}-0.019 \\
(0.038)\end{array}$ & \\
\hline Education & & & $\begin{array}{r}-0.060 \\
(0.024)\end{array}$ & * & & & & \\
\hline Listen $_{j}$ & & & & & & & $\begin{array}{r}0.916 \\
(0.042)\end{array}$ & $* * *$ \\
\hline Visit $_{j}$ & & & & & & & $\begin{array}{r}0.011 \\
(0.022)\end{array}$ & \\
\hline Constant & $\begin{array}{r}-0.491 \\
(0.268)\end{array}$ & & $\begin{array}{r}0.606 \\
(0.100)\end{array}$ & $* * *$ & $\begin{array}{r}-0.983 \\
(0.201)\end{array}$ & $* * *$ & $\begin{array}{r}-0.149 \\
(0.058) \\
\end{array}$ & * \\
\hline$\stackrel{\rho}{\text { F-stat (1st stage) }}$ & -0.79 & & & & & & $67 \cdot 48$ & \\
\hline Observations & 2,449 & & & & 1,577 & & & \\
\hline
\end{tabular}

Note: Robust clustered standard errors in parentheses.

$$
\text { *** } \mathrm{p}<0.001,{ }^{* *} \mathrm{p}<0.01,{ }^{*} \mathrm{p}<0.05
$$

ments of accessibility of five types of public services: education, water, health care, market, and transportation. 3 These fact-based indicators are not only more objective than the perception-based indicator but also better reflect the extent of improvement. Again, the estimated coefficient of the Listen variable remains statistically significant (Table 5.3). Moreover, results from the model using these alternative measures also suggest that 
improved provision of these public services does not play a (statistically) significant role in explaining positive changes in trust attitude when compared with development projects initiated by local councilors. This difference may be explained by the fact that these development projects are usually locally driven. A stronger sense of local ownership and engagement may make local projects a clearer signal of care and responsiveness.

To employ the selection model and the IV model, in my previous analysis, I mainly relied on the logit model. Given that the dependent variable in the logit model is binary in nature, I had to treat people who did not change their trust attitudes and those who adjusted their trust attitudes downward as the same. This treatment may affect the validity of the previous findings. To investigate whether or not the treatment may bias towards the previous results, I distinguished the differences in responses and re-estimated the model with specification similar to Model 3 . Model 8 essentially compares the people who changed from mistrusting to trusting with those who remained mistrusting (i.e. the baseline). The estimated coefficient of the Listen variable remains highly significant. Making yet another comparison, Model 9 compares the people who changed from trusting to mistrusting with those who remained trusting. Estimation results further reveal that the relationship between attitude change and active listening is symmetric: people would mistrust local politicians who did not listen to their needs.

Sacks and Larizza (2012) found that the quality of government services is a major contributing factor to political trust. Though my results do not provide any empirical support for the effects of public services, the non-finding may be explained by the use of different indicators. As a robustness check of my previous analysis, I used the satisfaction measures suggested by them (i.e. satisfaction with education and health care services). Although none of the satisfaction indicators is found to be statistically significant, the estimated coefficient of the Listen variable remains highly significant. 4

Corruption can be considered as an exploitation of the trust relationship between government and citizens (James, 2002). For this reason, as a

3 Accessibility remains a fundamental problem in Sierra Leone. For example, as in 2007, 76 per cent of households lived in villages or towns with no primary school in the areas. Improved accessibility of services has the power to considerably alter people's view towards the performance of the government.

4 Estimation results for the remaining robustness checks can be found in the appendix. I also used data from Bellows and Miguel (2009) and Glennerster, Miguel, and Rothenberg (2013) to perform some of the checks. 
Table 5.3: Robustness checks

\begin{tabular}{|c|c|c|c|c|c|c|}
\hline & LOGIT & & M. LOGIT & & M. LOGIT & \\
\hline Listen & $\begin{array}{r}0.932 \\
(0.147)\end{array}$ & $* * *$ & $\begin{array}{r}0.700 \\
(0.151)\end{array}$ & $* * *$ & $\begin{array}{c}-0.406 \\
(0.200)\end{array}$ & * \\
\hline Aware (2008) & $\begin{array}{c}-0.477 \\
(0.260)\end{array}$ & & $\begin{array}{r}-0.155 \\
(0.214)\end{array}$ & & $\begin{array}{r}-0.142 \\
(0.363)\end{array}$ & \\
\hline Aware (2007) & $\begin{array}{r}-0.225 \\
(0.155)\end{array}$ & & $\begin{array}{r}0.047 \\
(0.143)\end{array}$ & & $\begin{array}{r}-0.106 \\
(0.226)\end{array}$ & \\
\hline Market & $\begin{array}{r}0.007 \\
(0.005)\end{array}$ & & & & & \\
\hline Road & $\begin{array}{r}0.008 \\
(0.006)\end{array}$ & & & & & \\
\hline Water & $\begin{array}{r}0.004 \\
(0.005)\end{array}$ & & & & & \\
\hline Health & $\begin{array}{r}0.003 \\
(0.010)\end{array}$ & & & & & \\
\hline School & $\begin{array}{r}0.231 \\
(0.218)\end{array}$ & & & & & \\
\hline Benefit & & & $\begin{array}{r}0.459 \\
(0.219)\end{array}$ & * & $\begin{array}{c}-0.203 \\
(0.320)\end{array}$ & \\
\hline Victimization & $\begin{array}{r}0.096 \\
(0.077)\end{array}$ & & $\begin{array}{r}0.103 \\
(0.074)\end{array}$ & & $\begin{array}{r}0.104 \\
(0.110)\end{array}$ & \\
\hline Female & $\begin{array}{r}-0.169 \\
(0.140)\end{array}$ & & $\begin{array}{r}-0.031 \\
(0.132)\end{array}$ & & $\begin{array}{r}0.156 \\
(0.181)\end{array}$ & \\
\hline Asset & $\begin{array}{r}-0.098 \\
(0.047)\end{array}$ & * & $\begin{array}{r}-0.118 \\
(0.045)\end{array}$ & $* *$ & $\begin{array}{r}0.002 \\
(0.056)\end{array}$ & \\
\hline Community & $\begin{array}{r}1.992 \\
(0.240)\end{array}$ & $* * *$ & $\begin{array}{r}2.476 \\
(0.210)\end{array}$ & $* * *$ & $\begin{array}{c}-2.056 \\
(0.281)\end{array}$ & $* * *$ \\
\hline Age & $\begin{array}{r}0.001 \\
(0.005)\end{array}$ & & $\begin{array}{r}0.003 \\
(0.004)\end{array}$ & & $\begin{array}{r}-0.005 \\
(0.007)\end{array}$ & \\
\hline Migrant & $\begin{array}{r}-0.127 \\
(0.154)\end{array}$ & & $\begin{array}{r}-0.270 \\
(0.148)\end{array}$ & & $\begin{array}{r}0.545 \\
(0.238)\end{array}$ & * \\
\hline Member & $\begin{array}{r}0.032 \\
(0.058)\end{array}$ & & $\begin{array}{r}0.144 \\
(0.056)\end{array}$ & $* *$ & $\begin{array}{r}-0.017 \\
(0.078)\end{array}$ & \\
\hline Consensus & $\begin{array}{r}-0.711 \\
(0.278)\end{array}$ & * & $\begin{array}{c}-0.971 \\
(0.254)\end{array}$ & $* * *$ & $\begin{array}{r}0.287 \\
(0.389)\end{array}$ & \\
\hline Constant & $\begin{array}{r}-1.789 \\
(0.449)\end{array}$ & $* * *$ & $\begin{array}{r}-1.847 \\
(0.387) \\
\end{array}$ & $* * *$ & $\begin{array}{r}1.686 \\
(0.579) \\
\end{array}$ & $* * *$ \\
\hline Observations & 1,254 & & 1,769 & & 1,769 & \\
\hline
\end{tabular}

Note: Robust clustered standard errors in parentheses.

${ }^{* * *} \mathrm{p}<0.001,{ }^{* *} \mathrm{p}<0.01,{ }^{*} \mathrm{p}<0.05$.

further check, I used corruption perception as an alternative indicator of trustworthiness. Consistent with the previous findings, the estimate obtained from the new model indicates that responsiveness is an important factor explaining revision in trust attitude.

I also included some further controls that do not enter previous stages of my analysis due to a large amount of missing data or their less imme- 
diate relationship with trust building. Nevertheless, these additions do not refute the previous findings.

Finally, one may think that people from the same ethnic background might be more willing to trust one another. 5 Unfortunately, because information pertaining to the ethnic identity of the local councilors is not available, I am unable to control for the effect directly in the regression analysis. ${ }^{6}$ In spite of that, as I will show below, the data I used in this study suggest that this kind of ethnicity effect is irrelevant in my case.

One implication of this ethnicity hypothesis is that co-ethnics tend to respond similarly. For instance, if respondent $\mathrm{A}$ is more likely to become trusting towards a politician because of their shared ethnic background, respondent $\mathrm{B}$, from the same ethnic group, should also be more likely to do so if the hypothesis is true. The same pattern is expected to hold should respondent A become mistrusting. In short, an implication of the hypothesis is that respondents that share the same ethnic background should behave similarly, regardless of the directions of the changes.

To test whether or not co-ethnics tend to respond similarly, I employed a random sampling technique by selecting the first two individuals showing up in the sample list for all units contained in the surveys (i.e. systematic sampling). Then I used the z-test to check whether or not the pairs that share the same ethnic background are more likely to give similar responses. The null hypothesis is that the proportion of pairs that share the same ethnic identity and give the same trust evaluation is equal to the proportion of pairs that do not. The corresponding p-values of the twotailed tests are 0.84 (2007) and 0.64 (2008), implying that shared ethnic background does not have any statistical power in predicting whether or not a pair would give similar responses. Given the absence of regularity, co-ethnics are not more likely than non-co-ethnics in revising their trust evaluations.

\subsection{EXPLORING THE TRUST-BUILDING MECHANISM}

Results thus far reveal that the Benefit variable has no direct effect on the change in trust evaluation. But it is important to note that one factor can affect trust attitude through multiple mechanisms. For example, a person

5 For example, Habyarimana et al. (2007) showed that co-ethnics in Uganda are more likely to cooperate in their game experiments.

6 Details of the elected candidates (e.g. names, gender) are not available at the Sierra Leone's National Electoral Commission website. 
may interpret the undertaking of a project as demonstration of concern. In this case, whether or not the project will reap appreciable benefits is only a secondary concern. In contrast, the performance account usually implies that trust is conditional on having noticeable improvements. In that case, trust is based on exchange and the concern part may or may not be relevant. The question then becomes to what extent being responsive to the needs of people is the key mediating factor in the whole trustbuilding process. Is appreciable performance necessary for the purpose of signaling concern and responsiveness?

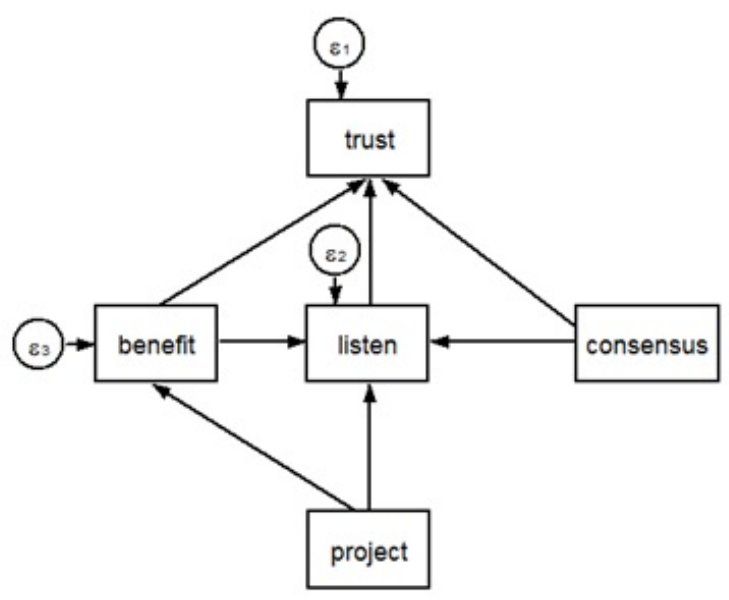

Figure 5.2: The mediation effects of responsiveness of government

To better assess the role of responsiveness in trust building, I estimated the structural equation model specified in Figure 5.2. The model allows the institution variable to influence trust building directly (i.e. the protection explanation) or indirectly via the variable Listen. It also allows development projects to affect trust attitude directly (i.e. performance is necessary) or indirectly, again, via the variable Listen.

The model contains a system of three equations with Trust, Listen, and Benefit as endogenous variables and Consensus and Project as exogenous variables. The Benefit variable is treated as endogenous because it is contingent upon the existence of a project (i.e. project benefits are derived 
from projects). The variable Project is treated as exogenous because the undertaking of a project was not completely controlled by the survey respondents. The Trust, Benefit, and Listen variables capture the subjective feelings of a respondent, while the Consensus and Project variables provide a more objective description of reality. In sum, the system of equations below tries to model the internal evaluation process of an individual. 7

$$
\begin{gathered}
\text { benefit }=\alpha_{0}+\alpha_{1} \text { project }+\epsilon_{1} \\
\text { trust }=\beta_{0}+\beta_{1} \text { listen }+\beta_{2} \text { consensus }+\beta_{3} \text { benefit }+\epsilon_{2} \\
\text { listen }=\gamma_{0}+\gamma_{1} \text { project }+\gamma_{2} \text { consensus }+\gamma_{3} \text { benefit }+\epsilon_{3}
\end{gathered}
$$

The direct and indirect effects of a variable can be obtained easily from the model. As Figure 5.2 shows, institution affects the likelihood of having a positive change in trust attitude through two paths: one by the link from Consensus to Trust (a direct effect) and the other by the link between Consensus and Listen and the link between Listen and Trust (an indirect or mediated effect). The total effect of the variable Consensus is the sum of the two. Mathematically, the size of the effect can be calculated after solving the system of Equations (3) to (5). As one can see, in a linear representation, after substituting Equation (5) into Equation (4), the direct effect of consensus is captured by the coefficient $\beta_{2}$, and its indirect effect is captured by the product of the coefficients, $\beta_{1} \gamma_{2}$, as shown below:

$$
\frac{\text { dtrust }}{\text { dconsensus }}=\frac{\partial \text { trust }}{\partial \text { consensus }}+\frac{\partial \text { trust }}{\partial \text { listen }} \frac{\partial \text { listen }}{\partial \text { consensus }}
$$

Table 5.4 reports the estimated direct and indirect effects and their corresponding robust and clustered standard errors. Estimates in the table are based on the linear model. They are reported because they directly give the average marginal effects of a variable on the dependent variable (Wooldridge, 2010). From Table 5.4, it is clear that only the effects that are mediated through the variable Listen are statistically significant. Without mediation, neither Project nor Consensus has any statistically significant direct effects on a positive change in trust evaluation. This finding sug-

7 Though I only present a parsimonious model here, I obtained similar results when other exogenous variables in Model 3, such as Female and Age, are also included. 
gests that the variable Consensus has an effect on attitude change when individuals feel that their voices or opinions are being valued. One can also conclude that project benefits per se are a secondary concern. Though project benefits have a substantive effect on trust building, the effect is significant only when they are mediated through the variable Listen.

\subsection{CONCLUSION}

The case of Sierra Leone has several features that may not allow my findings to be generalized to other post-conflict environments. Firstly, though Sierra Leone is characterized by its great ethnic diversity, the civil war did not stem from ethnic identity (Dupuy and Binningsbø, 2013; Fanthorpe, 2005). Whether the finding is generalizable to societies that suffered from a deep ethnic divide is subject to further examination. Secondly, the root cause of the civil war in Sierra Leone was the power imbalance between authority and villagers originating from the accountability deficit of the governing body (Jackson, 2007). As government responsiveness directly speaks to this problem and the whole point of decentralization reform was to address this issue (Casey, Glennerster, and Miguel, 2016), increased responsiveness may not work equally well if a war is fought for other reasons. Finally, accountability in rural Sierra Leone started at a low level. This low starting point may reduce the expectations of the public and makes every small improvement count. Given the above, the finding is most relevant to a post-conflict society that experienced non-ethnic civil war and suffered from serious accountability deficit.

Past research has shown that the lack of political trust is associated not only with the onset of civil war but also with the stability of negotiated settlement, the success of state-building, and the spell of peace. This article contributes to the literature by clarifying the causal mechanism of trust building. It argues that being responsive to the needs of people is the key to successful trust building. My findings confirm this hypothesis and suggest that demonstrating concern for the needs of people and engaging them in policy formulation have the most promising effect in enhancing political trust in a post-conflict environment. By contrast, though inclusive political institutions and improvements in public service provisions were deemed important, their effects are less relevant or indirect. These findings imply that although improvement of public services may 
Table 5.4: Direct and indirect effects of institution and development project on trust-building

\begin{tabular}{|c|c|c|}
\hline DIRECT / INDIRECT EFFECT & SEM & \\
\hline Consensus $\rightarrow$ Trust & $\begin{array}{r}-0.000 \\
(0.046)\end{array}$ & \\
\hline Consensus $\rightarrow$ Listen $\rightarrow$ Trust & $\begin{array}{r}0.020 \\
(0.008)\end{array}$ & $*$ \\
\hline Listen $\rightarrow$ Trust & $\begin{array}{r}0.168 \\
(0.024)\end{array}$ & $* * *$ \\
\hline Project $\rightarrow$ Listen $\rightarrow$ Trust & $\begin{array}{r}0.006 \\
(0.008)\end{array}$ & \\
\hline Project $\rightarrow$ Benefit $\rightarrow$ Listen $\rightarrow$ Trust & $\begin{array}{r}0.029 \\
(0.008)\end{array}$ & $* * *$ \\
\hline Project $\rightarrow$ Benefit $\rightarrow$ Trust & $\begin{array}{r}0.015 \\
(0.027)\end{array}$ & \\
\hline Benefit $\rightarrow$ Trust & $\begin{array}{r}0.023 \\
(0.040)\end{array}$ & \\
\hline
\end{tabular}

Note: Robust standard error in parentheses. Standard errors are clustered at the EA level. ${ }^{* * *} \mathrm{p}<0.001,{ }^{* *} \mathrm{p}<0.01,{ }^{*} \mathrm{p}<0.05$.

carry other strategic or normative values and can bring benefits to people, if the improvements do not reflect the needs of people, they will not be effective in changing their attitudes towards the government. Listening and responding to the demands of people are the most effective ways of restoring trust and peace. 


\subsection{APPENDIX}

Table 5.5: List of variables

\begin{tabular}{|c|c|c|}
\hline VARIABLE & SURVEY QUESTION & CODING \\
\hline trust & $\begin{array}{l}\text { In your opinion, do you } \\
\text { believe Local Councilors } \\
\text { or do you have to be care- } \\
\text { ful dealing with them? }\end{array}$ & $\begin{array}{l}=1 \text { only if answered 'have } \\
\text { to be careful' in } 2007 \text { but } \\
\text { answered 'can be believed' } \\
\text { in 2008; otherwise zero }\end{array}$ \\
\hline listen & $\begin{array}{l}\text { Do you think the Local } \\
\text { Council listens to what } \\
\text { people in this town / } \\
\text { neighborhood say or what } \\
\text { they need? }\end{array}$ & $\begin{array}{l}=1 \text { only if answered 'yes' } \\
\text { in } 2007 \text { but answered 'no' } \\
\text { in 2008; otherwise zero }\end{array}$ \\
\hline aware & $\begin{array}{l}\text { Have you heard about the } \\
\text { Local Councils? }\end{array}$ & $\begin{array}{l}=1 \text { if answered yes; other- } \\
\text { wise zero }\end{array}$ \\
\hline project & $\begin{array}{l}\text { Do you know of any } \\
\text { projects (anywhere in the } \\
\text { district / city) the Local } \\
\text { Council is doing or has } \\
\text { done? }\end{array}$ & $\begin{array}{l}=1 \text { if answered yes; other- } \\
\text { wise zero }\end{array}$ \\
\hline benefit & $\begin{array}{l}\text { Have you yourself bene- } \\
\text { fited from any of these } \\
\text { projects? }\end{array}$ & $\begin{array}{l}=1 \text { only if answered 'yes' } \\
\text { in } 2007 \text { but answered 'no' } \\
\text { in 2008; otherwise zero }\end{array}$ \\
\hline victimization & $\begin{array}{l}\text { (1) Were you or any mem- } \\
\text { ber of your household in- } \\
\text { jured or maimed during } \\
\text { the conflict? (2) Was any } \\
\text { member of your house- } \\
\text { hold killed during the con- } \\
\text { flict? }\end{array}$ & $\begin{array}{l}=2 \text { if answered yes to both } \\
\text { questions; =1 if answered } \\
\text { yes to only one of the ques- } \\
\text { tions; =o if answered no to } \\
\text { both questions }\end{array}$ \\
\hline female & & $\begin{array}{l}=1 \text { if female; otherwise } \\
\text { zero }\end{array}$ \\
\hline
\end{tabular}


asset

community

migrant

member

consensus
Does any member of your Number of items owned household own the fol- by the households lowing items? Bicycle; mobile phone; generator; electric fan; umbrella; TV; radio/radio cassette player

In your opinion, do you $=1$ if answered 'can be believe people from own believed'; $=0$ if answered town / neighborhood or 'have to be careful' do you have to be careful dealing with them?

Age of the respondents in 2008

In what district and chiefdom were you born?

Do you belong to any (of the following organizations)? Farmer or fisherman's group; religious group; credit or savings group; trade union; school management committee; political organization; labor gang When there is a decision Proportion of respondents to be made in the commu- in the evaluation unit nity/neighborhood on an agreed that 'The whole issue that affects you, such community/ neighboras deciding between build- hood makes the decision ing a new school or a road, at a public meeting how does this decision through consensus or usually get made? (Multi- voting' ple options allowed) 
$\begin{array}{ll}\text { In school, what was the } & =0 \text { if none; }=1 \text { if Primary } \\ \text { highest class or form you } & 1-\text { Primary } 7 ;=2 \text { if Se- } \\ \text { completed? } & \text { nior Secondary School } 1- \\ & 3 ;=3 \text { if Senior Secondary } \\ & \text { School } 4-6 ;=4 \text { if techni- } \\ & \text { cal / vocational / teacher } \\ & \text { training/ nursing / uni- } \\ & \text { versity (any year) }\end{array}$

visit In the past year, has this $=1$ if answered yes; othercommunity been visited wise zero by a Local Councilor?

market

road

water Is there a market in this community?

How far is it (in miles) to the nearest motorable 2008 and 2007 road?

How long does it take The difference between (minutes) to walk to this 2008 and 2007 place?

health Is there a clinic or hospi- =- 1 if answered no in 2008 tal in this village / town / but yes in 2007; =o if ancity?
$=-1$ if there was no market in 2008 but there was a permanent or periodic market in 2007; $=0$ if there was no market in both 2007 and 2008; $=0$ if there was permanent/ periodic market in both 2007 and 2008; =1 if there was no market in 2007 but permanent/ periodic market in 2008

The difference between swered yes (no) in both 2007 and 2008; =1 if answered yes in 2008 but no in 2007 
school Is there a primary school in this village / town / city? $=-1$ if answered no in 2008 but yes in 2007; $=0$ if answered yes (no) in both 2007 and 2008; $=1$ if answered yes in 2008 but no in 2007

stay

corrupt

If the Local Council was given 500 million Leones to complete a project in this area, do you believe they would spend all the money doing a good job on the project or would they cut some of the money?

$=1$ if the same household was interviewed in both 2007 and 2008

$I=$ they would do a great job and spend all the money; 2 = they would do a good job but cut a little money; 3 = they would do a bad job and cut most of the money; 4 = they would just take all the money $=1$ if perceived to be less corrupted than in 2007; otherwise zero

edu Sat In general, are you sat- $=1$ if answered yes; otherisfied with what your wise zero children are learning in school?

hea Sat In general, are you satis- $=1$ if answered yes; otherfied with the care you re- wise zero ceive at the clinic / hospital?

ELF Probability that two indi- From Glennerster, Miguel, viduals randomly selected and Rothenberg, 2013 in chiefdoms belong to different ethnic groups

diamond Number of diamond From Bellows and Miguel, mines in chiefdoms 2009 
Table 5.6: Summary statistics

\begin{tabular}{llllll}
\hline \multicolumn{1}{c}{ VARIABLE } & OBSERVATION & MEAN & \multicolumn{1}{c}{ SD } & MIN. & MAX. \\
\hline Trust & 1,929 & 0.33 & 0.47 & O & 1 \\
Listen & 2,380 & 0.43 & 0.50 & O & 1 \\
Aware (2008) & 2,356 & 0.88 & 0.33 & O & 1 \\
Aware (2007) & 2,404 & 0.70 & 0.46 & 0 & 1 \\
Benefit & 2,349 & 0.11 & 0.31 & 0 & 1 \\
Victimization & 2,414 & 0.90 & 0.88 & O & 2 \\
Female & 2,406 & 0.46 & 0.50 & 0 & 1 \\
Asset & 2,376 & 1.49 & 1.83 & 0 & 7 \\
Community & 2,361 & 0.75 & 0.43 & 0 & 1 \\
Age & 2,397 & 41.94 & 14.92 & 16 & 99 \\
Migrant & 2,422 & 0.40 & 0.49 & 0 & 1 \\
Member & 2,393 & 1.01 & 1.21 & 0 & 6 \\
Consensus & 2,422 & 0.61 & 0.29 & 0 & 1 \\
Market & 1,922 & 1.68 & 12.18 & -78 & 300 \\
Road & 1,928 & -0.08 & 7.53 & -83 & 89 \\
Water & 1,927 & 2.50 & 13.76 & -78 & 75 \\
Health & 1,898 & 0.53 & 4.97 & -30 & 68 \\
School & 1,974 & 0.03 & 0.32 & -1 & 1 \\
Diamonds & 1,788 & 3.38 & 6.54 & 0 & 35 \\
ELF & 1,788 & 0.27 & 0.19 & 0.02 & 0.79 \\
Edu satisfaction & 877 & 0.06 & 0.24 & 0 & 1 \\
Health satisfac- & 1,867 & 0.07 & 0.26 & 0 & 1 \\
tion & & & & & \\
\hline
\end{tabular}

Note: Robust clustered standard errors in parentheses.

${ }^{* * *} \mathrm{p}<0.001,{ }^{* *} \mathrm{p}<0.01,{ }^{*} \mathrm{p}<0.05$. 
Table 5.7: Robustness checks

\begin{tabular}{|c|c|c|c|c|c|c|c|c|}
\hline & TRUST & & CORRUPT & & TRUST & & TRUST & \\
\hline Listen & $\begin{array}{r}0.775 \\
(0.120)\end{array}$ & $* * *$ & $\begin{array}{r}0.781 \\
(0.116)\end{array}$ & $* * *$ & $\begin{array}{r}0.844 \\
(0.163)\end{array}$ & $* * *$ & $\begin{array}{r}0.770 \\
(0.226)\end{array}$ & $* * *$ \\
\hline Aware (2008) & $\begin{array}{r}-0.374 \\
(0.248)\end{array}$ & & & & $\begin{array}{r}-0.481 \\
(0.289)\end{array}$ & & $\begin{array}{c}-0.127 \\
(0.374)\end{array}$ & \\
\hline Aware (2007) & $\begin{array}{r}-0.127 \\
(0.147)\end{array}$ & & & & $\begin{array}{c}-0.336 \\
(0.180)\end{array}$ & & $\begin{array}{r}0.162 \\
(0.268)\end{array}$ & \\
\hline Benefit & $\begin{array}{r}0.274 \\
(0.171)\end{array}$ & & $\begin{array}{r}-0.306 \\
(0.156)\end{array}$ & * & & & & \\
\hline Market & & & & & $\begin{array}{r}0.001 \\
(0.007)\end{array}$ & & & \\
\hline Road & & & & & $\begin{array}{r}0.009 \\
(0.006)\end{array}$ & & & \\
\hline Water & & & & & $\begin{array}{r}0.003 \\
(0.005)\end{array}$ & & & \\
\hline Health & & & & & $\begin{array}{r}0.002 \\
(0.011)\end{array}$ & & & \\
\hline School & & & & & $\begin{array}{r}0.229 \\
(0.216)\end{array}$ & & & \\
\hline Vic & $\begin{array}{r}0.026 \\
(0.054)\end{array}$ & & $\begin{array}{r}0.104 \\
(0.062)\end{array}$ & & $\begin{array}{r}0.064 \\
(0.085)\end{array}$ & & $\begin{array}{r}0.126 \\
(0.115)\end{array}$ & \\
\hline Female & $\begin{array}{c}-0.091 \\
(0.129)\end{array}$ & & $\begin{array}{r}0.321 \\
(0.098)\end{array}$ & ** & $\begin{array}{r}-0.183 \\
(0.165)\end{array}$ & & $\begin{array}{r}0.250 \\
(0.231)\end{array}$ & \\
\hline Asset & $\begin{array}{r}-0.128 \\
(0.038)\end{array}$ & $* * *$ & $\begin{array}{r}-0.089 \\
(0.031)\end{array}$ & $* *$ & $\begin{array}{r}-0.079 \\
(0.063)\end{array}$ & & $\begin{array}{r}-0.064 \\
(0.068)\end{array}$ & \\
\hline Community & $\begin{array}{r}2.067 \\
(0.194)\end{array}$ & $* * *$ & $\begin{array}{r}-0.075 \\
(0.129)\end{array}$ & & $\begin{array}{r}2.040 \\
(0.306)\end{array}$ & **** & $\begin{array}{r}2.336 \\
(0.380)\end{array}$ & $* * *$ \\
\hline Age & $\begin{array}{c}-0.001 \\
(0.004)\end{array}$ & & $\begin{array}{r}-0.002 \\
(0.003)\end{array}$ & & $\begin{array}{r}-0.006 \\
(0.005)\end{array}$ & & $\begin{array}{r}0.002 \\
(0.008)\end{array}$ & \\
\hline Migrant & $\begin{array}{r}-0.074 \\
(0.136)\end{array}$ & & $\begin{array}{r}-0.054 \\
(0.124)\end{array}$ & & $\begin{array}{r}-0.104 \\
(0.181)\end{array}$ & & $\begin{array}{r}0.167 \\
(0.232)\end{array}$ & \\
\hline Member & $\begin{array}{c}0.089 \\
(0.059)\end{array}$ & & $\begin{array}{c}-0.144 \\
(0.041)\end{array}$ & $* * *$ & $\begin{array}{r}-0.023 \\
(0.062)\end{array}$ & & $\begin{array}{r}0.130 \\
(0.077)\end{array}$ & \\
\hline Consensus & $\begin{array}{r}-0.703 \\
(0.239)\end{array}$ & ** & $\begin{array}{r}0.434 \\
(0.213)\end{array}$ & * & $\begin{array}{r}-0.209 \\
(0.338)\end{array}$ & & $\begin{array}{c}-1.080 \\
(0.346)\end{array}$ & $* *$ \\
\hline Diamonds & & & & & $\begin{array}{r}0.008 \\
(0.013)\end{array}$ & & & \\
\hline ELF & & & & & $\begin{array}{r}0.471 \\
(0.478)\end{array}$ & & & \\
\hline Edu Satisfaction & & & & & & & $\begin{array}{c}0.614 \\
(0.411)\end{array}$ & \\
\hline Hea Satisfaction & & & & & & & $\begin{array}{r}-0.089 \\
(0.355)\end{array}$ & \\
\hline Constant & $\begin{array}{r}-1.820 \\
(0.351)\end{array}$ & $* * *$ & $\begin{array}{r}0.575 \\
(0.242)\end{array}$ & * & $\begin{array}{r}-1.792 \\
(0.556)\end{array}$ & $* *$ & $\begin{array}{c}-2.858 \\
(0.720)\end{array}$ & $* * *$ \\
\hline Observations & 1,769 & & 2,177 & & 918 & & 507 & \\
\hline
\end{tabular}

Note: Robust clustered standard errors in parentheses. ${ }^{* *} \mathrm{p}<0.001,{ }^{* *} \mathrm{p}<0.01,{ }^{*}$ $\mathrm{p}<0.05$ 
Table 5.8: Estimation results using multinomial logit (base outcome: Trust $_{2007}=$

\begin{tabular}{|c|c|c|c|c|c|c|}
\hline & $\begin{array}{l}2007=0 \\
2008=1\end{array}$ & & $\begin{array}{l}2007=1 \\
2008=1\end{array}$ & & $\begin{array}{l}2007=1 \\
2008=0\end{array}$ & \\
\hline Listen & $\begin{array}{r}0.700 \\
(0.151)\end{array}$ & $* * *$ & $\begin{array}{r}0.026 \\
(0.172)\end{array}$ & & $\begin{array}{r}-0.380 \\
(0.173)\end{array}$ & * \\
\hline Aware (2008) & $\begin{array}{r}-0.155 \\
(0.214)\end{array}$ & & $\begin{array}{r}0.539 \\
(0.307)\end{array}$ & & $\begin{array}{r}0.396 \\
(0.253)\end{array}$ & \\
\hline Aware (2007) & $\begin{array}{r}0.047 \\
(0.143)\end{array}$ & & $\begin{array}{r}0.412 \\
(0.190)\end{array}$ & * & $\begin{array}{r}0.306 \\
(0.183)\end{array}$ & \\
\hline Benefit & $\begin{array}{r}0.459 \\
(0.219)\end{array}$ & * & $\begin{array}{r}0.436 \\
(0.272)\end{array}$ & & $\begin{array}{r}0.233 \\
(0.289)\end{array}$ & \\
\hline Victimization & $\begin{array}{r}0.103 \\
(0.074)\end{array}$ & & $\begin{array}{r}0.113 \\
(0.093)\end{array}$ & & $\begin{array}{r}0.216 \\
(0.092)\end{array}$ & \\
\hline Female & $\begin{array}{r}-0.031 \\
(0.132)\end{array}$ & & $\begin{array}{r}0.060 \\
(0.158)\end{array}$ & & $\begin{array}{r}0.216 \\
(0.148)\end{array}$ & \\
\hline Asset & $\begin{array}{r}-0.118 \\
(0.045)\end{array}$ & $* *$ & $\begin{array}{r}0.020 \\
(0.050)\end{array}$ & & $\begin{array}{r}0.022 \\
(0.047)\end{array}$ & \\
\hline Community & $\begin{array}{r}2.476 \\
(0.210)\end{array}$ & $* * *$ & $\begin{array}{r}2.266 \\
(0.259)\end{array}$ & $* * *$ & $\begin{array}{r}0.210 \\
(0.158)\end{array}$ & \\
\hline Age & $\begin{array}{r}0.003 \\
(0.004)\end{array}$ & & $\begin{array}{r}0.009 \\
(0.005)\end{array}$ & & $\begin{array}{r}0.004 \\
(0.005)\end{array}$ & \\
\hline Migrant & $\begin{array}{r}-0.270 \\
(0.148)\end{array}$ & & $\begin{array}{r}-0.637 \\
(0.204)\end{array}$ & $* *$ & $\begin{array}{r}-0.092 \\
(0.180)\end{array}$ & \\
\hline Member & $\begin{array}{r}0.144 \\
(0.056)\end{array}$ & ** & $\begin{array}{r}0.115 \\
(0.068)\end{array}$ & & $\begin{array}{r}0.098 \\
(0.063)\end{array}$ & \\
\hline Consensus & $\begin{array}{r}-0.971 \\
(0.254)\end{array}$ & $* * *$ & $\begin{array}{r}-0.665 \\
(0.331)\end{array}$ & * & $\begin{array}{c}-0.378 \\
(0.305)\end{array}$ & \\
\hline Constant & $\begin{array}{r}1.847 \\
(0.387) \\
\end{array}$ & $* * *$ & $\begin{array}{r}-3.525 \\
(0.490) \\
\end{array}$ & $* * *$ & $\begin{array}{r}-1.840 \\
(0.433) \\
\end{array}$ & $* * *$ \\
\hline Observations & 1,769 & & 1,769 & & 1,769 & \\
\hline
\end{tabular}

Note: Robust clustered standard errors in parentheses.

${ }^{* * *} \mathrm{p}<0.001,{ }^{* *} \mathrm{p}<0.01,{ }^{*} \mathrm{p}<0.05$. 
Table 5.9: Estimation results using multinomial logit (base outcome: Trust $_{2007}=$

\begin{tabular}{|c|c|c|c|c|c|c|}
\hline & $\begin{array}{l}2007=1 \\
2008=0\end{array}$ & & $\begin{array}{l}2007=0 \\
2008=0\end{array}$ & & $\begin{array}{l}2007=0 \\
2008=1\end{array}$ & \\
\hline Listen & $\begin{array}{r}-0.406 \\
(0.200)\end{array}$ & * & $\begin{array}{r}-0.026 \\
(0.172)\end{array}$ & & $\begin{array}{r}0.674 \\
(0.155)\end{array}$ & $* * * *$ \\
\hline Aware (2008) & $\begin{array}{r}-0.142 \\
(0.363)\end{array}$ & & $\begin{array}{r}-0.539 \\
(0.307)\end{array}$ & & $\begin{array}{r}-0.693 \\
(0.311)\end{array}$ & * \\
\hline Aware (2007) & $\begin{array}{r}-0.106 \\
(0.226)\end{array}$ & & $\begin{array}{r}-0.412 \\
(0.190)\end{array}$ & $*$ & $\begin{array}{r}-0.366 \\
(0.180)\end{array}$ & * \\
\hline Benefit & $\begin{array}{r}-0.203 \\
(0.320)\end{array}$ & & $\begin{array}{r}-0.436 \\
(0.272)\end{array}$ & & $\begin{array}{r}0.022 \\
(0.241)\end{array}$ & \\
\hline Victimization & $\begin{array}{r}0.104 \\
(0.110)\end{array}$ & & $\begin{array}{r}-0.113 \\
(0.093)\end{array}$ & & $\begin{array}{r}-0.009 \\
(0.085)\end{array}$ & \\
\hline Female & $\begin{array}{r}0.156 \\
(0.181)\end{array}$ & & $\begin{array}{r}-0.060 \\
(0.158)\end{array}$ & & $\begin{array}{r}-0.091 \\
(0.159)\end{array}$ & \\
\hline Asset & $\begin{array}{r}0.002 \\
(0.056)\end{array}$ & & $\begin{array}{r}-0.020 \\
(0.050)\end{array}$ & & $\begin{array}{r}-0.138 \\
(0.045)\end{array}$ & $* *$ \\
\hline Community & $\begin{array}{r}-2.056 \\
(0.281)\end{array}$ & $* * *$ & $\begin{array}{r}-2.266 \\
(0.259)\end{array}$ & $* * *$ & $\begin{array}{r}0.210 \\
(0.310)\end{array}$ & \\
\hline Age & $\begin{array}{r}-0.005 \\
(0.007)\end{array}$ & & $\begin{array}{r}-0.009 \\
(0.005)\end{array}$ & & $\begin{array}{r}-0.006 \\
(0.005)\end{array}$ & \\
\hline Migrant & $\begin{array}{r}0.545 \\
(0.238)\end{array}$ & * & $\begin{array}{r}0.637 \\
(0.204)\end{array}$ & $* *$ & $\begin{array}{r}0.367 \\
(0.194)\end{array}$ & \\
\hline Member & $\begin{array}{r}-0.017 \\
(0.078)\end{array}$ & & $\begin{array}{r}-0.115 \\
(0.068)\end{array}$ & & $\begin{array}{r}0.029 \\
(0.062)\end{array}$ & \\
\hline Consensus & $\begin{array}{r}0.287 \\
(0.389)\end{array}$ & & $\begin{array}{r}0.665 \\
(0.331)\end{array}$ & * & $\begin{array}{r}-0.306 \\
(0.305)\end{array}$ & \\
\hline Constant & $\begin{array}{r}1.686 \\
(0.579) \\
\end{array}$ & $* *$ & $\begin{array}{r}3.525 \\
(0.490) \\
\end{array}$ & $* * *$ & $\begin{array}{r}1.678 \\
(0.526) \\
\end{array}$ & $* *$ \\
\hline Observations & 1,769 & & 1,769 & & 1,769 & \\
\hline
\end{tabular}

Note: Robust clustered standard errors in parentheses.

$$
\text { *** } \mathrm{p}<0.001,{ }^{* *} \mathrm{p}<0.01,{ }^{*} \mathrm{p}<0.05
$$




\section{CONCLUSION}

This thesis has critically examined the economic primacy in peace-making and peace-building. At the beginning of this book, I posted four different questions surrounding this theme. Here I will give a brief answer to each question.

1. What is the short-run effect of development aid on insurgent attacks? (Chapter 2) Development aid may not work as intended and encourage more violent attacks in the short run. Insurgents may benefit from foreign aid through different channels such as looting and corruption. Donors need to beware of the ties between aid recipients and other actors, provide better security to contractors, or try to allocate aid more strategically. Whenever possible, they should also provide assistance that is less likely to be looted (e.g. projects aiming at institution building).

2. What explains the decrease of insurgency in Iraq starting 2008? (Chapter 3) Development aid may not have contributed to the decline in the number of violent attacks in Iraq as existing studies have reported. Aid may induce cross-border rent-seeking behaviors. Analysts should also hold a more holistic view and be aware of the problem of insurgents' mobility when evaluating the impact of counterinsurgency policies.

3. Why do some ex-combatants choose to opt out of the DDR program? (Chapter 4) Apart from the economic and communal environment in which ex-combatants are embedded in, their wartime experience and their mental health condition may inhibit them to be fully reintegrated. Therefore, when conflict ends, more resources should be directed to take care of the trauma of ex-combatants, as their psychological health may weaken other reintegration measures, and hence, in some cases, contribute to future radicalization, posting security threats to nearby unstable regions.

4. How can political trust be built after civil wars? (Chapter 5) To achieve sustainable peace in the longer run, policy makers should 
also note that the process that decides what to provide is more important than what is actually provided. This finding challenges a common belief probably shared by many people in the policy world, that governments can buy trust with public services. Although enhancement of public services may carry certain strategic or normative values, if trust is considered to be a crucial step in state building, the strategy is unlikely to be effective through the trust-building mechanism. Listening and responding to the locals are the most effective ways of restoring trust and peace.

\subsection{TO VALORIZE}

(This addendum on valorization is added in accordance with article 23.5 of the "Regulation governing the attainment of doctoral degrees at Maastricht University" decreed by resolution of the Board of Deans.)

There are several policy lessons based on the findings documented in the dissertation, which can be of interest to policy makers. I have highlighted them in the introduction and delved into them in the corresponding chapters. To recap,

- One of the major findings in Chapter 2 is that insurgents can benefit from foreign aid through different channels such as looting and corruption. Donors need to bear in mind the ties between aid recipients and other actors. They should also be more selective in choosing partners. Whenever possible, they should also provide assistance that is less likely to be looted, so that it can be handed to the needed.

- Chapter 3 addresses a convenient assumption made in policy evaluation, that counterinsurgency effectiveness is usually tied to indicators that reflect only the local situation without taking possible spillover effects into consideration. In this regard, Chapter 3 introduces a theoretical framework and a practical tool to assist the monitoring of counterinsurgency efforts.

- Chapter 4 looks at disarmament, demobilization, and reintegration (DDR) and examines why some ex-combatants choose to fall outside the policy net and what are the possible consequences. It warns that the mental health condition of ex-fighters can potentially relate 
to further radicalization and hence contribute to regional security threats. However, it also notes that early intervention can be counterproductive as the debate over involuntary treatment is still active in the psychological literature. Primum non nocere (First, do no harm).

- Chapter 5 challenges a common belief probably shared by many people in the policy world, that government can buy trust with public services. In fact, Lake (2010) observes that the US government is 'field-testing' a new approach to state building in its foreign policy: build legitimacy for new states by providing essential public services to their people. The findings from the chapter imply that the question is not really about what to provide. Instead, it is about the way of deciding what to be provided. Although the enhancement of public services may carry certain strategic or normative values, if trust is considered to be a crucial step in state building, the strategy is unlikely to be effective through the trust building mechanism. Listening and responding to the locals are the most effective ways of restoring trust and peace, a finding that echoes with the agenda of 'local ownership' in the policy world.

These policy lessons have been shared on different occasions, including international conferences, workshops and meetings attended by policy makers. For example, the annual conventions of International Studies Association in Toronto and Atlanta; the Asian Political Methodology Meeting at Academia Sinica, the national academy of Taiwan; the Workshops at the Deutsches Institut für Entwicklungspolitik (German Development Institute) in Bonn, organized by the European Network for Conflict Research (ENCoRe) under the European Cooperation in Science and Technology (COST) Action. Some of the findings have also been disseminated via social media (i.e. the Conversation and the YouTube channel of United Nations University - Maastricht Economic and Social Research Institute on Innovation and Technology). While Chapters 2, 3 and 4 are under review at journals for publication, Chapters 2 and 3 have already appeared in the UNU-MERIT Working Paper Series, and are freely available to the public. Chapter 5 is published in the Journal of Peace Research. And thanks to the Universiteitsbibliotheken en de Koninklijke Bibliotheek (UKB, or the Dutch Library Consortium), the article is made open access.

The target group of the research includes policy makers working in governments, international agencies such as the United Nations, and research and policy institutes. The policy value of the findings appears to 
be well-received. For example, Chapter 3 is listed as the Top 1o Reads by the Stabilisation Unit of the UK Government. ${ }^{1}$

I http://sclr.stabilisationunit.gov.uk/top-10-reads/geographic/iraq. 


\section{BIBLIOGRAPHY}

Angrist, Joshua D. and Pischke, Jörn-Steffen (2009). Mostly Harmless Econometrics: An Empiricist's Companion. Princeton, NJ: Princeton University Press.

Anselin, Luc, Le Gallo, Julie, and Jayet, Hubert (2008). "Spatial Panel Econometrics." In: The Econometrics of Panel Data. Ed. by Mátyás, László and Sevestre, Patrick. Berlin: Springer, pp. 625-66o.

Arellano, Manuel and Bond, Stephen (1991). "Some tests of specification for panel data: Monte Carlo evidence and an application to employment equations." In: Review of Economic Studies 58.2, pp. 277-297.

Arreguín-Toft, Ivan (2001). "How the weak win wars: A theory of asymmetric conflict." In: International Security 26.1, 93-128.

Askvik, Steinar, Jamil, Ishtiaq, and Dhakal, Tek Nath (2011). "Citizens' trust in public and political institutions in Nepal." In: International Political Science Review 32.4, pp. 417-437.

Baudains, Peter, Braithwaite, Alex, and Johnson, Shane D. (2013). "Target choice during extreme events: A discrete spatial choice model of the 2011 London Riots." In: Criminology 51.2, pp. 251-285.

Bazzi, Samuel and Blattman, Christopher (2014). "Economic shocks and conflict: Evidence from commodity prices." In: American Economic Journal: Macroeconomics 6.4, pp. 1-38.

Belasco, Amy (2009). Troop Levels in the Afghan and Iraq Wars, FY2001FY2012: Cost and Other Potential Issues. Washington, DC: Congressional Research Service.

Bellows, John and Miguel, Edward (2009). "War and local collective action in Sierra Leone." In: Journal of Public Economics 93.11, pp. 1144-1157.

Bennett, Andrew and Checkel, Jeffrey T. (2014). Process Tracing: From Metaphor to Analytical Tool. New York: Cambridge University Press. 
Berman, Eli, Shapiro, Jacob N., and Felter, Joseph H. (2011). "Can hearts and minds be bought? The economics of counterinsurgency in Iraq." In: Journal of Political Economy 119.4, pp. 766-819.

Berman, Eli, Callen, Michael, Felter, Joseph H., and Shapiro, Jacob N. (2011). "Do working men rebel? Insurgency and unemployment in Afghanistan, Iraq, and the Philippines." In: Journal of Conflict Resolution 55.4, pp. 496-528.

Besley, Timothy and Persson, Torsten (2010). "State capacity, conflict, and development." In: Econometrica 78.1, pp. 1-34.

Betancourt, Theresa S., Simmons, Stephanie, Borisova, Ivelina, Brewer, Stephanie E., Iweala, Uzo, and La Soudière, Marie de (2008). "High hopes, grim reality: Reintegration and the education of former child soldiers in Sierra Leone." In: Comparative Education Review 52.4, pp. 565587 .

Bhui, Kamaldeep (2015). “Extremism's false trail.” In: New Scientist 226.3016, pp. 24-25.

Biddle, Stephen (2008). Stabilizing Iraq from the bottom. Testimony before the committee on foreign relations United States Senate second session. Washington, DC.

Biddle, Stephen, Friedman, Jeffrey A., and Shapiro, Jacob N. (2012). "Testing the surge: Why did violence decline in Iraq in 2007?" In: International Security 37.1, pp. 7-40.

Blattman, Christopher and Annan, Jeannie (2016). "Can employment reduce lawlessness and rebellion? A field experiment with high-risk men in a fragile state." In: American Political Science Review 110.1, pp. 1-17.

Blattman, Christopher, Fiala, Nathan, and Martinez, Sebastian (2014). “Generating skilled self-employment in developing countries: Experimental evidence from Uganda." In: Quarterly Journal of Economics 129.2, pp. 697-752. 
Blau, Peter Michael (1964). Exchange and Power in Social Life. New York: Wiley.

Blundell, Richard and Bond, Stephen (1998). "Initial conditions and moment restrictions in dynamic panel data models." In: Journal of Econometrics 87.1, pp. 115-143.

Boothby, Neil G. and Knudsen, Christine M. (2000). "Children of the Gun." In: Scientific American 282.6, pp. 60-65.

Braithwaite, Alex and Johnson, Shane D. (2012). "Space-time modeling of insurgency and counterinsurgency in Iraq." In: Journal of Quantitative Criminology 28.1, pp. 31-48.

Buhaug, Halvard and Gleditsch, Kristian Skrede (2008). "Contagion or confusion? Why conflicts cluster in space." In: International Studies Quarterly 52.2, pp. 215-233.

Buhaug, Halvard and Rød, Jan Ketil (2006). "Local determinants of African civil wars, 1970-2001." In: Political Geography 25.3, pp. 315-335.

Cameron, A Colin and Trivedi, Pravin K (2005). Microeconometrics. New York: Cambridge University Press.

Casey, Katherine, Glennerster, Rachel, and Miguel, Edward (2016). "Healing the wounds: Learning from Sierra Leone's postwar institutional reforms." In: African Successes: Government and Institutions. Ed. by Edwards, Sebastian, Johnson, Simon, and Weil, David N. Chicago: University of Chicago Press, pp. 15-32.

Cassar, Alessandra, Grosjean, Pauline, and Whitt, Sam (2013). "Legacies of violence: trust and market development." In: Journal of Economic Growth 18.3, pp. 285-318.

Cederman, Lars-Erik, Weidmann, Nils B., and Gleditsch, Kristian Skrede (2011). "Horizontal inequalities and ethnonationalist civil war: A global comparison." In: American Political Science Review 105.3, pp. 478-495.

Cederman, Lars-Erik, Wimmer, Andreas, and Min, Brian (2010). "Why do ethnic groups rebel? New data and analysis." In: World Politics 62.1, pp. 87-119. 
Chacón, Mario L. (2013). "In the line of fire: Political violence and decentralization in Colombia." Unpublished Manuscript. NYU-Abi Dhabi. Coalition Provisional Authority (2004). Development Fund for Iraq (DFI). URL: http : / / www . iraqcoalition . org / budget / DFI - introl . html (visited on 09/07/2016).

Cohen, Dara Kay (2013). "Female combatants and the perpetration of violence: Wartime rape in the Sierra Leone civil war." In: World Politics 65.3, pp. 383-415.

Cohen, Raphael S. (2014). "Just how important are 'hearts and minds' anyway? Counterinsurgency goes to the polls." In: Journal of Strategic Studies 37.4, pp. 609-636.

Collier, Paul and Hoeffler, Anke (1998). “On economic causes of civil war." In: Oxford Economic Papers 50.4, pp. 563-573.

Collier, Paul and Hoeffler, Anke (2002a). "Aid, policy and peace: Reducing the risks of civil conflict." In: Defence and Peace Economics 13.6, pp. 435-450.

Collier, Paul and Hoeffler, Anke (2002b). "On the incidence of civil war in Africa." In: Journal of Conflict Resolution 46.1, pp. 13-28.

Collier, Paul, Hoeffler, Anke, and Söderbom, Måns (2004). "On the duration of civil war." In: Journal of Peace Research 41.3, pp. 253-273.

Corner, Emily and Gill, Paul (2015). "A false dichotomy? Mental illness and lone-actor terrorism." In: Law and Human Behavior 39.1, pp. 23-34. Crenshaw, Martha (1998). "The logic of terrorism: Terrorist behavior as a product of strategic choice." In: Origins of Terrorism: Psychologies, Ideologies, Theologies, States of Mind. Ed. by Reich, Walter. Baltimore, MD: Johns Hopkins University Press, pp. 7-24.

Crost, Benjamin, Felter, Joseph, and Johnston, Patrick (2014). "Aid under fire: Development projects and civil conflict." In: American Economic Review 104.6, pp. 1833-1856.

Cuesta, José and Alda, Erik (2012). "The effects of trust on victimization in Colombia." In: Journal of Peace Research 49.6, pp. 833-846. 
Deutsch, Morton (1960). "Trust, trustworthiness, and the F scale." In: Journal of Abnormal and Social Psychology 61.1, pp. 138-140.

Dixon, Paul (2009). "'Hearts and minds'? British counter-insurgency from Malaya to Iraq." In: Journal of Strategic Studies 32.3, pp. 353-381.

Dobbins, James (2009). "Occupying Iraq: A short history of the CPA." In: Survival 51.3, pp. 131-162.

Drake, C. J. M. (1998). “The role of ideology in terrorists' target selection." In: Terrorism and Political Violence 10.2, pp. 53-85.

Dreher, Axel, Marchesi, Silvia, and Vreeland, James Raymond (2008). “The political economy of IMF forecasts." In: Public Choice 137.1, pp. 145171.

Dube, Oeindrila and Naidu, Suresh (2015). "Bases, bullets, and ballots: The effect of US military aid on political conflict in Colombia." In: Journal of Politics 77.1, pp. 249-267.

Dupuy, Kendra and Binningsbø, Helga Malmin (2013). Power-sharing and peace-building in Sierra Leone. Oslo: Center for the Study of Civil War, PRIO.

Ehlers, Anke and Steil, Regina (1995). "Maintenance of intrusive memories in posttraumatic stress disorder: A cognitive approach." In: Behavioural and Cognitive Psychotherapy 23.3, pp. 217-249.

Elhorst, J. Paul (2010a). "Dynamic panels with endogenous interaction effects when T is small." In: Regional Science and Urban Economics. Advances In Spatial Econometrics 40.5, pp. 272-282.

Elhorst, J. Paul (2010b). "Spatial panel data models." In: Handbook of Applied Spatial Analysis. Ed. by Fischer, Manfred M. and Getis, Arthur. Berlin: Springer, pp. 377-407.

Elhorst, J. Paul (2012). “Dynamic spatial panels: models, methods, and inferences." In: Journal of Geographical Systems 14.1, pp. 5-28.

Elliot, Andrew J., Gable, Shelly L., and Mapes, Rachael R. (2006). "Approach and avoidance motivation in the social domain." In: Personality and Social Psychology Bulletin 32.3, pp. 378-391. 
Enders, Walter and Sandler, Todd (1993). "The effectiveness of antiterrorism policies: A vector-autoregression-intervention analysis." In: American Political Science Review 87.4, pp. 829-844.

Fanthorpe, Richard (2005). "On the limits of liberal peace: Chiefs and democratic decentralization in post-war Sierra Leone." In: African Affairs 105.418, pp. 27-49.

Faria, João Ricardo (2006). "Terrorist innovations and anti-terrorist policies." In: Terrorism and Political Violence 18.1, pp. 47-56.

Fearon, James D. and Laitin, David D. (2003). "Ethnicity, insurgency, and civil war." In: American Political Science Review 97.1, pp. 75-90.

Fehr, Ernst and List, John A. (2004). "The hidden costs and returns of incentives-Trust and trustworthiness among CEOs." In: Journal of the European Economic Association 2.5, pp. 743-771.

Ferme, Mariane (1998). "The violence of numbers: Consensus, competition, and the negotiation of disputes in Sierra Leone." In: Cahiers d'Études Africaines 38.150, pp. 555-580.

Finlay, Keith and Magnusson, Leandro M. (2009). “Implementing weakinstrument robust tests for a general class of instrumental-variables models." In: Stata Journal 9.3, pp. 398-421.

Fjeldstad, Odd-Helge (2004). "What's trust got to do with it? Non-payment of service charges in local authorities in South Africa." In: Journal of Modern African Studies 42.4, pp. 539-562.

Franzese, Robert J. and Hays, Jude C. (2007). "Spatial econometric models of cross-sectional interdependence in political science panel and timeseries-cross-section data." In: Political Analysis 15.2, pp. 140-164.

Franzese, Robert J. and Hays, Jude C. (2008). "Interdependence in comparative politics: Substance, theory, empirics, substance." In: Comparative Political Studies 41.4, pp. 742-780.

Friedman, Jeffrey A. (2011). "Manpower and counterinsurgency: Empirical foundations for theory and doctrine." In: Security Studies 20.4, pp. 556-591. 
Fuchs, Andreas and Klann, Nils-Hendrik (2013). "Paying a visit: The Dalai Lama effect on international trade." In: Journal of International Economics 91.1, pp. 164-177.

Fukuyama, Francis (2004). "The imperative of state-building." In: Journal of Democracy 15.2, pp. 17-31.

Galtung, Johan (1969). "Violence, peace, and peace research." In: Journal of Peace Research 6.3, pp. 167-191.

Galula, David (1964). Counterinsurgency Warfare: Theory and Practice. New York: Praeger, Inc.

Gerring, John (2008). "The mechanismic worldview: Thinking inside the box." In: British Journal of Political Science 38.1, pp. 161-179.

Gilligan, Michael J., Mvukiyehe, Eric N., and Samii, Cyrus (2013). "Reintegrating rebels into civilian life: Quasi-experimental evidence from Burundi." In: Journal of Conflict Resolution 57.4, pp. 598-626.

Gleditsch, Kristian Skrede (2007). "Transnational dimensions of civil war." In: Journal of Peace Research 44.3, pp. 293-309.

Glennerster, Rachel, Miguel, Edward, and Rothenberg, Alexander D. (2013). "Collective action in diverse Sierra Leone communities." In: Economic Journal 123.568, pp. 285-316.

Gramzow, Richard and Tangney, June Price (1992). "Proneness to shame and the narcissistic personality." In: Personality and Social Psychology Bulletin 18.3, pp. 369-376.

Greenberg, Jerald (1994). "Looking fair vs. being fair: Managing impressions of organizational justice." In: Research in Organizational Behavior. Ed. by Staw, Barry M and Cummings, L L. Greenwich, CT.: JAI, pp. 111-157.

Greene, William H. (2011). Econometric Analysis. Upper Saddle River, NJ: Prentice Hall.

Griffin, Brandon J., Moloney, Jaclyn M., Green, Jeffrey D., Everett L. Worthington, Jr., Cork, Brianne, Tangney, June P., Tongeren, Daryl R. Van, Davis, Don E., and Hook, Joshua N. (2016). “Perpetrators' reactions 
to perceived interpersonal wrongdoing: The associations of guilt and shame with forgiving, punishing, and excusing oneself." In: Self and Identity 15.6, pp. 650-661.

Grossman, Herschel I. (1992). "Foreign aid and insurrection." In: Defence Economics 3.4, pp. 275-288.

Habyarimana, James, Humphreys, Macartan, Posner, Daniel N., and Weinstein, Jeremy M. (2007). "Why does ethnic diversity undermine public goods provision?" In: American Political Science Review 101.4, pp. 709-725.

Hagan, John, Kaiser, Joshua, Hanson, Anna, Lindsay, Jon R., Long, Austin G., Biddle, Stephen, Friedman, Jeffrey A., and Shapiro, Jacob N. (2013). "Correspondence: Assessing the synergy thesis in Iraq." In: International Security 37.4, pp. 173-198.

Haggard, Stephan and Kaufman, Robert R. (1995). The Political Economy of Democratic Transitions. Princeton, NJ: Princeton University Press.

Hardin, Russell (1996). "Trustworthiness." In: Ethics 107.1, pp. 26-42.

Hetherington, Marc J. (1998). "The political relevance of political trust." In: American Political Science Review 92.4, pp. 791-808.

Hill, Richard, Taylor, Gwendolyn, and Temin, Jonathan (2008). Would you fight again? Understanding Liberian ex-combatant reintegration. Washington, DC: United States Institute of Peace.

Hirshleifer, Jack (1991). "The technology of conflict as an economic activity." In: American Economic Review 81.2, pp. 130-134.

Hoffman, Aaron M. (2002). "A conceptualization of trust in international relations." In: European Journal of International Relations 8.3, pp. 375401.

Hoffman, Bruce (2004). Insurgency and Counterinsurgency in Iraq. Santa Monica, CA: RAND Corporation.

Holahan, Charles J., Moos, Rudolf H., Holahan, Carole K., Brennan, Penny L., and Schutte, Kathleen K. (2005). “Stress generation, avoidance cop- 
ing, and depressive symptoms: A 10-year model." In: Journal of Consulting and Clinical Psychology 73.4, pp. 658-666.

Holtz-Eakin, Douglas, Newey, Whitney, and Rosen, Harvey S. (1988). "Estimating vector autoregressions with panel data." In: Econometrica 55.6, pp. $1371-1395$.

Hughes, Geraint (2010). "The insurgencies in Iraq, 2003-2009: Origins, developments and prospects." In: Defence Studies 10.1, pp. 152-176.

Humphreys, Macartan and Weinstein, Jeremy M. (2007). “Demobilization and reintegration." In: Journal of Conflict Resolution 51.4, pp. 531-567.

Humphreys, Macartan and Weinstein, Jeremy M. (2008). "Who fights? The determinants of participation in civil war." In: American Journal of Political Science 52.2, pp. 436-455.

Hutchison, Marc L. and Johnson, Kristin (2011). "Capacity to trust? Institutional capacity, conflict, and political trust in Africa, 2000-2005." In: Journal of Peace Research 48.6, pp. 737-752.

Imai, Kosuke, Keele, Luke, Tingley, Dustin, and Yamamoto, Teppei (2011). "Unpacking the black box of causality: Learning about causal mechanisms from experimental and observational studies." In: American Political Science Review 105.4, pp. 765-789.

Jackson, Paul (2007). "Reshuffling an old deck of cards? The politics of local government reform in Sierra Leone." In: African Affairs 106.422, pp. 95-111.

Jahn, Beate (2007). "The tragedy of liberal diplomacy: Democratization, intervention, statebuilding (Part I)." In: Journal of Intervention and Statebuilding 1.1, pp. 87-106.

James, Harvey S. (2002). "The trust paradox: a survey of economic inquiries into the nature of trust and trustworthiness." In: Journal of Economic Behavior \& Organization 47.3, pp. 291-307.

Jenkins, Brian M. (1986). "Defense against terrorism." In: Political Science Quarterly 101.5, pp. 773-786. 
Jennings, Kathleen M. (2007). "The struggle to satisfy: DDR through the eyes of ex-combatants in Liberia." In: International Peacekeeping 14.2, pp. 204-218.

Joint Implementation Unit, (2003). DDRR Consolidated Report Phase 1, 2 \& 3. Monrovia: NCDDRR.

Jones, Karen (1996). “Trust as an affective attitude.” In: Ethics 107.1, pp. 425.

Juan, Alexander De and Pierskalla, Jan Henryk (2016). “Civil war violence and political trust: Microlevel evidence from Nepal." In: Conflict Management and Peace Science 33.1, pp. 67-88.

Kaldor, Mary (1999). New and Old Wars: Organized Violence in a Global Era. Stanford: Stanford University Press.

Kallert, Thomas W., Glöckner, Matthias, and Schützwohl, Matthias (2008). "Involuntary vs. voluntary hospital admission." In: European Archives of Psychiatry and Clinical Neuroscience 258.4, pp. 195-209.

Kaplan, Oliver and Nussio, Enzo (2015). "Community counts: The social reintegration of ex-combatants in Colombia." In: Conflict Management and Peace Science.

Kenworthy, Jared Bowden, Voci, Alberto, Al-Ramiah, Ananthi, Tausch, Nicole, Hughes, Joanne, and Hewstone, Miles (2016). "Building trust in a postconflict society: An integrative model of cross-group friendship and intergroup emotions." In: Journal of Conflict Resolution 6o.6, pp. 1041-1070.

Kilcullen, David (2006). "Counter-insurgency redux." In: Survival 48.4, pp. 111-130.

Kilroy, Walt (2015). Reintegration of Ex-Combatants After Conflict: Participatory Approaches in Sierra Leone and Liberia. New York: Palgrave Macmillan.

Kubiak, Sheryl Pimlott (2004). "The effects of PTSD on treatment adherence, drug relapse, and criminal recidivism in a sample of incar- 
cerated men and women." In: Research on Social Work Practice 14.6, pp. 424-433.

Labonte, Melissa T. (2012). "From patronage to peacebuilding? Elite capture and governance from below in Sierra Leone." In: African Affairs 111.442, pp. 90-115.

Lake, David (2010). "The practice and theory of US statebuilding." In: Journal of Intervention and Statebuilding 4.3, pp. 257-284.

LeSage, James and Pace, Robert Kelley (2009). Introduction to Spatial Econometrics. Boca Raton, FL: Chapman and Hall/CRC.

Lee, Deborah A., Scragg, Peter, and Turner, Stuart (2001). "The role of shame and guilt in traumatic events: A clinical model of shame-based and guilt-based PTSD." In: British Journal of Medical Psychology 74.4, pp. 451-466.

Lee, Lung-fei and Yu, Jihai (2010). "Estimation of spatial autoregressive panel data models with fixed effects." In: Journal of Econometrics 154.2, pp. $165-185$.

Leskela, Jennie, Dieperink, Michael, and Thuras, Paul (2002). "Shame and posttraumatic stress disorder." In: Journal of Traumatic Stress 15.3, pp. 223-226.

Levi, Margaret, Sacks, Audrey, and Tyler, Tom (2009). “Conceptualizing legitimacy, measuring legitimating beliefs." In: American Behavioral Scientist 53.3, pp. 354-375.

Levi, Margaret and Stoker, Laura (2000). "Political trust and trustworthiness." In: Annual Review of Political Science 3.1, pp. 475-507.

Levitt, Matthew (2008). Hamas: Politics, charity, and terrorism in the service of jihad. New Haven, CT: Yale University Press.

Lewis, J. David and Weigert, Andrew (1985). "Trust as a social reality." In: Social Forces 63.4, pp. 967-985.

Lindsay, Jon R. and Long, Austin G. (2013). "Correspondence: Assessing the synergy thesis in Iraq." In: International Security 37.4, pp. 181-189. 
Lindy, Jacob D., Grace, Mary C., and Green, Bonnie L. (1981). "Survivors: Outreach to a reluctant population." In: American Journal of Orthopsychiatry 51.3, pp. 468-478.

Long, Austin (2008). "The Anbar Awakening." In: Survival 50.2, pp. 67-94. Luca, Giacomo De and Verpoorten, Marijke (2015). "Civil war, social capital and resilience in Uganda." In: Oxford Economic Papers 67.3, pp. 661686.

Lyall, Jason (2010). "Are coethnics more effective counterinsurgents? Evidence from the Second Chechen War." In: American Political Science Review 104.1, pp. 1-20.

Lynch, Marc (2002). "Why engage? China and the logic of communicative engagement." In: European Journal of International Relations 8.2, pp. 187-230.

Lynch, Marc (2011). "Explaining the awakening: Engagement, publicity, and the transformation of Iraqi Sunni political attitudes." In: Security Studies 20.1, pp. 36-72.

Maconachie, Roy (2008). "New agricultural frontiers in post-conflict Sierra Leone? Exploring institutional challenges for wetland management in the Eastern Province." In: Journal of Modern African Studies 46.2, pp. 235-266.

Maedl, Anna, Schauer, Elisabeth, Odenwald, Michael, and Elbert, Thomas (2010). "Psychological rehabilitation of ex-combatants in non-western, post-conflict settings." In: Trauma Rehabilitation After War and Conflict. Ed. by Martz, Erin. Springer New York, pp. 177-213.

Malkasian, Carter (2006). "The role of perceptions and political reform in counterinsurgency: The case of western Iraq, 2004-05." In: Small Wars E Insurgencies 17.3, pp. 367-394.

Marten, Kimberly (2012). Warlords: Strong-arm Brokers in Weak States. Ithaca, NY: Cornell University Press. 
Martins, Mark (2004). “No small change of soldiering: The Commander's Emergency Response Program (CERP) in Iraq and Afghanistan." In: The Army Lawyer, pp. 1-20.

Martins, Mark (2005). "The Commander's Emergency Response Program." In: Joint Force Quarterly 37, pp. 46-52.

McAllister, Daniel J. (1995). "Affect- and cognition-based trust as foundations for interpersonal cooperation in organizations." In: The Academy of Management Journal 38.1, pp. 24-59.

McCartan, Lisa M., Masselli, Andrea, Rey, Michael, and Rusnak, Danielle (2008). "The logic of terrorist target choice: An examination of Chechen rebel bombings from 1997-2003." In: Studies in Conflict $\mathcal{E}$ Terrorism 31.1, pp. 60-79.

McCary, John A. (2009). "The Anbar Awakening: An alliance of incentives." In: The Washington Quarterly 32.1, pp. 43-59.

McCormick, Gordon H., Horton, Steven B., and Harrison, Lauren A. (2006). Things Fall Apart: The 'End Game' Dynamics of Internal Wars. Santa Monica, CA.

McFall, Miles, Fontana, Alan, Raskind, Murray, and Rosenheck, Robert (1999). "Analysis of violent behavior in Vietnam combat veteran psychiatric inpatients with posttraumatic stress disorder." In: Journal of Traumatic Stress 12.3, pp. 501-517.

McGillivray, Fiona and Smith, Alastair (2000). "Trust and cooperation through agent-specific punishments." In: International Organization 54.4, pp. 8o9-824.

McKay, Susan and Mazurana, Dyan (2004). Where Are the Girls? Girls in Fighting Forces in Northern Uganda, Sierra Leone, and Mozambique: Their Lives during and after War. Montreal: Rights \& Democracy.

McMullin, Jaremey R. (2013). "Integration or separation? The stigmatisation of ex-combatants after war." In: Review of International Studies 39.2 , pp. $385-414$. 
Menocal, Alina Rocha (2011). “State building for peace: A new paradigm for international engagement in post-conflict fragile states." In: Third World Quarterly 32.10, pp. 1715-1736.

Midlarsky, Manus I., Crenshaw, Martha, and Yoshida, Fumihiko (1980). "Why violence spreads: The contagion of international terrorism." In: International Studies Quarterly 24.2, pp. 262-298.

Mishler, William and Rose, Richard (2001). "What are the origins of political trust? Testing institutional and cultural theories in post-communist societies." In: Comparative Political Studies 34.1, pp. 30-62.

Nannestad, Peter (2008). "What have we learned about generalized trust, if anything?" In: Annual Review of Political Science 11.1, pp. 413-436.

Narang, Neil (2014). "Humanitarian assistance and the duration of peace after civil war." In: Journal of Politics 76.2, pp. 446-460.

Narang, Neil (2015). "Assisting uncertainty: How Hhmanitarian aid can inadvertently prolong civil war." In: International Studies Quarterly 59.1, pp. 184-195.

Nichols, Ryan (2005). "Disarming Liberia: Progress and pitfalls." In: Armed and Aimless: Armed Groups, Guns, and Human Security in the ECOWAS Region. Ed. by Florquin, Nicolas and Berman, Eric G. Geneva: A Small Arms Survey, pp. 108-143.

Nickell, Stephen (1981). “Biases in dynamic models with fixed effects." In: Econometrica 49.6, pp. 1417-1426.

Nielsen, Richard A., Findley, Michael G., Davis, Zachary S., Candland, Tara, and Nielson, Daniel L. (2011). "Foreign aid shocks as a cause of violent armed conflict." In: American Journal of Political Science 55.2, pp. 219-232.

Nunn, Nathan and Qian, Nancy (2014). "US food aid and civil conflict." In: American Economic Review 104.6, pp. 1630-1666.

Nussio, Enzo (2011). "How ex-combatants talk about personal security. Narratives of former paramilitaries in Colombia." In: Conflict, Security $\mathcal{E}$ Development 11.5, pp. 579-606. 
Ord, Keith (1975). "Estimation methods for models of spatial interaction." In: Journal of the American Statistical Association 70.349, pp. 120-126.

Owens, Patricia (2013). "From Bismarck to Petraeus: The question of the social and the social question in counterinsurgency." In: European Journal of International Relations 19.1, pp. 139-161.

Paes, Wolf-Christian (2005). "The challenges of disarmament, demobilization and reintegration in Liberia." In: International Peacekeeping 12.2, pp. 253-261.

Pettigrew, Thomas F. (1998). "Intergroup contact theory." In: Annual Review of Psychology 49.1, pp. 65-85.

Pettigrew, Thomas F. and Tropp, Linda R. (2006). "A meta-analytic test of intergroup contact theory." In: Journal of Personality and Social Psychology 90.5, pp. 751-783.

Pettigrew, Thomas F. and Tropp, Linda R. (2008). "How does intergroup contact reduce prejudice? Meta-analytic tests of three mediators." In: European Journal of Social Psychology 38.6, pp. 922-934.

Podder, Sukanya (2012). "From recruitment to reintegration: Communities and ex-combatants in post-conflict Liberia." In: International Peacekeeping 19.2, pp. 186-202.

Porch, Douglas (2013). Counterinsurgency: Exposing the myths of the new way of war. Cambridge University Press.

Pugel, James (2007). What the fighters say: A survey of ex-combatants in Liberia. United Nations Development Programme.

Pugel, James (2009). "Measuring reintegration in Liberia." In: Security and Post-Conflict Reconstruction: Dealing with Fighters in the Aftermath of War. Ed. by Muggah, Robert. London: Routledge, pp. 70-102.

Putnam, Robert D. (1993). Making Democracy Work: Civic Traditions in Modern Italy. Princeton, NJ: Princeton University Press.

Rangwala, Glen (2009). "Counter-insurgency amid fragmentation: The British in southern Iraq." In: Journal of Strategic Studies 32.3, pp. 495513. 
Richman, Laura Smart and Leary, Mark R. (2009). "Reactions to discrimination, stigmatization, ostracism, and other forms of interpersonal rejection: A multimotive model." In: Psychological Review 116.2, pp. 365383.

Rivers, Douglas and Vuong, Quang H. (1988). "Limited information estimators and exogeneity tests for simultaneous probit models." In: Journal of Econometrics 39.3, pp. 347-366.

Rohner, Dominic, Thoenig, Mathias, and Zilibotti, Fabrizio (2013). "Seeds of distrust: Conflict in Uganda." In: Journal of Economic Growth 18.3, pp. 217-252.

Romano, David, Calfano, Brian, and Phelps, Robert (2015). "Successful and less successful interventions: Stabilizing Iraq and Afghanistan." In: International Studies Perspectives 16.4, pp. 388-405.

Roodman, David (2009). "How to do xtabond2: An introduction to difference and system GMM in Stata." In: Stata Journal 9.1, pp. 86-136.

Ross, Michael L. (2004). "What do we know about natural resources and civil war?" In: Journal of Peace Research 41.3, pp. 337-356.

Rothstein, Bo (2000). "Trust, social dilemmas and collective memories." In: Journal of Theoretical Politics 12.4, pp. 477-501.

Rothstein, Bo (2009). "Creating political legitimacy: Electoral democracy versus quality of government." In: American Behavioral Scientist 53.3, pp. 311-330.

Ruokonen, Floora (2013). "Trust, trustworthiness, and responsibilities." In: Trust: Analytic and Applied Perspectives. Ed. by Makela, Pekka and Townley, Cynthia. New York: Rodopi, pp. 1-14.

SIGIR (2012). SIGIR Special Report Number 1: Reconstruction Leaders' Perception of the Commander's Emergency Response Program in Iraq. Arlington, VA: SIGIR.

Sacks, Audrey and Larizza, Marco (2012). "Why quality matters: Rebuilding trustworthy local government in post-conflict Sierra Leone." Policy Research Working Paper 6021, Washington, DC: World Bank. 
Saunders, Stephen M., Zygowicz, Karen M., and D'Angelo, Benjamin R. (2006). "Person-related and treatment-related barriers to alcohol treatment." In: Journal of Substance Abuse Treatment 30.3, pp. 261-270.

Savun, Burcu and Tirone, Daniel C. (2012). "Exogenous shocks, foreign aid, and civil war." In: International Organization 66.3, pp. 363-393.

Seed, Tara, Fox, John R. E., and Berry, Katherine (2016). “The experience of involuntary detention in acute psychiatric care. A review and synthesis of qualitative studies." In: International Journal of Nursing Studies 61, pp. 82-94.

Shelton, J. Nicole and Richeson, Jennifer A. (2006). "Interracial interactions: A relational approach." In: Advances in Experimental Social Psychology 38, pp. 121-181.

Singer, Mel (2004). "Shame, guilt, self-hatred and remorse in the psychotherapy of Vietnam combat veterans who committed atrocities." In: American Journal of Psychotherapy 58.4, pp. 377-385.

Sky, Emma (2011). "Iraq, from surge to sovereignty: Winding down the war in Iraq." In: Foreign Affairs 90.2, pp. 117-127.

Sollenberg, Mararet (2012). "A Scramble for Rents: Foreign Aid and Armed Conflict." PhD Dissertation, Uppsala University.

Staiger, Douglas and Stock, James H. (1997). "Instrumental variables regression with weak instruments." In: Econometrica 65.3, pp. 557-586.

Stecker, Tracy, Shiner, Brian, Watts, Bradley V., Jones, Meissa, and Conner, Kenneth R. (2013). "Treatment-seeking barriers for veterans of the Iraq and Afghanistan conflicts who screen positive for PTSD." In: Psychiatric Services 64.3, pp. 280-283.

Steenbergen, Marco R. and Jones, Bradford S. (2002). "Modeling multilevel data structures." In: American Journal of Political Science 46.1, pp. 218-237.

Stoyan, Alissandra T., Niedzwiecki, Sara, Morgan, Jana, Hartlyn, Jonathan, and Espinal, Rosario (2016). "Trust in government institutions: The 
effects of performance and participation in the Dominican Republic and Haiti." In: International Political Science Review 37.1, pp. 18-35.

Strauss, John and Thomas, Duncan (1995). "Human resources: Empirical modeling of household and family decisions." In: Handbook of Development Economics. Ed. by Behrman, Jere and Srinivasan, T N. Vol. 3A. Amsterdam: North-Holland, pp. 1883-2023.

Tangney, June P., Stuewig, Jeffrey, and Martinez, Andres G. (2014). “Two faces of shame: The roles of shame and guilt in predicting recidivism." In: Psychological Science 25.3, pp. 799-805.

Tangney, June P., Miller, Rowland S., Flicker, Laura, and Barlow, Deborah Hill (1996). "Are shame, guilt, and embarrassment distinct emotions?" In: Journal of Personality and Social Psychology 70.6, pp. 12561269.

Tangney, June Price and Dearing, Ronda L. (2002). Shame and Guilt. New York: Guilford Press.

Touchton, Michael (2016). "Campaigning for capital: Fair elections and foreign investment in comparative perspective." In: International Interactions 42.2, pp. 271-294.

US Department of Army (2006). Field Manual 3-24: Counterinsurgency. Washington, DC: US Department of Army and US Marine Corps.

US Department of Defense (2012). Security Assistance Management Manual. URL: http : //Www. samm. dsca.mil/table/table-c15t2\#ISFF (visited on 09/07/2016).

US Department of Defense, (2007). Measuring stability and security in Iraq March 2007. Washington, DC: U.S. Department of Defense.

US Department of Defense, (2008). Measuring stability and security in Iraq March 2008. Washington, DC: U.S. Department of Defense.

US Department of State (2006). Rebuilding Iraq: U.S. Achievements Through the Iraq Relief and Reconstruction Fund. uRL: http : //2001-2009. state. gov/p/nea/rls/rpt/60857. htm (visited on 09/o7/2016). 
US Department of State (2010). Economic Support Fund. URL: http : / / Www . state .gov/documents / organization / 101425 . pdf (visited on 09/07/2016).

United Nations Department of Peacekeeping Operations (2010a). DDR in Peace Operations: A Retrospective. New York: United Nations.

United Nations Department of Peacekeeping Operations (2010b). Second Generation Disarmament, Demobilization and Reintegration (DDR) Practices in Peace Operations. New York: United Nations.

Vangelisti, Anita L., Young, Stacy L., Carpenter-Theune, Katy E., and Alexander, Alicia L. (2005). "Why does It hurt? The perceived causes of hurt feelings." In: Communication Research 32.4, pp. 443-477.

Walter, Barbara F. (1997). "The critical barrier to civil war settlement." In: International Organization 51.3, pp. 335-364.

Walter, Barbara F. (1999). "Designing transitions from civil war: Demobilization, democratization, and commitments to peace." In: International Security 24.1, pp. 127-155.

Walter, Barbara F. (2004). "Does conflict beget conflict? Explaining recurring civil war." In: Journal of Peace Research 41.3, pp. 371-388.

Whitener, Ellen M., Brodt, Susan E., Korsgaard, M. Audrey, and Werner, Jon M. (1998). "Managers as initiators of trust: An exchange relationship framework for understanding managerial trustworthy behavior." In: The Academy of Management Review 23.3, pp. 513-530.

Wong, Martin R. and Cook, David (1992). "Shame and its contribution to PTSD." In: Journal of Traumatic Stress 5.4, pp. 557-562.

Wong, Pui-Hang (2014). "Insurgents in motion: Counterinsurgency and insurgency relocation in Iraq." UNU-MERIT Working Paper 2014-045. Wong, Pui-Hang (2016). "How can political trust be built after civil wars? Evidence from post-conflict Sierra Leone." In: Journal of Peace Research 53.6, pp. 772-785. 
Wong, Pui-Hang (2017a). "Explaining dropout from reintegration programme in Liberia." Paper prepared for the Research School on Peace and Conflict Symposium, Oslo, 20-21 April, 2017.

Wong, Pui-Hang (2017b). "How development aid explains (or not) the rise and fall of insurgent attacks in Iraq." UNU-MERIT Working Paper 2017-006.

Wood, Elisabeth Jean (2013). “Transnational dynamics of civil war: Where do we go from here?" In: Transnational Dynamics of Civil War. Ed. by Checkel, Jeffrey T. New York: Cambridge University Press, pp. 231258.

Wood, Reed M. and Sullivan, Christopher (2015). "Doing harm by doing good? The negative externalities of humanitarian aid provision during civil conflict." In: Journal of Politics 77-3, pp. 736-748.

Wooldridge, Jeffrey M (2010). Econometric Analysis of Cross Section and Panel Data. Cambridge, MA: MIT Press.

$\mathrm{Yu}$, Jihai, de Jong, Robert, and Lee, Lung-fei (2008). “Quasi-maximum likelihood estimators for spatial dynamic panel data with fixed effects when both $n$ and T are large." In: Journal of Econometrics 146.1, pp. 118134.

Zeidner, Moshe and Saklofske, Donald (1996). "Adaptive and maladaptive coping." In: Handbook of Coping: Theory, Research, Applications. Ed. by Zeidner, M. and Endler, N. S. New York: John Wiley \& Sons, pp. 505-531.

de Ree, Joppe and Nillesen, Eleonora (2009). “Aiding violence or peace? The impact of foreign aid on the risk of civil conflict in sub-Saharan Africa." In: Journal of Development Economics 88.2, pp. 301-313.

de Vries, Hugo and Wiegink, Nikkie (2011). "Breaking up and going home? Contesting two assumptions in the demobilization and reintegration of former combatants." In: International Peacekeeping 18.1, pp. $38-51$. 
van Vliet, K. Jessica (2010). "Shame and avoidance in trauma." In: Trauma Rehabilitation After War and Conflict. Ed. by Martz, Erin. Springer New York, pp. 247-263.

van de Ven, Wynand P. M. M. and Van Praag, Bernard M. S. (1981). “The demand for deductibles in private health insurance." In: Journal of Econometrics 17.2, pp. 229-252. 

Pui Hang Wong obtained his Bachelor's degree in economics from Monash University, Australia and his Master's degrees in economics from the University of Essex, UK, and the Chinese University of Hong Kong. Before joining the Maastricht Graduate School of Governance, now part of UNUMERIT, as a PhD fellow, he worked at the Aviation Policy and Research Center at the Chinese University of Hong Kong. In Maastricht, he taught public economics at the School of Governance, as well as introductory economics and international relations at the Faculty of Arts and Social Sciences of Maastricht University. He has been a visiting researcher at the Peace Research Institute Oslo (PRIO). His research interests include conflict, security and development, peacekeeping, and applied econometrics. His research appears in the Journal of Peace Research. 


\section{UNU-MERIT/MGSOG DISSERTATION SERIES}

2017

188. Brenda Yamba

Schooling Despite All Odds: Evidence from Lesotho on Female Child Carers who Stayed in School

\section{Sheng Zhong}

Moving Towards an Energy Efficient Future: Essays on Energy Efficiency, Technology and Development

\section{Julieta Marotta}

Access to Justice and Legal Empowerment of Victims of Domestic Violence through Legal Organisations in the City of Buenos Aires: A Qualitative Empirical Legal Study

\section{Andrea Franco-Correa}

On the Measurement of Multidimensional Poverty as a Policy Tool: Empirical Applications to Chile, Colombia, Ecuador and Peru

\section{6}

Yesuf Awel. UNU-MERIT No. 108

Insurance for Growth: Empirical Essays on Insurance Demand and Impacts in Africa

Tigist Mekonnen Melesse. UNU-MERIT No. 107

Grow More Food using Fewer Resources: Agricultural Technology Adoption and Innovation Practices for Inclusive and Sustainable Development

\section{Eleni Yitbarek. UNU-MERIT No. 106}

Getting Ahead or left Behind? Essays on Poverty Dynamics and Social Mobility in Africa

Thuy Dieu Nguyen. UNU-MERIT No. 105

Firm-Level Theory and Evidence of Corruption

Raquel Tsukada Lehman. UNU-MERIT No. 104

Essays on Household Production with Labor-Saving Technology

\section{Eva Barteková. UNU-MERIT No. 103}

Multi-Problem Challenges for a Renewable Future: Empirical Studies on Competitive: Disadvantages from Electricity Price Differentials and Mineral Supply Risk in an Open Economy

Jocelyn Olivari. UNU-MERIT No. 102

Entrepreneurial Traits and Innovation: Evidence from Chile

Muhammad Shafique. UNU-MERIT No. 101

Essays on the role of knowledge, R\&D, and Technology-based

Firms in the Evolution of Sociotechno-economic System

\section{Serdar Türkeli. UNU-MERIT No. 100}

Governance of Innovation Policy: Empirical Studies on Applied Political Economy by Multi-Methods Analysis

Ayokunu Adedokun. MGSoG No. 75

Pathways to Sustainable Peacebuilding in Divided Societies: Lessons and Experiences from Mozambique

Luiz Rothier Bautzer. MGSoG No. 74

Organizing Concurrent Engineering through ICT Platforms: Blueprinting Product Lifecycle Management Platforms across Disciplinary Agencies

\section{Natalia Popova. MGSoG No. 73}

Migration in the Periphery of the European Union: Determinants of Successful and Sustainable Labour Market Integration of Return Migrants in Albania, Egypt, Moldova and Tunisia

Richard A. Martina. MGSoG No. 72

Uncertainty and Resource Constraint in the Small Island Developing States: Essays in Entrepreneurial Cognition

\section{Cécile Cherrier. MGSoG No. 71}

The Expansion of Basic Social Protection in Low-income Countries: An Analysis of Foreign Aid Actors' Role in the Emergence of Social Transfers in Sub-Saharan Africa

\section{Paul Caldron. MGSoG No. 70}

The Tacit Bargain in Short-Term Medical Missions: Why U.S Physicians Go and What it Costs

\section{Mahmut Kobal. MGSoG No. 69}

Customs \& Excellence: A Comparative Approach on Administrative and Regulatory Compliance Perspectives of the EU-Turkey Customs Union

Craig Loschmann. MGSoG No. 68

Essays on Conflict-related Migration and Development in the Case of Afghanistan

\section{Andrea Milan. MGSoG No. 67}

Rural Livelihoods, Location and Vulnerable Environments: Approaches to Migration in Mountain areas of Latin America

\section{Farida Lada. MGSoG No. 66}

On Guarding the Welfare of Clinical Trial Subjects While Promoting Novel Drug Innovation: A Game Theoretical Approach

\section{5}

Hibret Belete Maemir. UNU-MERIT No. 96

Dissecting Aggregate Productivity: International Integration and Growth with Heterogeneous Firms 
Giorgio Triulzi. UNU-MERIT No. 95

Looking for the Right Path: Technology Dynamics, Inventive Strategies and Catching-up in the Semiconductor Industry

\section{Abdul Baseer Qazi. UNU-MERIT No. 94}

Knowledge flows and networks in the ICT sector: The Case of Pakistan

\section{Ajay Thutupalli. UNU-MERIT No. 93}

Technology Paradigm Shifts in Agriculture: Drivers of Sustainability and Catch up

\section{Eduardo Urias. UNU-MERIT No. 92}

Improving access to HIV/AIDS treatment in Brazil: When are Compulsory Licenses Effective in Price Negotiations?

\section{Francesca Guadagno. UNU-MERIT No. 91}

Why Have so Few Countries Industrialised?

\section{Daniel Opolot. UNU-MERIT No. 90}

The Evolution of Beliefs and Strategic Behaviour

\section{Alejandro Lavopa. UNU-MERIT No. 89}

Structural Transformation and Economic Development: Can Development Traps be Avoided

\section{Jinjin Zhao. UNU-MERIT No. 88}

Urban Water Management Reform: The Case of China

\section{Simona Vezzoli. MGSoG No. 65}

Borders, Independence and Post-colonial Ties: the Role of the State in Caribbean Migration

\section{Silvia Consuelo Gómez Soler. MGSoG No. 64}

Civil Conflict and Education: How Does Exposure to Civil Conflict Affect Human Capital Accumulation? Evidence from Standardized Exit Exams in Colombia

\section{Paula Nagler. MGSoG No. 63}

Occupational Choice in the Developing World

\section{Jasmin Kientzel. MGSoG No. 62}

Determinants of Professional Commitment to Environmental Sustainability

\section{Mehmet Güney Celbiş. MGSoG No. 61}

Regional Policies: Convergence, Trade, and the Allocation of Public Capital

\section{Florian Henning. MGSoG No. 60}

Living Up to Standard: Interoperability Governance and Standards Adoption in Government Information Networks

\section{Niels P. Groen. MGSoG No. 59}

The Never-Ending Project: Understanding E-Government Project Escalation

\section{Derek Copp. MGSoG No. $5^{8}$}

Teacher-Based Reactivity to Provincial Large-scale Assessment in Canada

\section{Michaella Vanore. MGSoG No. 57}

Family-Member Migration and the Psychosocial Health Outcomes of Children in Moldova and Georgia

Sonja Fransen. MGSoG No. 56

The Economic and Social Effects of Remittances and Return Migration in Conflict-Affected Areas: The Case of Burundi

\section{Ibrahim Khalil Conteh. MGSoG No. 55}

The Impact of Floods on Primary School Education in Zambia

\section{Richard Bluhm. MGSoG No. 54}

Growth Dynamics and Development: Essays in Applied Econometrics and Political Economy

\section{Nevena P. Zhelyazkova. MGSoG No. 53}

Work-Family Reconciliation and Use of Parental Leave in Luxembourg: Empirical Analysis of Administrative Records

\section{4}

\section{Dirk Crass. UNU-MERIT No. 87}

The Impact of Brands on Innovation and Firm Performance: Empirical Evidence from Germany

\section{Samyukta Bhupatiraju. UNU-MERIT No. 86}

The Geographic Dimensions of Growth and Development

\section{François Lafond. UNU-MERIT No. 85}

The Evolution of Knowledge Systems

\section{Annalisa Primi. UNU-MERIT No. 84}

Promoting Innovation in Latin America: What Countries Have Learned (and What They Have Not) in Designing and Implementing Innovation and Intellectual Property Policies

Fatoumata Lamarana Diallo. UNU-MERIT No. 83 Evaluation of Meal and Deworming Programs for Primary Schools in Rural Senegal

Sachin Kumar Badkas. MGSoG No. 52

Metachoice and Metadata: Innovating with Environmental Policy Analysis in Europe

\section{Irina S. Burlacu. MGSoG No. $5^{1}$}

An Evaluation of Tax-Benefit Systems Impact on the Welfare of Frontier Worker: The Case of Luxembourg and Belgium

\section{Özge Bilgili. MGSoG No. 50}

Simultaneity in Transnational Migration Research: Links Between Migrants' Host and Home Country Orientation 
Yulia Privalova Krieger. MGSoG No. 49

Reshaping the Big Agenda: Transnational Politics and Domestic Resistance Financial Crisis and Social Protection Reform in Bosnia and Herzegovina

\section{Marieke van Houte. MGSoG No. 48}

Moving Back or Moving Forward? Return Migration after Conflict

\section{Oxana Slobozhan. MGSoG No. 47}

Global Governance in the Management of Natural Resources: The Case of the Extractive Industries Transparency Initiative (EITI)

Luis Bernardo Mejia Guinand. MGSoG No. 46

The Changing Role of the Central Planning Offices in Latin America: A Comparative Historical Analysis Perspective (1950-2013)

\section{Cheng Boon Ong. MGSoG No. 45}

Ethnic Segregation in Housing, Schools and Neighbourhoods in the Netherlands

Luciana V. Cingolani. MGSoG No. 44

Bureaucracies for Development: Oxymoron or Reality? Studies on State Capacity in Challenging Governance Contexts

Carlos Cadena Gaitán. MGSoG No. 43

Green Politics in Latin American Cities - Sustainable Transport Agendas

Katie Kuschminder. MGSoG No. 42

Female Return Migration and Reintegration Strategies in Ethiopia

Metka Hercog. MGSoG No. 41

Highly-Skilled Migration and New Destination Countries

Margaret Agaba Rugadya. MGSoG No. 40

Can Remittances Influence the Tenure and Quality of Housing in Uganda?

Ilire Agimi. MGSoG No. 39

New Governance Under Limited Statehood: The Case of Local Government Reform in Kosovo

\section{3}

Anant Kamath. UNU-MERIT No. 82

Information Sharing through Informal Interaction in Low-Tech Clusters

Flavia Pereira de Carvalho. UNU-MERIT No. 81

What we talk about when we talk about Brazilian Multinationals: An Investigation on Brazilian FDI, Economic Structure, Innovation and the Relationship between them

\section{Jun Hou. UNU-MERIT No. 80}

Complementarity in Innovation and Development: A Crosscountry Comparison
Rufin Baghana. UNU-MERIT No. 79

Impacts of Government Incentives to R\&D, Innovation and Productivity: A Microeconometric Analysis of the Québec Case

\section{Lilia I. Stubrin. UNU-MERIT No. 78}

High-Tech Activities in Emerging Countries: A Network Perspective on the Argentinean Biotech Activity

\section{Kristine Farla. MGSoG No. 38}

Empirical Studies on Institutions, Policies and Economic Development

\section{Marina Petrovic. MGSoG No. 37}

Social Assistance and Activation in the Pursuit of Happiness: Shedding New Light on Old Policy Solutions to Social Exclusion

Laura Torvinen. MGSoG No. 36

Assessing Governance Assessments: The Case of Mozambique: Governance Assessments in the Context of Aid Effectiveness Discourse

\section{Biniam Egu Bedasso. MGSoG No. 35}

Institutional Change in the Long Shadow of Elite: Essays on Institutions, Human Capital and Ethnicity in Developing Countries

Sepideh Yousefzadeh Faal Deghati. MGSoG No. 34

Childhoods Embargoed: Constructing and Reconstructing Multidimensional Child Poverty in Iran 1984-2009

Robert Bauchmüller. MGSoG No. 33

Investing in Early Childhood Care and Education: The Impact of Quality on Inequality

Martin Rehm. MGSoG No. 32

Unified Yet Separated: Empirical Study on the Impact of Hierarchical Positions within Communities of Learning

\section{2}

Abdul Waheed. UNU-MERIT No. 77

Innovation Determinants and Innovation as a Determinant: Evidence from Developing Countries

Bilal Mirza. UNU-MERIT No. 76

Energy Poverty and Rural Energy Markets in Pakistan

Benjamin Engelstätter. UNU-MERIT No. 75

Enterprise Software and Video Games: An Empirical Analysis

\section{Fulvia Farinelli. UNU-MERIT}

Natural Resources, Innovation and Export Growth: The Wine Industry in Chili and Argentina

\section{Rodolfo Lauterbach. UNU-MERIT}

Innovation in Manufacturing: From Product Variety and Labor Productivity Growth to Economic Development in Chile 
Kirsten Wiebe. UNU-MERIT No. 74

Quantitative Assessment of Sustainable Development and Growth in Sub-Saharan Africa

Julio Miguel Rosa. UNU-MERIT No. 73

Organizational Strategies, Firms' Performance and Spatial Spillovers: The Canadian Case in Research and Development

\section{Johannes Wilhelmus Marie Boels. UNU-MERIT}

Joseph Schumpeter, Honderd Jaar Economische Ontwikkeling: Een Historisch-theoretische Beschouwing. UNU-MERIT Dissertation Series

\section{Dorcas Mbuvi. MGSoG No. 31}

Utility Reforms and Performance of the Urban Water Sector in Africa

\section{Lina Salanauskaite. MGSoG No. 30}

Distributional Impacts of Public Policies: Essays in Ex-Ante and Ex-Post Evaluation

\section{Esther Schüring. MGSoG No. 29}

To Condition or Not - Is that the Question? An Analysis of the Effectiveness of Ex-Ante and Ex-Post Conditionality in Social Cash Transfer Programs

\section{Joe Abah. MGSoG No. 28}

Strong Organisations in Weak States: Atypical Public Sector Performance in Dysfunctional Environments

\section{Zina Samih Nimeh. MGSoG No. 27}

Social Citizenship Rights: Inequality and Exclusion

\section{1}

\section{Daniel Vertesy. UNU-MERIT No. 72}

Interrupted Innovation: Emerging Economies in the Structure of the Global Aerospace Industry

\section{Tina Saebi. UNU-MERIT No. 71}

Successfully Managing Alliance Portfolios: An Alliance Capability View

\section{Nora Engel. UNU-MERIT No. $7^{0}$}

Tuberculosis in India: A Case of Innovation and Control

\section{Evans Mupela. UNU-MERIT No. 69}

Connectivity and Growth in Sub-Saharan Africa: The Role of Communication Satellites

\section{Nantawan Kwanjai. UNU-MERIT No. 68}

Cross Cultural Intelligence amid Intricate Cultural Webs: A Tale of the UnDutchables in the Land of 1002 Smile

\section{Lina Sonne. UNU-MERIT No. 67}

Innovation in Finance to Finance Innovation: Supporting ProPoor Entrepreneur-Based Innovation
Lenka Eisenhamerová. MGSoG No. 26

Legitimacy of 'Humanitarian Military Intervention'

Sonila Tomini. MGSoG No. 25

Informal Payments for Health Care Services in Albania

\section{Jinjing Li. MGSoG No. 24}

Dynamic Microsimulation in Public Policy Evaluation

\section{Aziz Atamanov. MGSoG No. 23}

Rural Nonfarm Employment and International Migration as $\mathrm{Al}-$ ternatives to Agricultural Employment: The Case of Kyrgyzstan

Frieda Vandeninden. MGSoG No. 22

Poverty Alleviation: Aid and Social Pensions

Juliana Nyasha Tirivayi. MGSoG No. 21

The Welfare Effects of Integrating AIDS Treatment with Food Transfers: Evidence from Zambia

Agnieska Ewa Sowa. MGSoG No. 20

Who's Left Behind? Social Dimensions of Health Transition and Utilization of Medical Care in Poland

Emmanaouil Sfakianakis. MGSoG No. 19

The Role of Private Actors in the Provision of Public Goods with Applications to Infrastructure and Financial Stability

\section{Siu Hing Lo. MGSoG No. 18}

White Collars Green Sleeves: An Inter-organizational Comparison of Determinants of Energy-Related Behaviors among Office Workers

Treena Wu. MGSoG No. 17

Constraints to Human Capital Investment in Developing Countries: Using the Asian Financial Crisis in Indonesia as a Natural Experiment

HeNo. y Espinoza Peña. MGSoG No. 16 Impact Evaluation of a Job-Training Programme for Disadvantaged Youths: The Case of Projoven

2010

Fernando Santiago. UNU-MERIT No. 66

Human Resources Management Practices and Learning for Innovation in Developing Countries: Pharmaceutical Firms in Mexico

\section{Zakaria Babutsidze. UNU-MERIT No. 65}

Essays on Economies with Heterogeneous Interacting Consumers

\section{Bertha Vallejo. UNU-MERIT No. 64}

Learning and Innovation Under Changing Market Conditions: The Auto Parts Industry in Mexico

\section{Donatus Ayitey. UNU-MERIT No. 63}

Technical Change, Competitiveness and Poverty Reduction: A Study of the Ghanaian Apparel Industry 
Sergey Fillipov. UNU-MERIT No. 62

Multinational Subsidiary Evolution: Corporate Change in New EU Member States

\section{Asel Doranova. UNU-MERIT No. 61}

Technology Transfer and Learning under the Kyoto Regime: Exploring the Technological Impact of CDM Projects in Developing Countries

Florian Tomini. MGSoG No. 15

Between Family and Friend: Understanding the Interdependency of Private Transfers

\section{Michał Polalowski. MGSoG No. 14}

The Institutional Transformation of Social Policy in East Central Europe: Poland and Hungary in Comparative and Historical Perspective

\section{Maha Ahmed. MGSoG No. 13}

Defining, Measuring and Addressing Vulnerability: The Case of Post Conflict Environments

\section{Pascal Beckers. MGSoG No. 12}

Local Space and Economic Success: The Role of Spatial Segregation of Migrants in the Netherlands

\section{Victor Cebotari. MGSoG No. 11}

Conflicting Demands in Ethnically Diverse Societies: Ethnopolitical Contention and Identity Values in Europe

Dennis Gyllensporre. MGSoG No. 10

Competing and Complementary Perspectives on the EU as a Crisis Management Actor: An Examination of the Common Security and Defence Policy through the Lenses of Idealism and Realism

Judit Vall Castello. MGSoG No. 9

Business Cycle and Policy Effects on Labour Market Transitions of Older and Disabled Workers in Spain

Keetie Roelen. MGSoG No. 8

False Positives or Hidden Dimensions: The Definition and Measurement of Child Poverty

Denisa Maria Sologon. MGSoG No. 7

Earning Dynamics in Europe

Melissa Siegel. MGSoG No. 6

Money and Mobility: Migration and Remittances

Jessica S. Hagen-Zanker. MGSoG No. 5

Modest Expectations: Causes and Effects of Migration on Migrant Households in Source Countries

\section{9}

Alexis Habiyaremye. UNU-MERIT No. 60

From Primary Commodity Dependence to Diversification and Growth: Absorptive Capacity and Technological Catch Up in Botswana and Mauritius
Yoseph Getachew. UNU-MERIT No. 59

The Role of Public Capital in Economic Development

Sandra Leitner. UNU-MERIT No. 58

Embodied Technological Change and Patterns of Investment in Austrian Manufacturing

Semih Akçomak. UNU-MERIT No. 57

The Impact of Social Capital on Economic and Social Outcomes

Abraham Garcia. UNU-MERIT No. 56

The Role of Demand in Technical Change

Saurabh Arora. UNU-MERIT No. 55

Coherence in Socio-technical Systems: A Network Perspective on the Innovation Process

Mirtha R. Muniz Castillo. MGSoG No. 4

Human Development and Autonomy in Project Aid: Experiences from Four Bilateral Projects in Nicaragua and El Salvador

Christiane Arndt. MGSoG No. 3

Governance Indicators

Britta Augsburg. MGSoG No. 2

Microfinance: Greater Good or Lesser Evil?

2008

Rutger Daems. UNU-MERIT No. 54

Medicines for the Developing World

Johannes Hanel. UNU-MERIT No. 53

Assessing Induced Technology: Sombart's Understanding of Technical Change in the History of Economics

Rifka Weehuizen. UNU-MERIT No. 52

Mental Capital: the Economic Significance of Mental Health

Danielle Cloodt. UNU-MERIT No. 51

The Relationship between R\&D Partnership Formation, Social Embeddedness and Innovative Performance

Sabine Fuss. UNU-MERIT No. $5^{\circ}$

Sustainable Energy Development under Uncertainty

Geranda Notten. MGSoG No. 1

Measuring and Managing Poverty Risks

2007

Tobias Kronenberg. UNU-MERIT No. 49

Reconciling Environmental Conservation with Economic Prosperity: The Feasibility of Double Dividends in the Short and Long Run

\section{Viktoria Kravtsova. UNU-MERIT No. 48}

Assessing the Impact of Foreign Direct Investment in Transition Economies 
Suhail Sultan. UNU-MERIT No. 47

The Competitive Advantage of Small and Medium Sized Enterprises: The Case of Jordan's Natural Stone Industry

2006

Bulat Sanditov. UNU-MERIT No. 46

Essays on Social Learning and Imitation

Mamata Parhi. UNU-MERIT No. 45

Dynamics of New Technology Diffusion: A Study of the Indian Automotive Industry

Andreas Reinstaller. UNU-MERIT No. 44

Social Structures and the Innovation Process: Their Role in the Demand of Firms and Consumers

Rose Kiggundu. UNU-MERIT No. 43

Innovation Systems and Development: The Journey of a Beleaguered Nile Perch Fishery in Uganda

\section{Thomas Pogue. UNU-MERIT No. 42}

The Evolution of Research Collaboration in South African Gold Mining: 1886-1933

\section{Geoffrey Gachino. UNU-MERIT No. $4^{1}$}

Foreign Direct Investment, Spillovers and Innovation: The Case of Kenyan Manufacturing Industry

\section{Önder Nomaler. UNU-MERIT No. 40}

Technological Change, International Trade and Growth: An Evolutionary, Multi-Agents-Based Modeling Approach

\section{5}

Samia Satti Osman Mohamed-Nour. UNU-MERIT No. 39 Change and Skill Development in the Arab Gulf Countries

\section{Elad Harison. UNU-MERIT No. 38}

Intellectual Property Rights: Economics and Policy Analysis

\section{Daniel Dalohoun. UNU-MERIT No. 37}

The Relationship between R\&D Partnership Formation, Social Embeddedness and Innovative Performance: a Multi-Level Approach of Social Embeddedness

\section{Müge Ozman. UNU-MERIT No. 36}

Networks, Organizations and Knowledge

Bas Straathof. UNU-MERIT No. 35

Product Variety and Economic Growth: The Counteracting Effects of Scale and Idiosyncrasy

\section{Wilfred Schoenmakers. UNU-MERIT No. 34}

Knowledge Flows between Multinational Companies: A Patent Data Analysis
Myriam Cloodt. UNU-MERIT No. 33

Mergers and Acquisitions ( $\mathrm{M}$ and As) in High-Tech Industries: Measuring the Post-M and A Innovative Performance of Companies

\section{4}

Paola Criscuolo. UNU-MERIT No. 32

R\&D Internationalisation and Knowledge Transfer: Impact on MNEs and their Home Countries

\section{Maarten Verkerk. UNU-MERIT No. 31}

Trust and Power on the Shop Floor

\section{Gottfried Leibbrandt. UNU-MERIT No. 30}

Adoption, Harmonization and Succession of Network Technologies across Countries

\section{Mark Sanders. UNU-MERIT No. 29}

Skill Biased Technical Change: Its Origins, the Interaction with the Labour Market and Policy Implications

2003

Nadine Roijakkers. UNU-MERIT No. 28

Inter-firm Cooperation in High-tech Industries: a Study of R\&D

Partnerships in Pharmaceutical Biotechnology

Viki Sonntag. UNU-MERIT No. 27

Speed, Scale and Sustainability

Masaru Yarime. UNU-MERIT No. 26

From End-of-Pipe Technology to Clean Technology

Stéphane Malo. UNU-MERIT No. 25

The Combinatorial Chemistry Revolution: Sustaining a Superior Performance Position through Technological Learning

2002

Annelies Hogenbirk. UNU-MERIT No. 24

Determinants of Inward Foreign Direct Investment: the Case of the Netherlands

Bastiaan Johan ter Weel. UNU-MERIT

The Computerization of the Labour Market

2001

John Adeoti. UNU-MERIT No. 23

Technology Investment in Pollution Control in Sub-Saharan Africa: The Case of the Nigerian Manufacturing Industry

Edward Huizenga. UNU-MERIT No. 22

Innovation Management: How Frontrunners Stay Ahead: An Empirical Study on Key Success Factors in the ICT sector 
Machiel van Dijk. UNU-MERIT No. 21

Technological Change and the Dynamics of Industries: Theoretical Issues and Empirical Evidence from Dutch Manufacturing

\section{9}

Jan Cobbenhagen. UNU-MERIT No. 20

Managing Innovation at the Company Level: A Study on NonSector-Specific Success Factors

\section{Marjolein Caniëls. UNU-MERIT No. 19}

Regional Growth Differentials: The Impact of Locally Bounded Knowledge Spillovers

\section{8}

Aldo Geuna. UNU-MERIT No. 18

Resource Allocation and Knowledge production: Studies in the Economics of University Research

\section{6}

Reinoud Joosten. UNU-MERIT No. 17

Dynamics, Equilibria, and Values

Hugo Kruiniger. UNU-MERIT No. 16

Investment, R\&D, and the Financing Decisions of the Firm

\section{5}

Hans van Meijl. UNU-MERIT No. 15

Endogenous Technological Change: The Case of Information Technology, Theoretical Considerations and Empirical Results

\section{René Kemp. UNU-MERIT No. 14}

Environmental Policy and Technical Change: A Comparison of the Technological Impact of Policy Instruments

Rohini Acharya. UNU-MERIT No. 13

The Impact of New Technologies on Economic Growth and Trade: A Case Study of Biotechnology

\section{Geert Duysters. UNU-MERIT No. 12}

The Evolution of Complex Industrial Systems: The Dynamics of Major IT Sectors

\section{Marjan Groen. UNU-MERIT No. 11}

Technology, Work and Organisation: A Study of the Nursing Process in Intensive Care Units
Huub Meijers. UNU-MERIT No. 10

On the Diffusion of Technologies in a Vintage Framework: Theoretical Considerations and Empirical Results

\section{Theon van Dijk. UNU-MERIT No. 9}

The Limits of Patent Protection: Essays on the Economics of Intellectual Property Rights

\section{Hans Voordijk. UNU-MERIT No. 8}

Naar Integrale Logistiek in Bedrijfsketens: Ontwikkelingen in de Bouw

1993

\section{Paul Diederen. UNU-MERIT No. 7}

Technological Progress in Enterprises and Diffusion of Innovation: Theoretical Reflections and Empirical Evidence

\section{Ben Dankbaar. UNU-MERIT No. 6}

Economic Crisis and Institutional Change: The Crisis of Fordism from the Perspective of the Automobile Industry

\section{Hanno Roberts. UNU-MERIT No. 5}

Accountability and Responsibility: The Influence of Organisation Design on Management Accounting

\section{2}

\section{Bart Verspagen. UNU-MERIT No. 4}

Uneven Growth Between Interdependent Economies: An Evolutionary View on Technology Gaps, Trade and Growth

Sjoerd Romme. UNU-MERIT No. 3

A Self-organization Perspective on Strategy Formation

\section{9}

John Spangenberg. UNU-MERIT No. 2

Economies of Scale, and Atmosphere in Research Organisations

1988

John Hagedoorn. UNU-MERIT No. 1

Evolutionary and Heterodox Innovation Analysis: A Study of Industrial and Technological Development in Process Control and Information Technology 